\title{
Whole gut irrigation and antimicrobial prophylaxis in elective colorectal surgery
}

Citation for published version (APA):

Weidema, W. F. (1982). Whole gut irrigation and antimicrobial prophylaxis in elective colorectal surgery. [Doctoral Thesis, Maastricht University]. Rijksuniversiteit Limburg. https://doi.org/10.26481/dis.19820827ww

Document status and date:

Published: 01/01/1982

DOI:

10.26481/dis.19820827ww

Document Version:

Publisher's PDF, also known as Version of record

\section{Please check the document version of this publication:}

- A submitted manuscript is the version of the article upon submission and before peer-review. There can be important differences between the submitted version and the official published version of record.

People interested in the research are advised to contact the author for the final version of the publication, or visit the DOI to the publisher's website.

- The final author version and the galley proof are versions of the publication after peer review.

- The final published version features the final layout of the paper including the volume, issue and page numbers.

Link to publication

\footnotetext{
General rights rights.

- You may freely distribute the URL identifying the publication in the public portal. please follow below link for the End User Agreement:

www.umlib.nl/taverne-license

Take down policy

If you believe that this document breaches copyright please contact us at:

repository@maastrichtuniversity.nl

providing details and we will investigate your claim.
}

Copyright and moral rights for the publications made accessible in the public portal are retained by the authors and/or other copyright owners and it is a condition of accessing publications that users recognise and abide by the legal requirements associated with these

- Users may download and print one copy of any publication from the public portal for the purpose of private study or research.

- You may not further distribute the material or use it for any profit-making activity or commercial gain

If the publication is distributed under the terms of Article $25 \mathrm{fa}$ of the Dutch Copyright Act, indicated by the "Taverne" license above, 


\section{Whole Gut Irrigation and antimicrobial prophylaxis in elective colorectal surgery}

Proefschrift

Ter verkrijging van de graad van doctor in de geneeskunde aan de Rijksuniversiteit Limburg te Maastricht, op gezag van de Rector Magnificus Prof. Dr. H.C. Hemker, volgens besluit van het College van Dekanen in het openbaar te verdedigen in de aula van de universiteit op vrijdag 27 augustus 1982 des namiddags te vier uur.

door

Wibo. F. Weidema

geboren te Utrecht 


\section{Promotor}

Prof. Dr. C.P.A. van Boven

Co-promotor

Prof. Dr.J.M. Greep

Referenten

Prof. Dr. W.H. Brummelkamp

Prof. Dr. E.H.M.A. Marres

Prof. Dr. D. van der Waaij 
To my parents,

Mariëlle, Jikke and Anne 
Part I: Survey of the literature.

Chapter 1: Bacteriology of the gastro-intestinal tract.

1.1. Ecology and bacteriology of the healthy gastro-intestinal tract. 1

1.2. Changes in micro-flora in diseases of the gastro-intestinal tract.

1.3. Bacteriology in septic complications after colorectal surgery.

Chapter 2: Septic complications after colorectal surgery. $\quad 7$

$\begin{array}{ll}2.1 . & \text { Host defence mechanisms. }\end{array}$

2.2. Wound infections.

2.3. Dehiscence of the colonic anastomosis. 10

$\begin{array}{ll}2.4 . & 11\end{array}$

\begin{tabular}{lr} 
2.5. Septicaemia. & 12 \\
\hline
\end{tabular}

2.6. Prevention of septic complications.

Chapter 3: Large bowel preparation before elective colorectal surgery.

3.1. Introduction.

3.2. Mechanical cleansing of the large bowel. 15

3.2.1. Conventional method. 15

3.2.2. Whole gut irrigation.

3.2.3. Mannitol. 16

3.2.4. Elemental diets. 16

3.3. Use of antibiotics in elective colorectal surgery.

3.3.1. Prophylactic use of antibiotics.

3.3.2. Antimicrobial prophylaxis in elective colorectal surgery. 20

$\begin{array}{ll}3.3 .2 .1 \text {. Lincomycin and clindamycin. } & 21 .\end{array}$

3.3.2.2. Aminoglycosides. $\quad 22$

3.3.2.3. Metronidazole. 23

$\begin{array}{lr}3,3,2.4 . \text { Cephalosporins. } & 24\end{array}$

3.3.2.5. Tetracyclines. $\quad 26$

$\begin{array}{ll}3.3 .3 . & 27 \\ 3.3 .4 . & 27 \text { Topical application of antibiotics. }\end{array}$

3.3.4. Chemotherapeutic agents.

3.3.5. Influence of mechanical cleansing and antibiotics on the colonic microflora. 29

Part II: Climical trials and bacteriological investigations.

Chapter 4: Considerations and aims of the studies. 
5.1. Introduction.

5.2. Method and materials.

5.2.1. Patients.

5.3. Results.

5.3.1. Duration of the irrigation and amounts of irrigation fluid. 36

5.3.2. Body weight variation.

5.3.3. Metabolic disturbances.

$\begin{array}{ll}\text { 5.3.4. Vacuity. } & 37\end{array}$

5.3.5. Complications.

$\begin{array}{lll}\text { 5.4. Discussion. } & 38\end{array}$

Chapter 6: Bacteriological and clinical evaluation of three methods of large bowel preparation before elective colorectal surgery. 41

6.1. Introduction.

6.2. Methods and materials. 41

6.2.1. Pre- and peroperative evaluation methods.

6.2.2. Operative procedures. 43

6.2.3. Postoperative evaluation methods. $\quad 43$

6.2.4. Microbiological methods and techniques. 44

6.2.4.1. Specimen collection. 44

6.2.4.2. Isolation and identification. 45

6.2.4.3. Levels of metronidazole in serum and faeces.

6.2.5. Statistical evaluation. 46

6.3. Results. $\quad 46$

6.3.1. Patient population. 46

$\begin{array}{ll}\text { 6.3.2. Bacteriological results. } & 47\end{array}$

6.3.2.1. Reduction of aerobic and anaerobic faecal microflora. 47

6.3.2.2. Acrobic and anaerobic bacterial counts in the biopsies.

6.3.2.3. Serum levels of metronidazole. $\quad 50$

6.4. Clinical results. 51

6.4.1. Wound infections. $\quad 51$

6.4.2. Intra-abdominal sepsis.

6.4.3. Septicaemia. $\quad 54$

6.4.4. Anastomotic dehiscence. $\quad 55$

6.4.5. Lethality.

6.4.6. Other postoperative infective complications. 55

6.4.7. Postoperative hospital stay. 55

6.5. Discussion. 
Chapter 7: 24 Hours systemic antimicrobial prophylaxis with gentamicin and metronidazole or with metronidazole alone in elective colon surgery after mechanical bowel preparation with mannitol and whole gut irrigation.

7.1. Introduction.

7.2. Methods.

7.2.1. Pre and peroperative evaluation methods. 62

7.2.2. Postoperative evaluation methods. 62

7.3. Materials. 63

7.4. Results of mechanical bowel preparation. 64

7.5. Bacteriological results. 65

7.5.1. Reduction of acrobic- and anaerobic faecal microflora. 65

7.5.2. Aerobic- and anaerobic bacterial counts in the biopsies. 66

$\begin{array}{ll}\text { 7.6. Clinical results. } & 67\end{array}$

$\begin{array}{ll}\text { 7.6.1. Wound infections. } & 67\end{array}$

7.6.2. Other septic complication. 68

7.6.3. Postoperative hospital stay. 69

$\begin{array}{lll}\text { 7.7. Discussion. } & 69\end{array}$

Chapter 8: Recolonization and Colonization Resistance of the large bowel after three methods of preoperative preparation of the gastro-intestinal tract.

$\begin{array}{ll}\text { 8.1. Introduction. } & 73\end{array}$

$\begin{array}{ll}\text { 8.2. Material and Methods. } & 74\end{array}$

8.2.1. Evaluation methods during bowel preparation.

8.2.2. Evaluation methods after bowel preparation.

8.2.3. Microbiological methods and techniques.

8.2.3.1. Specimen collection. $\quad 75$

8.2.3.2. Isolation and identification.

8.2.3.3. Identification of $\beta$-aspartylglycine. $\quad 76$

8.2.3.4. Determination of Volatile Fatty Acids. 76

8.3. Results. 77

8.3.1. Reduction of the aerobic and anacrobic faccal microflora.

$\begin{array}{ll}\text { 8.3.2. Recolonization. } & 77\end{array}$

$\begin{array}{ll}\text { 8.3.3. Colonization Resistance. } & 79\end{array}$

$\begin{array}{ll}\text { 8.3.4. B-aspartylglycine in the faeces. } & 82\end{array}$

8.3.5. Volatile Fatty Acids in the faeces. $\quad 82$

8.3.6. Levels of mannitol in faeces.

8.4. Discussion. 
Chapter 9: General discussion.

Summary.

Samenvatting.

References.

Acknowledgements.

Curriculum Vitae. 

Chapter 1:

\section{Bacteriology of the gastrointestinal tract.}

\subsection{Ecology and bacteriology of the healthy gastro-intestinal tract}

From birth man is subject to bacterial contamination from his environment. Some of these contaminants are able to colonize his body; they start the ecological succession of bacteria which constitute the indigenous flora.

The human gastro-intestinal tract in utero is sterile. Within a few hours after birth, the oral and anal orifices are colonized, and micro-organisms can be cultured from the rectum. The intestinal flora at this time is variable and is derived from the environment of the infant. On the fifth day of life bacterial species normally found in the adult intestine can be isolated. During the first month of life large fluctuations in the numbers of bacteria are observed, indicating that the indigenous flora and the defence mechanisms are not yet well balanced (Hoogkamp-Korstanje et al. 1979).

\section{Upper gastrointestinal tract}

Studies on the human intestinal flora are complicated by the problems of obtaining specimens from locations other than the mouth and the anus. Our present knowledge about the microflora of the stomach and small bowel comes mainly from intubation studies (Bornside et al., 1966; Gorbach et al., 1967; Gorbach, 1971). Normally, there are viable bacteria in all parts of the gastro-intestinal tract. The saliva contains, in different counts, approximately the same species of bacteria as the faeces. Escherichia coli as well as Bacteroides fragillis will be absent in the saliva. Other Bacteroides species i.e. Bacteroides melaninogenicus are present in the saliva. The upper region, including stomach, duodenum, jejunem and upper ileum has a sparse microflora consisting predominantly of Gram positive facultative anaerobic organisms.

Most bacteria ingested with food are destroyed by gastric acid (pH 2-3). Other bactericidal factors associated with the mucosa are probably responsible for the abscence of Gram-negative micro-organisms in the upper gastro intestinal tract (Goldman, 1924). The bacteria that occur in the small intestine are generally acid- and bile resistant Gram-positive bacteria. Streptococci, ac robic lactobaccilli, staphylococci, diphtheroids, and fungi are the major constituents and their total concentration is generally less than $10^{4}$ per $\mathrm{ml}$ of intestinal fuid. No Bacteroides nor other obligate anaerobes are cultured from this area. Coliforms are also absent from the upper small bowel. Table 1.1 shows the occurence of selective bacterial groups in the small intestines of normal people.

Table 1. 1

Occurrence of sellected bacterial groups in the small intestine of normal people. (From Drasar and Hill 1974).

Log 10 bacteria/ml intestinal contents. Mean(Range)

\begin{tabular}{|c|c|c|c|c|c|c|}
\hline & $\begin{array}{l}\text { Number of } \\
\text { subjects } \\
\text { References }\end{array}$ & $\begin{array}{c}\text { Entero- } \\
\text { bacteriaceae }\end{array}$ & Bacteroides & Streptococcus & Lactobacillus & $\begin{array}{l}\text { Gramtnon. } \\
\text { sporing } \\
\text { anaerobes }\end{array}$ \\
\hline \multirow[t]{4}{*}{ Jejurnum } & 6 & $\mathrm{~N}$ & $\mathrm{~N}$ & $3.5(\mathbb{N}-5.5)$ & $\mathrm{N}$ & $\mathrm{N}$ \\
\hline & 20 & D & D & $2.4(\mathrm{~N}-3.9)$ & $2.4(\mathbb{N}-3.9)$ & D \\
\hline & 22 & $D(N-3)$ & $D(N-3.9)$ & $D(N-6)$ & D & $D(N-3.2)$ \\
\hline & 12 & $D(N-3)$ & $\mathrm{N}$ & $4.2(\mathrm{~N}-8.9)$ & $2.2(\mathrm{~N}-6)$ & $D(N-5)$ \\
\hline Ileum & 6 & $D(N-6)$ & $\mathrm{N}$ & $N$ & $\mathrm{D}(\mathrm{N}-3.7)$ & $\mathrm{D}$ \\
\hline \multicolumn{7}{|l|}{ Distal } \\
\hline lleum & 12 & $5.4(3.5-6.3)$ & $5.5(3.11-8.8)$ & $2.5(2-6.3)$ & $3.5(3 \times 4)$ & $2.5(2-3)$ \\
\hline Terminal & 7 & $3.3(\mathrm{~N}-6)$ & $5.7(3.4-8)$ & $3.4(3.1-4.1)$ & $D(N-8)$ & $5.7(4.1-8)$ \\
\hline Ileum & 6 & $5.6(\mathrm{~N}-8.5)$ & $5.2(\mathrm{~N}-8)$ & $4.9(N-8)$ & $4.2(N-8)$ & $4(\mathrm{~N}-8)$ \\
\hline
\end{tabular}

$\mathrm{N}=$ Not detected; $\mathrm{D}=$ Less than 100 bacteria 
In fddition to gastric acid and bile, intestinal motility plays an important role in controlling the size of the bacterial population in the small bowel. Drasar et al. (1969) suggest that the motility of the intestines is its major cleansing mechanism. The normal peristaltic flow is fastest in the jejunum and upper ileum and slows in the distal ileum, and there is nomally a degree of stagnation proximal to the ileccaecal valve. The stasis at the ileocaecal valve and the diminished motility of the lower intestinal tract allows the bacteria to multiply to higher concentrations in that area. While Gram-positive batcteria predominated in the upper small bowel, Gram-negative micro-organisms are often found in the distal ilewm. The flora of the lower ileum is qualitatively similar to that of faecal flora. The predominant aerobic micro-organisms are enterococci, colliforms and lactobaccilli at a concentration of $10^{5}-10^{8}$ per $\mathrm{ml}$ intestinal juice. Bacteroides fragilis is the most prevalent anaerobic bacteria reaching a concentration of $10^{4}-10^{6 /}$ per ml. (Bornside et al, 1966; Moore et al., 1969; Sykes et al., 1976).

\section{Distal gastrointestinal tract}

Although peristalsis plays an important role in the intestinal micro-ecology of man, it cannot explain the differences in numbers and types of micro-organisms on the two sides of the ileocaecal valve. Simultaneous sampling, with a double lumen tube, of contents from the small- and large intestine reveals a marked increase in the numbers of bacteria in the caecum. Here the oxygen sensitive bacteria reach high concentrations, due to a low oxidation-reduction potential (Gorbach et al., 1967).

The anaerobic, non-sporing, Gram-negative Bacteroides overwhelmingly predominate in the human faecal flora, accounting for more than $99 \%$ of the total number of micro-organisms. Together with anaerobic lactobaccilli and clostridia they become the major constituents of the microflora, outnumbering the aerobic and facultative aerobic flora by a factor 1000 to 10.000 . The facultative aerobic flora consists of Escherichia coli, Streptococcus viridans, and Streptococcus salivarius. In addition, a great variety of bacterial species occur in relatively low concentrations. They include species of Veillonella, Baccillus, Peptococcus, Peptostreptococcus, Clostridium, Streptococcus, Pseudomonas and enterobacteriaceae other than Escherichia coli (e.g. Klebsiella species, Proteus species). It must, however, be stressed that although these species are minor components of the average normal flora, they may be of major importance in an individual person (Hill and Drasar, 1975). Furthermore, fungi and yeasts, particularly Candida albicans, can be isolated from the bowel contents of most adults (Cohen et al., 1969; Drasar and Hill, 1974).

\section{Mucosal microbial flora}

Besides the longitudinal location of micro-organisms in the gastro-intestinal tract, there is also across-sectional distribution (Gorbach, 1971). Studies of human intestinal mucosa in jejunal and ileal biopsies of healthy individuals reveal small numbers of organisms embedded in the mucous covering the epithelium. No micro-organisms could be found within the microvilli, the mucosal cell or lamina propria (Nelson and Mata, 1970). The colonic microflora can therefore be divided into faecal and mucosal microflora. The mucosal microflora growing in close association with the mucosal surface may differ quantitatively, and in proportion to the faecal flora, but the same bacterial species do occur in faccal - and mucosal flora. Few studies have been made of the mucosal micro-flora of the large intestine; it seems, however, to be qualitatively similar to that of faecal flora. Estimates of total bacterial numbers vary. The results of Moore et al. (1969) suggests higher counts than those in faeces. Nelson and Mata (1970) reported in their study on biopsies of healthy colons counts of at least $10^{7}$ anacrobic- and $10^{6}$ aerobic bacteria per gram of tissue homogenate. The most prevalent organisms were anaerobic and microaerophilic streptococci, and enterobacteriaceae.

Bacteroides and Clostridium species were also found in all biopsies. Peach et al., (1972) reported that the mucosal flora and flora found in colonic tumors were similar to the faecal flora but differed in quantity. Unlike the faecal flora, the mucosal flora was not dominated by anaerobic bacteria. Whereas in the lumen of the large bowel anaerobic bacteria outnumbered aerobic bacteria, this ratio was close to unity from mucosal specimens.

\section{Environmental factors}

In adults the intest inal flor a is quite constant and well balanced. Interactions specific for the environment in the intestimes will control the composition of the flora (Hoogkamp-Korstanje et al., 1979). Although differences are demonstrable between groups of people living on different diets, attempts to change the composition of the flora by variations in diet have been in general unsuccessful (Drasar et al. 1973). A non - or low residue diet, for example, will greatly reduce the wolume of the faeces, but 
the concentration of bacteria is not substantially altered (Russel et al, 1975; Schiessel er al., 1978). This would be consistent with the idea that the colonic bacteria are normally living on gut secretions and the products of shed cells from the mucosa, rather than on unabsorbed residues of the diet (Peach et al., 1972).

\subsection{Changes in microflora in diseases of the gastro-intestinal tract}

Bacterial overgrowth may be a nonspecific finding in a variety of serious illnesses. There are, however, certain situations in which bacterial contamination induces a physiolog ical malfunction, or influences the clinical course. Some of these diseases are mentioned in some detail.

\section{Upper gastrointestinal tract}

Jejunal bacterial concentrations are elevated in 50 to $100 \%$ of patients with achlorhydria (Drasat et al. 1969). There may be increased concentrations of the normally occurring flora as well as organisms generally confined to the lower reaches of the bowel. An increasing colonization in patients undergoing vagotomies and drainage procedures was seen by Browning et al. (1969). The type of gastrectomy influences postoperative colonization. Billroth II operation involving an afferent loop results in significantly higher microbial concentrations than Billroth I procedures which preserve gastro-intestinal continuity. Billroth II patients have a preponderance of coliforms in the jejunum whereas Billnroth I subjects have mostly Srreptococcus viridans (Wirts and Goldstein, 1963).

Impaiment of the normal peristalsis of the gut frequently leads to a greatly increased population in the stagnant area"s. This has been observed in disorders like Crohn's disease, tuberculosis, sclerodermia, diabetic neuropathy, or complete obstruction, (Drasar et al, 1969; Gorbach, 1971). The bacteria in the stagnant area are often referred to as "colonic" or "faecal" bacteria.

The very high anaerobic counts in the small bowel in patients with a large bowel obstruction, suggest that probably the incompetence of the ileocaecal valve is the cause of the contamination of the small bowel. The morbidity and mortality in patients with acute large bowel obstruction appeared to be associated with a high anaerobic bacterial count in the small bowel. In patients recovering from intestimal obstruction the jejunal micro-flora returned to normal within 4-5 days. The most important factor in restoring the ileal microflora, (in case of a dysbacteriosis) is the transport of the ileal content into the caecum (Sykes et al., 1976).

\section{Distal gastro-intestinal tract}

The examination of stools in patients with a surgical disease of the collon showed in over $90 \%$ an abnormal flora of the large bowel. An increase of Escherichia coli, Klebsiella, Proteus and Pseudomonas or a decrease of the physiological anaerobic flora was seen (Schneiders et al. 1976). Vargo et al., (1980) compared stools of patients with colonic carcinomas, carcinomas not concerning the gastro-intestinal tract and a control group. Significantly more anaerobes were cultured from faeces of the control group as compared to the non gastro-intestinal cancer group.

No differences in the aerobic flora were seen. The colonic cancer group and the control group neither differ significantly in aerobic nor in anaerobic micro-flora. The anaerobic/aerobic ralio, however, was lowered significantly in the colonic cancer group compared to the normal group due to a greater predominance of aerobic bacteria and a decrease in anaerobic cocci (Eubacterium and Fusobacterium).

Patients with ulcerative colitis have no significant difference in micro-flora of the ileum and colon (Jacomina et al., 1975; Keighley, 1978). Patients with Crohn's disease, however, showed a dysbacteriosis in illeum and colon (Barker er al., 1971). Keighley et al. (1978) found an increase of $E S$ cherichia coli and Bacteroides fragilis in the ileum and of Escherichia coli and lactobacilli in the colon. This dysbacteriosis was not related to Crohn's activity index nor to resection of ileocaecal valve, or the diameter of the illeum.

\section{Ileostomy and colostomy}

In collorectal surgery colostomies and ileostomies are frequently performed. The microbial flora in these stomas appeared to be different from the normal flora in the colon and terminal illeum.

The ileostomy represents a new ecological situation and is rapidly colonized. Bacterial counts in 
Heostomy faceces were much higher than those aspirates from the normal ileum, but rather lower than those from faces; aerobic bacteria were observed in large numbers but anacrobic microorganisms are decreased 5 to 10 logarithms. In patients with a transwerse colostomy this decline of anaerobes is 2-3logarithms. It appears that the unique environment of the colon with its oxydationreduction potential and stasis provides anaerobic micro-organisms with optimal conditions for propagation (Drasar et al. 1969; Finegold ef al, 1970).

\subsection{Bacteriology in septic complications after colorectal surgery}

When the colon is opened, faeces containing $200-400$ or more species of bacteria might be spilled into the peritomeal cavity and surgical wound. Both clinical and experimental evidence indicates that the number of species in the bacterial inoculum is rapidly reduced when it introduced into the peritoneal cavity (Onderdonk et al, 1974). It seems therefore apparent that the defence systems of the peritoneal cavity provide an inimical environment for the majority of the colonic bacteria which are rapidily eliminated. Only the potential pathogenic organisms will survive, either alone or in combination.

Escherichia coli and Bacteroides fragilis are by far the most frequent isolates from infections due to colonic discase or following collorectal surgery (Leigh, 1975; Keighley et al., 1976; Willis et al., 1977; Yura et al. 1978). Mixed aerobic-anaerobic infections after colorectal surgery were seen in $75-93 \%$ (Swenson elal., 1974; Stone et al., 1975; Leigh, 1975). In previous investigations of intra-abdominal sepsis the synergistic combination of aerobes and anaerobes has appeared to represent a valid argument to support the polymicrobial basis, rather than a monomicrobial cause. Altemeier (1942), for example, noted that single species isolated from specimens from patients with appendicitis seldom produced fatal peritonit is in experimental animals.

In an experimental model the role of aerobes and anaerobes in peritonitis was evaluated by using antibiotics active against either aerobes or anaerobes (Weinstein et al., 1975). Treatment with geniamicin reduced the acute mortality rate to $4 \%$, but $98 \%$ of the animals developed intra-abdominal abscesses. Clindamycin was associated with $35 \%$ mortality and an incidence of $5 \%$ abscesses. The combination of gentamicin / clindamycin yielded the salutary effect of each agent: $7 \%$ mortality and $6 \%$ incidence of abscesses. These investigations suggest that coliforms caused early mortality while anaerobes were primarily responsible for the late complication of intra-abdominal abscess formation.

Onderdonk et al. (1976) have studied the interaction between Bacteroides fragilis, Fusobacteritum warwm, Escherichia coli, and Streptococcus faccalis. A single species did not produce an abscess when implanted in a gelatin capsule in the peritoneal cavity of the rat. Also combinations of only acrobes or only anacrobes failed to produce an abscess. However, any combination of an aerobe and an anserobe resulted in marked absecs formation.

The interaction between aerobic- and anaerobic bacteria has also been noted in clinical studies. Influencing the aerobic colonic flora by means of enteral or parenteral administration of antimicrobial drugs active against the acrobes did not decrease the postoperative septic complications after elective colorectal surgery (Washington ef al, 1974). However, when antimicrobial drugs against anaerobes were given at reduction of the postoperative septic complications was seen (Eykyn et al., 1979. Willisetal., 1977).

The mechanisms by which bacteria interact in the peritoneal cavity have been investigated only to a limited extent. A few pathophysiologic mechanisms for synerchism between bacteria have been suggested. One bacterium can produce a growth factor or nutrient that allows the survival and growth of another (Mergenhagen er al, 1958; Rudek and Haque, 1976). Another mechanism could be the blockade of a specific host defence mechanism, either endogenous, such as blockade of the neutrophil phagocytosis by producing a leukocidin (Ingham et al., 1977), or exogenous, such as providing an enzym which degrades antibiotics (Rudek and Haque, 1976; Louie et al., 1977). One of the most prominent mechanisms is that of the alteration of the environment by an organism which allows the persistence of another organism i.e. acidifing the environment or lowering the oxydation-reduction potential. The last mentioned mechanism is the most important one in the symbiose between aerobes and anaerobes. Coliforms have been demonstrated to lower the oxidation-reduction poten- 
tial within the peritoneal cavity and allow the growth of obligate anderobes like Bacteroides. The oxidation-reduction potential is a measure of the tendency of a system to give up electrons. A low oxidation-reduction potential facilitates anaerobic growth and a low pH permits anacrobic growth. on a higher oxidation-reduction state. The most common clinical cause of a lowered oxidationreduction potential is anoxia of the tissue which can result from vascular injuries, compression, hypothermia, shock, tissue edema or other conditions causing poor perfusion. In addition, the anoxia produces acidosis which further facilitates anaerobic growth (Andersonet al., 1976. Tally and Gorbach, 1979).

Certain bacteria have surface receptors that permit them to adhere to normal or altered surface epithetial components. This allows the bacteria to escape from the normal cleansing mechanisms (Costerton et al, 1978). Onderdonk ef al. (1978) has demonstrated increased adherence to peritoneal mesothelium in Bacteroides fragilis strains which elaborate a capsule as compared to those which do not. Since Bacteroides fragilis is able to adthere to the peritoneal mesothelium it may cause intraperitoneal abscesses.

Anaerobic bacteria have always been important pathogens, but the "anaerobic renaissance" that has occurred over the past decade may probably be attributed to greatly improved laboratory techniques resulting in increased isolation of these organisms (Kislak, 1972; Gorbach and Bartlett, 1974). The viability of anaerobic bacteria decreases rapidly. In patients operated upon for a perforation of the large bowel samples taken immediately after opening the abdomen yielded positive cultures in $100 \%$, cultures taken after one and two hours were positive in only $30 \%$ or less than $10 \%$ respectiveIy (Stone et al. 1975). Failure to deliver a proper specimen promptly and under strict anaerobic conditions to a bacteriology laboratory that is experienced in and adequately equipped for anatrobe work has been the major reason for a lack of knowledge in this area. At present, however, most medical centers do have the facilities for reasonably accurate anaerobic bacteriology, and thus the culprit now responsible for a report of "no anaerobic growth" may well be the sampler, that is the sur" geon himself. Even a delay of only a few minutes in the inoculation of the specimen into an environment relatively devoid of oxygen can cause the death of the very species of anaerobes that causes a life-threatening infection. The importance of the anaerobic micro-flora in intestinal surgery is presently well established. One may conclude that through the improvement of anaerobic culture techniques the role of anaerobic micro-organisms in post-operative infections became more obvious. Most of the infections that complicate colorectal surgery have a poly-microbial aetiology, in which the anaerobes are the most important. However, the exact mechanism of the interaction between the aerobic and anaerobic micro-organisms of the large bowel in the aetiology of these septic complications remains unknown. 


\section{Septic complications after colorectal surgery}

\subsection{Host defence mechanisms against infection}

Despite major advances in surgical techniques, availability of antibiotics, and a variety of preventive and therapeutic adjuncts, infection continues to be a major problem in surgery. In any infectious process, there are three principle factors involved in the production of that intection: the number and virulence of contaminating micro-organisms, the local conditions, and the systemic host defence mechanisms.

In surgery the bacteria gain access into the tissues of the host due to the disruption of the naturall skin - and mucosal membrane barrier - and their local resistance factors, such as tears, cilla, mucous and normal resident flora. The barriers prevent infection of the underlying tissues; the systemic host defences contain and resolve the infectious process.

Due to the entrance of bacteria into the body through traumatic or surgically created wounds an inflammatory process develops which is characterised primarily by a vascular response. A momentary constriction of vessels is rapidly followed by a dilatation of the local capillaries and venules. A variety of substances-collectively called leukotaxines - are released in these carly moments of the inflammatory response. Leukotaxines then call up the primary inflammatory cells to face the bacterial challenge. The leukocytes, especially the polymorphonuclear leukocytes, stick to the wall of the venules and then migrate across the wall into the area of contamination. Phagocytosis is facilitated by the process of opsonization. Opsonizing factors in the serum act in a non-specific- (via the alternative complement pathway) and specific manner (via specific antibodics alone or acting in concert with complement).

The opsonization process - whether by specific or non-specific mechanisms - enhance the active ingestion of the organisms by polymorphonuclear leukocytes. Once in contact with the bacterium, the polymorphonuclear leucocyte actively ingests the organism and forms through the process of phagocytosis, a phagosome. Lysosomes are packages of active digestive enzymes. The membrane of the lysosomes fuses with the phagosomal membrane to form a phagolysosome and thereby delivers its antibacterial enzymes into contact with the ingested bacterium. When the metabolism of the polymorphonuclear leucocytes is normal, these enzymes kill and digest the ingested microorganisms. The performance of a single polymorphonuclear leucocyte is not impressive: however, when $10^{7}$ and more of these leucocytes are delivered to an inflammatory focus they become a poteni and valuable antibacterial force.

In addition to polymorphonuclear leucocytes, mononuclear leucocytes can ingest and kill invading micro-organisms, however, their importance in resistance to infection is still argued. It is gencrally accepted that polymorphonuclear leucocytes are almost entirely responsible for primary deficnce in acute localized lesions, whereas the mononuclear leucocytes in the reticulo-endothelial system play a major role in systemic infections such as septicaemia.

If the phagocytic process is successful in killing the inwading micro-organisms, the process is arrested. While an overwhelming innoculum of bacteria introduced into a wound can result in clinical infection, surprisingly large numbers are necessary in individuals possessing intact defence mechanisms, and clinical infection is usually associated with an abnormality in some segments of the normal general host defence mechanism.

In addition to general host defence mechanisms, a local host defence mechanism of the gut or mucosal immunity should be noted. In this local defence mechanism of the gut, chyle-filled lacteals in the mesentery and gut associated lymphoid wissue are distinguished.

The tissue fluid of the gut is formed, just as in other tissues in the body, by proteins, including immunoglobulins, water and crystalloids. In contrast to other tissues the concentration of $\lg \mathrm{A}$ in the interstitial fluid of the gut is much higher than in the plasma. These immunoglobulins are produced by the 
plasma cells in the lamina propria of the gut and secreted into the surrounding interstutial fluid. The observed difference in the amount of IgA in the blood plasma and interstitial fuid of the gut could be explained by an excretion mechanism. The IgA antibodies, that are formed locally in response to gut antigens are partly discharged into the intestinal lymph, instead of being secreted directly into the mucous secretions. The $\operatorname{Ig} A$ is discharged via the mesenteric lymphnodes and the major lymph trunks into the great veins of the systemic blood circulation. From the blood the IgA is transported directly into the hepatocytes, which transfere it via the bile canaliculi into the duode= num. In this way the IgA could reach the lumen of the bowel (Hall et al., 1979). This mechanism might protect the patient against ascending infections of the gastrointestinal tract.

Factors involved in the failure of the inflammatory response in infective processes can be subdivided into local and general factors. In surgical practices the most significant local factors predisposing to infection are a poor circulation (Stevenson et al., 1975), presumably because vascular responses are impaired; the presence of dead tissue, limiting the access of humoral and cellular factors of inflammation, and, at worst potentiating infections with anaerobes; and the presence of foreign bodies (Elek and Conen, 1957) favouring the persistence of infection because pockets of pus can collect against surfaces of the foreign material. Furthermore, the foreign body will prevent the healing of the abscess.

The general factors which affect general host defence mechanisms include a variety of general diseases such as malnutrition.

Hypoproteinaemia have been shown to be related with the impairment of host defence mechanisms especially on cellular level. This impaiment has been reported to be reversible with nutritional replacement therapy (Law et al., 1974).

Diabetic patients have small vessel sclerotic changes which may lead to local ischemia. Various deficiencies in neutrophil function in diabetic patients and the responses of micro-organisms to hyperglycemia have been reported (Robertson et Polk, 1974). Documentation of consistent impairment of neutrophil function or a direct relationship between complications of the diabetic state and clinical infection was not discovered.

The patient who recieves corticosteroid drugs may demonstrate suppression of defence mechanisms because of an underlying disease process or because of a primary effect of the ste roid drugs.

Experimentally, exogenous steroids impair neutrophil function and bacterial chearance by the pulmonary reticuloendothelial system (Skornik and Dressler, 1974 Fuenfer etal., 1975).

Cancer apparently seems not to be predispose to infection. However, patients with advanced malignancy may have depressed capacity to mount an inflammatory response. Hodgkin's disease and chronic lymphatic leucatemia are associated with an increased incidence of infection (Johnson et al., 1971). Exogenous influences such as chemotherapy and irradiation adversely affect the ability of the patient with cancer to withstand infection through direct effects on the production of neut rophils and lymphocytes.

\subsection{Wound infections}

The problem of surgical wound infections plays an important role in the daily life of any surgeon. For the patient is a wound sepsis not necessarily a life threatening complication, as is intraperitoneal infection, anastomotic dehiscence, or septicaemia, but it causes a patient suffering and prolongs hopitalization. It has been shown that wound sepsis can double the length of time spent in a hospital and increased the cost to the community because of the illness and its complications (Brass et al. 1978: Collins and Butterfield, 1978).

Creating a wound that is less hospatible to bacterial colonization and this to subsequent infection is primatrily a product of the dedication and ability of the surgeon. It is the technical skill, meticulous attention to detail, and gentle handling of tissue that reduce the amount of clot and cellular necrosis and thus the ready availability of nutrition to any bacterial inoculum. The development of infection is related to the degree of the initial bacterial inoculum in a wound and the success of systemic and, more particularly, local host defence mechanisms in preventing the bacteria from reacting the critical level of growth necessary for infection. It requires a surprisingly large number of bacteria to produce an infection, $10^{5}$ bacteria per $\mathrm{ml}$ or gram seems to be the significant number (Krizek and Rob- 
son, 1975). Infections of surgical wounds offer results from organisms contaminating the wound at time of operation. These organisms can come from the members of the surgical team, from the patients skin, or from the organisms in the patients alimentary, respiratory or genitourinary tract. Concerning the nosocomial infections the exogenous infections become less important than endogenous infections caused by Gram-negative micro-organisms. In colorectal surgery the endogenous infections are of main importance. There are such a myriad of factors involved in wound infection-systemic, local, technical and environmental factors-, that it is very difficult to isolate and measure the effect of anyone variable. The most strict attention should be payed to any detail which influences the incidence of wound infection.

Some systemic host factors are associated with an increased susceptibility to infection. A clear direct relationship between wound sepsis and increasing age has been demonstrated. (National Research Councel, 1964; Davidson et al. 1971; Cruse and Foord, 1973). A deficient immune status (Fekety and Murphy, 1972) as well as reduced resistance due to underlying diseases increase the rate of development of wound sepsis. Malignant disease, (Irwin, 1978) obesity (Cruse and Foord, 1973; Pollock et al., 1978) malnutrition and hypoalbuminaemia (Cruse and Footd, 1973, Law et al., 1974, Lewis et al., 1978) and diabetes mellitus (Robertson and Polk, 1974) are the most mentioned diseases in this field.

The duration of preoperative hospitalization must be kept to a minimum to prevent colonization of the patient with established hospital flora. Cruse and Foord (1973) have noted a two-fold increase in clean-wound infections with preoperative hospitalization of 2106 days and a four-fold increase when such hospitalization is 14 days or longer. Likewise, remote infections present at the time of the operative procedure denote pathogenic colonization of the patient and are associated with a strikingly higher incidence of wound infection. (Polk, 1973; Davidson et al., 1978). The patient who receives corticosteroid drugs may demonstrate suppression of defenses because of underlying disease process or because of a primary effect of the steroid drugs (Skornik and Dressler, 1974; Fuenfer et al., 1975).

Concerning factors during operation which are related to an increase of postoperative wound sepsis; the use of the electro-surgical knife (Cruse and Foord, 1973), experience and fitness of the operation team (Cruse and Foord, 1973; Higson and Kettlewell, 1978), blood losses greater than $1200 \mathrm{ml}$ (De Gennaro et al., 1978), the duration of the operation (Altmeier 1966; Davidson et al. 1971; Cruse and Foord, 1973; Lykkegaterd, 1978) and the use of drains must be mentioned. Open parietal drains are harmful in all types of wounds and has been shown to double the postoperative wound sepsis. However, in obese patients a non suction drain may decrease the infection rate (Davidson et al., 1971; Cruse and Foord, 1973; Higson, 1978).

A linear-regression analysis of 1000 patients showed that the bacterial contamination of the wound during operation was found to be the most important factor in determining the ultimate behaviour of the wound. A positive culture at the end of the operation would appear to be more than three times as significant as any other single factor such as age of the paticnt, duration of the operation longer than 60 minutes or potentially dirty operation (Davidson et al., 1971). This computer finding could be confirmed by Polk (1973); Clarke et al. (1977); Pollack ef al. (1978) and Scheibel er al. (1978). But Bartlett et al. (1978) could not prove this correlation between positive wound irrigation cultures and subsequent wound infections. It will be clear that potentially dirty operations such as colorectal surgery are of a greater risk than clean operations. Faccal spilling in the wound and peritoncal cavity during the operation has been recognized therefore as the major determinant of endogenous wound infection in colorectal surgery. (Polk, 1973; Leigh, 1975; Keighley et al., 1976; Pollack el al. 1978). Even the most skilled surgeon is bound to live with the fact that cutting the bowel between clamps is associated with the release of bacteria.

Transient bacteraemia occurs often after various operations (Lawrence et al., 1976; Sykes et al., 1976; Slama et al. 1979). It is logical to assume that in the presence of bacteraemia, a surgical wound as a locus minoris resistentiae would be susceptible to blood borne infections. Burton, 1972 found in $35 \%$ undergoing elective colorectal surgery a bacteraemia during the period of hospitalization. In these patients bacteraemia was as common before surgery as in the postoperative period. Suggesting that it result from the undergoing colonic disease rather than from handling of the bowel at surgery. A postoperative wound infection, in a patient having as it source abloodstream infection, has never 
been clearly documentated, athough the possibility has been suggested (Howe et al, 1968) There is howewer, good experimental evidence that chrculating bacteria can lodge in surgical wounds and cause an infection. (Howe efal, 1969).

\subsection{Dehiscence of the colonic anastomosis}

In elective colorectal surgery, anastomotic complications such as leakage and dehiscence are serious because they carry a high incidence of morbidity and mortality. Anastomotic breakdown is associated with a twofold increase in the duration of hospital stay and a threefold increase in hospital mortality (Schrock et al., 1973; Irwin and Goligher, 1973). Data from controlled trials show a surprising variation of $8-50 \%$ in the incidence of anastomotic leakage (Goligher et al, 1970; Matheson and Irvin, $1975 ;$ Ficlding et al, 1980). These differences are partly explained by the methods of defining anastomotic dehiscence. The incidence being higher when results of water soluble contrast radiography are compared with clinical evidence alone. Anterior resections below the peritoneal reflection are more at risk than colonic anastomoses above this reflection (Goligher et al., 1970; Matheson and Irvin, 1975).

The healing of anastomoses is dependent on technical factors, which include healthy intestine at the site of anastomoses, absence of tension, good blood supply and accurate placement of sutures to ensure a water-tight seal.

Anastomoses in the gastro-intestinal tract can be performed in one - or two inverting layers. Much work has been done on the relative merits of the different techniques, but there seem to be no great differences between one - or two layered anastomoses in regard to a good result as long as the anastomosis is performed above the pelvic peritoneal reflection. In anastomoses performed below the pelvic peritoncum leakage occur more frequently when a two layer technique is used (Irvin and Goligher, 1973). This partly reflects the difficulty of using this technique low in the pelvis, where a one layer technique is relatively easier. Of more importance than the choice of a one or two layer technique as such is the accurate placing of the sutures and the atraumatic handling of the tissues. (Irvin and Goligher, 1973; Everett 1975; Goligher et al., 1977).

Clinical and experimental studies revealed little difference in the security of at hand-sewn anastomosis for high and low anterior resections compared with that of stapled anastomoses (Heald and Leicester, 1981; Beart and Kelly, 1981; Thiede et al, 1981). A lower anastomosis can better be done with the circular stapling instrument than with the hand sewn technique. Approximately $12 \%$ of such patients had the rectum preserved when otherwise it might have been sacrificed (Goligher et al. 1979; Beart and Kelly, 1981). Long torm results concerning the formation of strictures of the anastomoses and tumor recurrence are not well known when stapling instruments are used (Graham atal., 1981).

There are many other factors which may also inhibit the healing of anastomoses. Non technical clinical factors are the primary factors determining whether or not an anastomosis fails (Hawley, 1981) The incidence of anastomotic breakdown was not depending on Dukes classification, but in patients who underwent a palliative resection, or in cases where the bowel was adherent to the parietes or other viscera more anastomotic dehiscences were seen (Irvin and Goligher, 1973: Fielding et al. 1980). A significant reduction in preoperative plasma protein was found in patients who developed anastomotic dehiscences and the incidence of disruption was highest in patients over the age of 60 years (Irvin and Goligher, 1973). Inadequate preoperative mechanical preparation of the colon is at significant factor in the pathogenesis of disruption of the colonic and colorectal anastomoses (Le Veen et al. 1976; Irvin and Bostock, 1976).

Intraluminal bacteria were of importance only if spillage caused contamination during operation and thereby subsequent infection of the peritoneal surface of the suture line (Hawley et al., 1970; Foad Naha $i_{*}$ 1977). Infected accumulations of presacral space fluid is an important cause of suture line disruption and anastomotic sepsis in patients undergoing anastomoses involving the rectum (Hilsabeck 1981). The high incidence of anastomotic breakdown in low anterior resections can be explained partly by technical factors, but it is an important fact that the surrounding structures cannot seal off minor leakage of the anastomosis, something which nearly always occurs. This can result in major 
leakage, infection and subsequent anastomotic breakdown. Another weighty role is played by adhesions which act as vascular ingrowth into the anastomosis. Necrotic and badly vascularized tissue is always present at the anastomotic line but adhesions help to maintain circulation during the vital early days of wound healing (McLachlin er al., 1976; Ellis, 1980\%.

The strength of an anastomosis depends on the amount of mature collagen in the submucosal layer. Mature collagen is lysed by collagenase and new collagen is synthesized by fibroblasts. Cronin (1968) demonstrated that the integrity of an anastomosis becomes a race between the tendencey of the inflammatory reaction to lyse old collagen and the ability of fibroblasts to make new collagen. Experimental work has shown that the level of collagenase activity is lowest in the stomach and greatest in the distal collon. The postoperative increase of connective tissue breakdown is most marked in the lower colon anastomoses (Irwin and Hunt, 1974; Delaney and Lalor, 1976). Collagen - and collagenase synthesis is influenced by many factors which act at cellular level, such as infection, trama, malnutrition, hypoxia and hypovolaemia (Hawley et al., 1970; Withaker et al., 1970; Irvin and Hunt, 1974; De Graaf, 1981).

No single one of the described non technical factors is vital in the breakdown of anastomoses, but collectively these factors become important.

\subsection{Intra-abdominal sepsis}

Bacterial peritonitis is not simply the result of bacterial contamination of the peritoneal cavity. For establishing this infection process the local host defence mechanisms must be overcome either by the bacteria, by other adjuvant substances, or by detrimental effects triggered by the inflammatory response. Classically, surgeons for convenience have divided peritonitis in to primary and secondary peritonitis. The former is caused after hematogenous and lymphogenous spread of a single organism (e.g. Pneumococcus, E. Coli). Whereas characteristically the latter is a polymicrobial infection arising most often after injuries or lesions of the gastrointestinal tract, biliary system, pancreas and genitourinary tract (Altemeier et al., 1973).

Peritonitis after elective colorectal surgery is mainly the consequent of a breakdown of a colonic anastomosis or from faecal spilling during operation. Despite the prophylactic and therapeutic use of antimicrobial agents the morbidity of intra-abdominal sepsis remains high (Alteneier et al., 1973; Wenzel et al., 1977). Perforations of the large bowel are lethal $20 \%$ of the time (Miller and Wichern, 1971; Welch and Donaldson, 1974). Miller and Wichern (1971) found a mortality of $40 \%$ for freely perforated diverticulitis and $6 \%$ for pericolonic abscesses. The outcome of a peritonitis depends on the general condition of the patient before the peritonitis occurred. Welch and Donaldson (1974) re* ported 118 cases of free perforation of colon carcinoma, with a $30 \%$ incidence of death. The age of the patient is a determining factor in the outcome of peritonitis. Dawson (1963) analyzed 665 cases of peritonitis with a mortalitiy of less than $10 \%$ up to the age of 50 . The incidence of death increased with age, until $50 \%$ of the patients over 70 years of age died of all forms of secondary peritonitis, ex. cept that associated with appendicitis. The mortality of peritonitis also rises dramatically in patients who developed renal insufficiency due to the septic process (Braun eval, 1974).

Particular matter up to about 10 microms in diameter is principally removed from the peritoneal cavity by lymphatics. Only the lymphatics of the diaphragm appear to participate in this activity. Electron micrographs have demonstrated the presence of stomata which are automatically limited to the peritoneal mesothelium overlying diaphragmatic lymphatics (Tsilibary and Wissig, 1977). Particles and fluid in the peritoneal cavity were rapidly swept upward by normal respiratory movements and appear in the diaphragmatic lymphatic within a few minutes (Steinberg, 1944; Autio, 1964). Via the thoracic duct the bacteria are filtered in the retrosternal lymph nodes or passed into the systemic circulation where the reticuloendothelial system cleans them from the blood. By means of this mechanism large numbers of a single bacterial species can be cleared from the peritoneal cavity without long-term adverse effects. However, the addition of many, but not all, foreign substances will increase the lethality of a given bacterial inoculum. These include increased necrotic tissue (Altemeicr and Cincinnati, 1942), Barium salts (Sisel et al., 1972), gastric mucin (Ofitzki, 1948), bile salts (Schneierson et al. 1976) and haemoglobin.

Of these, heamoglobin has received the greatest attention as an adjuvant substance. Evidence 
strongly suggest that the bacterial inoculum and the haenoglobin must co-exist within the peritoneal cavity for the adjuvant effect of haemoglobin to be demonstrable and that haemoglobin has no systemic toxic effect which makes the animals susceptible to intraperitoneal bacteria. The clearance of bacteria from the peritoneal cavity is inhibited by haemoglobin. After a pure bacterial inoculation intw the perimneal civily the presence of haemoglobin leads to proliferation of the bacterid rather than rapid clearance (Hau el al. 1978; Yull et al, 1962; Filler and Sleeman, 1967). Polk and Miles (1971) have shown cxperimentally that the presence of ferri-iron in the wound compromise host defence.

Rapid physical absorption of bacteria from the peritoneal cavity is the first line of defence against intraperitoneal infection. However, contamination of the peritoneal cavity results in a stereotyped infammatory response, including degranulation of mast cells with release of histamine and other vasoactive substances. These chemicals cause a local vasodilatation and ontpouring of fluid, containing antibodies and other serum proteins including fibrinogen. The fibrinogen is converted into solid fibrin by local tissuc thromboplastin. Although solid fibrin can seal the preforation of hollow organs, it may catuse trapping of bacteria making it impossible for the leucocytes to reach the micro-orgamisms. The exact role of the fibrin in the establishment of peritonitis is unknown. Trapping of bacteria may present rapid absorption and death of the host from endotoxic shock. So, the peritoneal cavity and its contents can isolate infections into localized pockets by exuding large amounts of fibrin containing fluid. This fibrin network isolates the process by sticking adjacent peritoneal surfaces together. Whether this mechanism ultimately leads to abscess formation is unknown so far. Furthermore, fibrinogen, opsonins, pollymorphonuclear leucocytes and macrophages are exuded into the peritoneal cavity where phagocytosis and destruction of bacteria can take place. The omentum owes its defence properties to its mobility and the sticky properties of fibrin exudates. The sticky omentum may also contribute a collateral vascular supply to ischemic tissue.

\subsection{Septicaemia}

The second serious infective complication after colorectal surgery is septicaemia. Clinically septicaemia is distinguished into a primary and secondary septicaemia. Primary septicaemia is initiated during operation either by inoculating intestinal bacteria into the wound and peritoneal cavity, or by disscminating these organisms into the bloodstream during surgical manipulation. Secondary septicacmia is caused in the postoperative period mainly due to the release of intestinal content in the peritoncal cavity alter anastomotic dehiscence.

The incidence of septicaemia, as such, after colorectal surgery is not well known but is strongly re. lated tho the incidence of anastomotic dehiscence and peritonitis. The incidence of anastomotic breakdown is $9.5 \%(0-52 \%)$ when no prophylactic antibiotics are used and $3.5 \%(0-24 \%)$ when these drugs are given (Clatke et al., 1977; Eykyn et al., 1979; Kusche and Stahlknecht, 1981). Peritonitis, without preoperative antibiotics is reported in an average of $6.5 \%$ of patients $(3-13 \%)$. and when prophylactic antibiotics are used preoperatively in $0.5 \%(0-3 \%)$ (Washington et al., 1974 ; Stonce tal. 1976; Hojer and Wetterfors, 1978; Kusche and Stahlknecht, 1981).

Burton (1973) detected an incidence of $27 \%$ of systemic and portal bacteraemia in patients with large bowel pathology. Positive bloodcultures are most often obtained before or during the operation, suggesting that the bacteraemia results from the colonic disease rather than from the handling of the bowel at surgery. Orthe al. (1972) on the contrary discovered in 15 out of 57 patients a bacteraemia in the peritoneal bloodstream after manipulation of the colon without opening it. $50 \%$ Of these patients had positive bloodcultures from samples of the mesenterial blood. When the large bowel was not handled only 2 out of 46 patients had a positive bloodculture. Positive bloodcultures are rarely found after the third postoperative day unless the patient develops severe septicaemia (Burton, 1973).

Whether a bacteriaemia will give rise to a septicaemia depends on the host defence mechanisms and local circumstances. Bacteria from an intraperitoneal infection can reach the systemic circulation, manly via the diaphragmatic lymphatics and the thoracic duct. While mononuclear phagocytes play 
a minor role in the primary defense of most localized infections, they are clearly important in the septicaemic challenge. The reticulo-endothelial system is a diffuse system of fuxed and wandering mesenchymally derived mononuclear phagocytes which have the common property of being able to ingest foreign particular matter. This system of macrophages has a number of functions, many of which are related to resistance to infection. Reticulo-endothelial depression has been found in a variety of states which are associated with a decreased resistance to the development of infection such as shock during the postoperative period, during bacterial infection, and in warious states associated with immumologic depression. To support the potential role of the reticulo-endothelial system in in. fection, numerous experiments have been done in which a decreased activity of the reticuloendothelial system has been associated with decreased resistance to selected bacterial challenges. On the other hand, other aspects of immunologic defence have not been studied to confirm that it is indeed the recticulo-endothelial system which is contributing most to decreased resistance to infection. Numerous other instances exist in which reticulo-endothelial system depression is not associated with a decreased resistance to infection, and in a few cases, resistance to infection seems to be increased (Bohme, 1960). Furthermore, an increase in reticulo-endothelial activity is usually, but not always, accompanied by an increase in resistance to bacterial infection. Despite lhese conflicting findings, it is relatively clear that removal of micro-organisms from the blood is accomplished primarily by the reticulo-endothelial system, and in doing so, the reticulo-endothelial system contributes to resistance in a major way. (Weslley Alexander, 1972; Meakins, 1976).

\subsection{Prevention of septic complications in colorectal surgery}

If the patient who requires an operation is debilitated and the time permits, careful evaluation of his deficiencies should be made and corrected. The rutritional state of the patient is important for satisfactory healing as well as for avoiding infection. The serum proteins, electrolyte balance and fluid volume should be normal or as near as normal as possible before operation. If there has been a long period of decreased food intake prior to the operation, the body level of trace elements should be evaluated and replaced if necessary. The use of oral or intravenous routes of replacements depends upon the individual patient's condition and the time interval available before operation. Vitamins should also be replaced in these circumstances. The patient should be examined for infections, which if found should be treated during the preoperative period. This would include conditions such as bronchitis, superficial lesions anywhere on the body and chronic urinary tract infections.

It is helpfu\| to shave the operative site as close to the time of operation as is technically feasible to predude the development of infectious lesions in the inevitable nicks and cuts. As a matter of fact, there is some evidence that clipping of hair without shaving is substantially better than shaving alone. Furthermore, utilization of depilatory agents instead of conventional shaving procedures and preoperative cleansing of the surgical site have all been stated to be favorable on the incidenec of wound sepsis.

Contradictory findings concerning skin preparation in the operation theatre are described. Cruse and Foond (1973) found that careful preparation of the skin with povidone-iodine and a mixture of chlorhexidine did reduce the infection rate. This effect could not be confirmed by Davidson et al. (1971), who could not find a significant effect of any agent for desinfecting the skin. Skin carriage of pathogenes and poor skin preparation assessed before desinfection had no effect on wound behaviour.

Plastic adhesive skin drapes, often used in surgery, seem to be of no benefit, other than to fix the Hinen drapes. Raahaven (1976) found a significant difference between the bacterial densities on and under a wound drape in dirty, contaminated operations. However, no effect of plastic wound guards by others could be demonstrated (Jackson et al. 1971; Alexander-Williams et al., 1972; Psaila er al. 1977). Also the ring wound protector type of drape did not seem to offer any particular advantage even in potentially contaminated wounds (Psaila et al. 1977).

Bacterial contamination of the wound with colonic microflora is the most important determining factor in the ultimate behaviour of the wound. The importance of isolating the area of anastomosis from the rest of the abdominal cavity with packs, of discarding all dirty instruments and of changing gloves and gowns before wound closure has been stressed by Hughes (1972). 
The rationale of leaving a wound open is that the bacterial load is spread over a greater area. Host resistance can cope better with the bacteria since the function of granulation tissue prowides a better blood supply to the wound (Stone and Hester, 1973; Paul et al., 1976). Furthermore, the poorly vascularized subcutaneous tissue is not damaged and the drainage of the wound garanteed. In a prospective randomized study the closure of contaminated wounds was compared with the method of delayed primary suture. A significant reduction in postoperative wound infection was seen from 48.7 to 15.6 percent. Most of the wound infections were caused by endemic micro-organisms of the hospital (Stone and Hester, 1973).

Duration of the operation has a significant effect on the wound behaviour. Cruse and Foord (1973) reported that the clean rate doubles with every hour the operation continues. The wound infection rate increases from 7 to 52 percent when an operation goes on for $3 / 2$ hours (Lykkegaard and Nielsen, 1978).

The use of non suction drains increases the chance of postoperative woundsepsis and disruption of a suture line. However, one of the major causes of anastomotic brcakdown after elective colorectal surgery is infection, especially after low anterior resections. Active suction drainage to remove presacral contaminated fluid accumulation showed a decrease of anastomotic dehiscence from $6.9 \%$ in patients without - to $1.1 \%$ in patients with active suction drainage (Hilsabeck, 1981).

Numerous techniques to reduce anastomotic leakage has been described. In general, most patients submitted to low anterior resection are given a colostomy, the only exception to this rule being cases where the colon is found to be virtually empty and the anastomosis is not to low and looks particularly secure when completed. By contrast, in performing high anterior resection, transwerse colostomy is usually omitted unless the colon is exceptionally loaded or gross infection is encountered in the form of peridiverticular abscess (Goligher et al., 1970; Irvin and Goligher, 1973; Abrams et al., 1979). Irvin and Golligher (1973) found as much disruption of the anastomosis in patients treated with or without a colostomy. Simultaneous colostomy prevents not so much anastomotic dehiscence as it renders it less dangerous and facilitates its management if it does occur. However, it cannot be concluded that a defunctioning colostomy affords no protection, since it is frequently reserved for cases which might be expected to do badly. The precise value of a proximal colostomy needs to be evalluated in a randomized prospective trial.

In the prevention of intraperitoneal sepsis and septicaemia in principle, all possible bacteria should be operatively removed from the peritoneal cavity, or killed in situ. The peritoneum should be washed free of all adjuvant substances such as necrotic tissue, mucus, and blood because they may interfere with the physiological host defence mechanisms. After irrigation of the peritoneal cavity with saline it is important to dry the peritoneum because the locomotion and phagocytosis by the neutrophil is best accomplished on a surface, and floating bacteria are difficult to engulf. Fluid accumulation in the peritoneal cavity is detrimental to host defences in other ways as well. The oxygen tension of the fluid within the peritoneal cavity depends on close proximity to peritoneal capillaries. When fluid accumulates in the peritoneal cavity, the poor solubility of oxygen results in a depressed redox potential. Bacteria survive because neutrophils require oxygen for their optimal killing. 


\section{Chapter 3:}

\section{Large bowel preparation before elective colorectal surgery.}

\subsection{Introduction}

As mentioned in chapter 2, the normal bacterial flora of the intestinal tract presents a hazard of infection to the patient in any procedure which involves penetration or opening of the gut wall and the possible escape of contents. Thus it seems rational to attempt to reduce the bacterial content of the intestine when preparing patients for elective surgery so that the danger of contamination from this source with ensuing infection is reduced to a minimum. This has been a challenge for many surgeons throughout this century. The large number of micro-organisms present in the lower gastrointestinal tract makes their removal difficult unless large quantities of substances with wide antibacterial spectra are used. For these reasons complete removal of bacteria from the lumen of the large bowel is difficult if not impossible.

There are three aspects to the prevention of septic complication after elective colorectal surgery:

- Meticulous operative technique.

- Adequat preoperative mechanical cleansing.

- Use of adjuvant chemotherapy.

\subsection{Mechanical cleansing of the large bowel}

\subsubsection{Conventional method}

The object of bowel preparation in colorectal surgery is to empty the colon and rectum of faecal material to prevent faecal impaction proximall to the anastomosis and to avoid the risk of spilling faeces into the peritoneal cavity and into the wound. The large number of organisms present in the lower intestines makes their complete removal difficult if not impossible. The term "sterilization of the bowel" cannot be used in the strict meaning of the term. Conventional mechanical cleansing of the large bowel using a 3-5 day regimen of low or non-residue diet, purgatives and enemas undoubtly reduces the faecal content of the collon, so that less spillage will occur at the time of operation. One of the most used methods of conventional mechanical cleansing is described in Table 3.1. Drawbacks of the conventional methods of preparing the bowel are dehydration and sometimes a catabolic state at time of operation due to the restricted fluid and coloric intake (Sellwood $a t a l$, 1969). The use of enemas is not without drawbacks, especially in case of a partial success, when the content of the bowel is altered from firm faeces to a fluid, the resultant inoculum of potential pathogens, when the gut is opened, may be greater than if no preparation has been used. Furthermore, the conventional cleansing procedure causes discomfort for the patient, a protonged hospital stay and is time consuming for the nursing staf. Nichols ef al. (1977) advised to omit the administration of a cleansing enema on the evening before operation because of the possibility to introduce bacteria back into the colon, not only from the enema itself but also from the perineum and the anal canal. In a colon in which the normal microflora is already suppressed this may lead to colonization and overgrowth with undesirable organisms. It is postulated that mechanical cleansing prior to the oral administration of antimicrobial drugs improves the local concentration of intraluminal antibiotics by shortening the gastro-intestinal transit time and by eliminating gross stool (Nichols et al., 1977) ${ }^{\text {at }}$

\subsubsection{Whole gut irrigation}

Hewitt ef al. (1973) reported an alternative method for preoperative mechanical clleansing of the large bowel. Whole gut irrigation is carried out on the day prior to operation and no dietary restrictions were placed upon the patient. Via a nasogastric tube an irrigation fluid is introduced into the patient with a constant rate of $30-75 \mathrm{ml}$ per minute. The irrigation has to be continued till the rectal effluent is completely clear. This method is rapid, economical and very effective. The absolute con- 
tra-indications for this mechanical bowel preparation are obstruction, perforation of the gastro-intestinal tract and toxic mega-colon. As relative contra-indications renal insufficiency, congestive heart failure and stenosis of the bowel should be mentioned. The method of whole gut irrigation will be discussed at greater length in chapter 5 .

Table 3.1 .

Conventionallarge bowel preparation.

\begin{tabular}{|c|c|}
\hline Day 1: & $\begin{array}{l}\text { - Low residue diet. } \\
\text { - Bisácodyl, I capsule orally at } 6 \text { p.m. }\end{array}$ \\
\hline Dayz: & $\begin{array}{l}\text { - Low residue diet } \\
\text { - Magnesium sulfate, } 30 \mathrm{ml} 50 \% \text { solution ( } 15 \mathrm{~g} \text { ) orally at } \\
10.00 \mathrm{a} . \mathrm{m} ., 2.00 \mathrm{p} . \mathrm{m} \text {. and } 6.00 \mathrm{p} . \mathrm{m} \text {. }\end{array}$ \\
\hline
\end{tabular}

Day 3: $\quad$ - Cleartiquid diet: supplement iv. fluid as needed.

- Magnesium sulfate, $30 \mathrm{ml} 50 \%$ solution ( $15 \mathrm{mg}$ ) orally at

$10.00 \mathrm{a} . \mathrm{m}$. and $2.00 \mathrm{p} . \mathrm{m}$.

- No enemas.

- Nomycin I g and erythromycin base lg orally at 1.00

p.m. 2.00 p.m. and 11.00 p.m.

Day 4: - Operation scheduled at $8.00 \mathrm{a} . \mathrm{m}$.

\subsubsection{Mannitol}

After its introduction whole gut irrigation was proved in general successful. However, the passing of a nasogastric tube and the chance on a fluid retention accompaning this method. These could be avoided by the use of osmotic cathartics, and the oral administration of a $10 \%$ mannitol solution was introduced, used alone or in combination with whole gut irrigation. Mannitol is not absorbed and by osmotic forces fluid is moved from the circulation into the lumen of the bowel (Davis et al., 1980; Donovan et al., 1980; Minervini et al. 1980, Taat et al., 1981). Minervini et al., (1980) reported a reduction in the fluid gain from $2740 \mathrm{ml}$ in a group of patients prepared by whole gut irrigation alone to $1160 \mathrm{ml}$ in a group prepared by means whole gut irrigation which was preceded by the oral administration of a $500 \mathrm{ml} 10 \%$ mannitol solution. When the mechanical cleansing was performed with the oral administration of $5 \%$ mannitol solution, 4.4 liters of this solution were required to clean the colon.

Mannitol is a non absorbed oligosaceharid and a relative high concentration will be present in the colon where it is likely to be motabolised by faccal bacteria. The fermentation products are methane and hydrogen (Davis et al., 1980; Bigard et at., 1979). Taylor et al. (1981) and Keighley et al. (1981) found a high incidence of potentially explosive gases in patients prepared with oral mannitol. In palients having only whole gut irrigation or no bowel preparation at all, there was still a percentage with oxplosive gas but the amount was less than in paticnts prepared with oral mannitol. In patients, receiving orall mannitol and a combination of neomycin and metrondazole, no explosive gases were found. The production of hydrogen results from the metabolism of carbohydrates. The production of methane appears, to have no relation to diet and seems to depend upon the constitution of the intestinal micro-flora. Bigard ef al. (1979) reported the deat h of a patient due to colonic explosion during colonscopic polypectomy after large bowel preparation with or al mannitol.

Oral mannitol avoids the need for repeated enemas and the passage of a nasogastric tube, which are disadvamtages of conventional bowel preparation and whole gut irrigation respectively. Further, oral mannitol, unlike whole gut irrigation, is not associated with water retention and therefore makes it a much safer method for bowel preparation in the elderly patient with cardiac disease.

\subsubsection{Elemental diet}

Non of the usual methods of bowel preparation guarantec an aseptic large bowel. The purpose is to reduce the intestinal flora quantitatively, which cannot be achieved by mechanical cleansing alone. During the conventional preparation, which lasts for several days, caloric and amino-acid intake is 
insufficient. Therefore alimentation with elemental diet often has been used. The aim of the diet is that it is totally absorbed in the small intestine, leawing the large bowel clean, and reduces the bacterial flora. Winitzet al. (1970) found that the provision of a glucose-based diet during two weeks as the sole source of nutritional support was accompanied by faecal specimens which showed marked reductions in microbial population. Arabi et al. (1978) reported a small reduction in the numbers of E. coll after the administration of an elemental diet. However, further studies failed to demonstrate these findings (Glotzer et al, 1973; Russel, 1975; Schiessel et al. 1978). In general it can be concluded. that an elemental diet produces a low faecal bulk, but does not cause a significant reduction in bacterial counts nor changes in specific species or types of aerobic and anaerobic bacteria. (Glotzer et al. 1973).

One of the disadvantages of this form of treatment is the relative unpalatability of the diet. A variety of flavourings are available which can improve the taste and makes it more acceptable to patients. Nausea ma occur if an elemental diet is ingested too rapidly and sometimes overhydration may occur (Glotzer et al, 1973; Johnson, 1974; Russel, 1975).

Gurry and Ellis-Pegler (1976) compared a group of patients receiving a preoperative bowel preparation with an elemental diet with a control group. No significant differences were seen in postoperat tive wound infections or other septic complications. Furthermore, the colonic microflora was not influenced, neither qualitatively nor quantitatively, after a 2 or 4 day regimen of elemental diet.

\subsection{Use of antibiotics in elective colorectal surgery}

\subsubsection{Prophylactic use of antibiotics}

Whether infection develops in the contaminated wound depends upon both local and systemic factors. Local factors include the amount of nonviable and contaminated tissue, the number and specics of bacteria present, the adequacy of blood supply to the injured tissue, the adequacy of postoperative drainage of loculated fluid, the presence of a foreign body in the wound, and a sufficient concentration of antimicrobial substances in the tissue at time of contamination. Systemic factors, influencing wound infection rates include: age of the patient, underlying disease(s) and nutritional status. Additional factors include the duration of the operation and the skill of the surgeon.

The degree of bacterial contamination of the operative site during surgery exerts a profound effect on the subsequent rate of wound infection. For this reason, preoperative or intraoperative classification of surgical procedures according to parameters known to correlate with bacterial contamination permits more accurate assessment of the likelihood of wound infection and of the need for antimicrobial prophylaxis. According to the standards of the American College of Surgeons (Flynn and. Lawrence 1979) operations are classified in clean, clean contaminated, contaminated and dity (Table 3.2.)

Table 3.2 .

Intraoperative classification of surgical procedures.

Clean

The gastrointestinal, respiratory and urinary tracts are not entered, no appesurent inflammation is encountered and no breaks in aseptic technique occur. Cholecystectomy, incidental appendectomy and hysterectomy are included in this category if no inflammation is present.

Clean-contaminated - A contaminated area is entered, there is no significant spillage.

Contaminated

Acute inflammation (but without pus) is encounterd, or gross spillage from a hollow viscus occurs. Fresh tramatic wounds and operations in wich major break in aseptic technique occurs are included.

Dirty

Pus spillage, perforation of a viscus, and tranmatic wounds untreated for more than four hours are included in this category.

Antimicrobial prophylaxis is the administration in the absence of infection with the aim to prevent infection when contamination occurs. Unlike the therapeutic situation in which the identity of the 
offending microbe might be in doubt and there is urgency in selecting therapy, with chemoprophylaxis there is usually no urgency, and the microbes in question are known. Consequently, the use of untimicrobial drugs in che moprophylaxis should be more rational than in therapy.

In clean surgical wounds the infection rate is below $5 \%$. In these operations the disadvantages of antimicrobial prophylaxis, financial and ecologic, probably will exceed the benefits in most cases. A large number of patients will receive medication unnecessaraly to prevent infection in a few. Also the costs necessary to prevent these few infections will far exceed the costs of treatment of infections.

In clean-contaminated operations there is entry into tracts that have an abundlant resident flora, and minor spillage is difficult to awoid, even with the most scrupulous technique. The rational for the use of an antimicrobial agent, is either to reduce the resident flora before surgery to such a low level that normal host defences can handle the number of organisms involved in minor spillage, or to have adequate drug levels in tissue during and directly after surgery in order to kill the organisms that gained entry into the normally sterile tissues. Infection is sufficiently frequent in these operations to wartant an effective prophylaxis that reduces postoperatiwe morbidity, and costs and duration of hospitalization. Paradoxically, routine prophylaxis in this class of operations may reduce the total use of antimicrobial agents by decreasing their use in relatively protracted courses of therapy for established postoperative infections.

In contaminated or dirty operations, organisms are already present in normally sterile sites, and the use of antimicrobial agents respresents "early therapy" rather than prophylaxis.

Surgical antimicrobial prophylaxis requires adherance to certain principles. Flynn and Lawrence (1979) have stated and explained these as follows:

Limit the use to procedures associated with a relatively high rate of postoperative sepsis, or in which consequences of infection are particularly serious.

A reasonable approach to the use of antibiotics to supplement host resistance and prevent postoperative infection may be stated as follows: Preventive antibiotics are indicated if there is a high probability that a patient's normal resistance to bacterial invasion will not overcome the combined bacterial and physiological challenge of a surgical procedure. Or in other words; prophylactic antibiotic supplement is reasonable, only if the risk of infection or infectious morbidity or mortality is clearly greater than the risk of side reactions to the prophylactic antibiotic drug.

Use of antimicrobial agents effective against major anticipated contaminating bacterial species.

Use effective agent of lowest possible toxicity and cost to the patient.

Maintain serum and tissue levels of the agent above the Minimum Inhibitory Concentration (M.I.C.) of contaminating species throughout the procedure.

To make most effective use of prophylactic antibiotics it is not only necessary to choose an agent which is effective against organisms most likely to cause postoperative infections but the antimicrobial drug must be present in the circulating blood and more especially in local tissues at the time of contamination in a concentrations of at least the Minimum Inhibitory Concentration (M.I.C.). The M.I.C. is defined as the lowest concentration of antimicrobial agent which prevent visible growth of bacteria in vitro. Furthermore, the physician must give careful consideration to the pharmacology of the antimicrobial agent and must be thoroughly acquainted with its potential side effects.

Administer agent sufficiently in advance of operation to permit absorption and distribution to tissue but not so long as to promote bacterial resistance.

The keystone of the perception of the appropriate principles lies in a series of simple but ellegant experiments done by Miles et al. (1957).

Using interdermal lodgement of bacteria in Guinea pigs as the index for degree of infection, they 
were able to show that antibiotics administered before or simultaneously with challenge by bacteria sensitive to the antibiotic in question were just as efficacious as autoclaving the bacterial challenge mixture. They also demonstrated that initiation of such prophylaxis four hours or move after the bacterial challenge was securely implanted allowed lesions to develop just as if the antimicrobial agent had never been given at all. The rationale is clear and should have been perceived long before: systemic antibiotics given before or simultaneously with challenge by bacteria sensitive to those antibiotics produce a profound effect. Delayed administration of antibiotics produced essentially no effect. Subsequently Polk and Miles (1973), in a sophisticated system for the assessment of in vivo bacterial growth, demonstrated that these concepts were absolutely valid in an entirely dissimilar system and that the inflammatory response was appropriately and precisely representative of numbers of viable bacteria. These observations led to a new series of clinical studies emphasizing the value of antibiotics systemically administered for all sites of operative manipulation and contamination before the inevitable contamination. Stone et al. 1976, distinguished four treatment categorics with the antibiotics being instituted 12 hours preoperatively, just prior to operation or not at all, in patients undergoing elective surgery of the large bowel, stomach or biliary tract. A routine preoperative bowel treatment with mechanical cleansing, neomycin and erythromycin orally administered was performed in patients scheduled for elective colorectal surgery. The incidence of wound infection was reduced significantly by the preoperative administration of antibiotic in operation on the stomach (22\% to $4 \%$ ) on the biliary tract (11\% to $2 \%$ ) and large bowel (16\% to $6 \%$ ). Less impressive results were obtained for peritoneal sepsis. Initiation of antibiotic postoperatively gave an almost identical infection rate as if antibiotic had not been given (15\% and $16 \%$ ).

Polk and Lopez-Major (1964) reported a statistically significant reduction in postoperative wound infections after gastrointestinal surgery with the use of cephaloridine as prophylactic antimicrobial agents.

Accepting the concept of the decisive period, antibiotic prophylaxis after the moment of contamination conceivably would not likely to be effective. However, animal experiments have consistently shown some reduced benefit from antibiotics initiated one to two hours after contamination (Burke, 1961).

Although not controlled and retrospective, the important study of Fullen et al. 1972, indicated that penetrating abdominal wounds received some protection if antibiotic prophylaxis (early treatment) was initiated promptly when the patient reached the hospital.

Prolonged administration is rarely indicated in clean or clean-contaminated surgery.

The experimental evidence underlying the use of preventive antibiotics indicates that the antibiolic substance is most effective if it is circulating in the interstitial space when the contaminating bacteria arrive. For the large proportion of surgical procedures, this penod is the time during which the wound is open. After closure of the wound the risk of bacterial contamination is clearly reduced. Since that antibiotics are effective in preventing infection is three hours after the occurrence of bacterial contamination of the tissues, and since bacterial contamination in most surgical procedures ends when the wound is closed, there is little evidence to support prophylactic administration of antibiotics past the period of operation and recovery of normal physiology after anesthesia. On these theoretical grounds one might expect that one single dose is as effective as a prolonged regimen (Burke, 1964). However, other experimental studies have shown somewhat longer effective periods of preventive antibiotic action in primary closed wounds, varying from 12 hours (Alexander and Altemeier, 1965) to 24 hours (Edlich et al.,1973; Ulrich, 1981). Moreover, an outgrowth of bacteria that survive the preoperative antibiotic administration can be expected 5 - 7 hours after the initial contamination, as was demonstrated in an experimental situation by Polk and Miles(1973). Antibiotic prophylaxis should in their opinion produce adequate antibiotic concentrations ower somewhat longer periods of time.

In the clinical trials of recent years there is a trend to give only an antimicrobial prophylaxis of short duration. A short prophylaxis of 24 hours perioperative proved often to be as successful as a more prolonged administration of 3-5 days in reducing postoperative septic complications (Washington et al., 1974; Downing et al., 1976; Stone et al., 1976; Clarke et al., 1977; Nielsen et al., 1978; Eykyn et 
al. 1979; Hofman et al. 1980). A single dose of an appropriate antibiotic drug given preoperatively proved to be effective in reducing wound infections in studies by Griffith et al. (1976); Leigh et al. (1976) and Hanel ef al. (1980). Ulrich (1981) in contrary found better results with a 24 hours regimen than with a single dose of antibiotics.

The duration of the prophylaxis depends on the pharmacokinetics and the antibacterial activity of the drug administered. Especially the time needed to reach the M.I.C. value at the site, the time the M.I.C. is maintancd and the killing-rate at the M.I.C. or higher concentration values are of impor. tance. In witro studies showed that metronidazole produced sterile cultures after 6 hours, clindamycin took over 30 hours to produce a similar effect and cefoxitin, offer an initial reduction, allowed regrowth of the organisms (Selkon, 1980).

Potential harm resulting from antibiotic therapy cannot be ignored. Drug toxicity, allergic reactions, and in particular the development of resistant bacterial strains certainly appear to be potential if not actual significant threats. However, a short regimen of antimicrobial prophylaxis, allows literally no patient to serve as a focus for emergence and selection of resistant organisms.

In conclusion, it must be emphasized that there is a definite place for the prophylactic use of antibiotics. However, it can never substitute for excellence in operative skills, patient and procedure selection, thoroughness of postoperative care, and, most important of all, operating room discipline.

\subsubsection{Antimicrobial prophylaxis in elective colorectal surgery.}

The most common finding in septic complications following colorectal surgery is a mixed enteric flora of acrobes and anaerobes. E. coli and B. fragilis are by far the most frequent isolates from septic foci and it is probable that a reduction in these organisms is the most important factor in the protection agaunst septic complications (Keighley et al., 1976; Bartlett et al., 1978; Yura et al., 1978).

Prophylactic administration of antibiotics has two, not necessarily exclusive objectives. First, an increase in wound defences against bacterial invasion by increasing tissue antibiotic levels, achicved by systemic or topical administration. Second, reduction of the number of bacteria in the resident col. onic flora, and ${ }_{x}$ therefore the number likely to gain access to sterille tissues, by administration of oral antimicrobial agents. With the use of oral antibiotics even for a few days there is always the risk of the emergency of resistant strains and, due to a change in the intestinal flora, a risk of superinfection by staphylococci or candida. (Altemeier et al., 1963; Nichols and Condon, 1971; Hartley et al., 1978, Keighley et al. 1979). A theoretical advantage of oral use of non absorable antibiotics is the minimized risk of systemic drug-related reactions due to poor absorption.

One of the principles of effective antimicrobial prophylaxis is the use of antimicrobial agents effective against the principal bacterial species which can be anticipated to contaminate the wound area. As already mentioned $E$. coliand $B$. fragiles are the most frequent organisms aecovered from infectious complications of colorectal operations. The effective antimicrobial therapy has therefore to be directed against $E$. coli and $B$. fragilis. $E$. coli is sensitive to the antibiotics listed undre group II in Table 3.3. and B. fragilis is sensitive to those listed under group II. As yet there is no single antibiotic avalable which is active on all of the bacterial species likely to be present in the intestinal tract and therefore the best results have been obtained with the use of a combination of agents.

Table 3.3 .

Antibiotic sensitives of faecal bacteria

$\begin{array}{ll}\text { Groupl } & \begin{array}{l}\text { Group II } \\ \text { Anti-Anoerobe }\end{array} \\ \text { Ant-Aerobe } & \text { Clindamycin } \\ \text { Aminoglycosides } & \text { Metronidazole } \\ \text { Cephalosporins } & \text { Cefoxitin } \\ \text { Anpicillin } & \text { Tetracyclines } \\ \text { Tetracyclines } & \text { Etythromycin } \\ \text { Chloramphenicol } & \end{array}$

In the following review of the literature only the prospective randomized well controlled studies, about oral - and systemic antibiotic prophylaxis, in elective colorectal surgery, will be mentioned. 
Trials performed before 1970 were excluded because changes, during the last decade, in medical and surgical care make the older work difficult to interpret and to apply to contemporary practice.

The most frequent but less serious complication after colorectal surgery is wound sepsis. The rate of wound sepsis is used as parameter for the effectiveness of antimicrobial prophylaxis in colorectal surgery. It is suggested that the rate of wound infections is closely correlated with the more serious complications such as peritonitis, septicaemia, intra-abdominal abscesses and leakage of anastomoses. In a review of recent literature Kusche and Stahlknecht (1981) reported the following incidences of serious septic complications after elective colorectal surgery. Table 3.4 .

Table 3.4.

Intluence of antimicrobial prophylaxis on serious postoperative septic complications after elective colorectal surgery.

(Kusche and Stahlknecht, 1981).

\begin{tabular}{lcc} 
Complication & $\begin{array}{c}\text { Complication rate }(\%) \\
\text { with prophylaxis }\end{array}$ & $\begin{array}{c}\text { Complication rate } \\
\text { without prophylaxis }\end{array}$ \\
\hline Dehiscence of anastomosis & $3.5(0-24)$ & $9.5(0-52)$ \\
Intratabdominal abscess & $2.5(0-13)$ & $1.0(4-21)$ \\
Peritonitis & $0.5(0-3)$ & $6.5(3-13)$ \\
\hline
\end{tabular}

\subsubsection{Lincomycin and clindamycin.}

Table 3.5. summarizes the studies on antimicrobial prophylaxis with lincomycin or clindamycin in elective colorectal surgery. Keighley et al. (1976) showed that a 5 days course of parenteral lincomycin reduced the total postoperative septic complications from $45 \%$ to $18 \%$. The wound infection rate was significantly reduced from 38 to $12 \%$. All wound infections in the placebo group were mixed aerobic/anaerobic infections while in the antibiotic group one mixed infection occurred. Similar results were reported by Downing et al. (1976). In his series only one mixed anaerobic infection was seen in the treated group. In the same study hardly any difference was seen between a 5 dany course of systemic administered lincomycin and a 24 hours regimen. The investigations of Keighley er al. (1976) were continued by Alexander-Williams et al. (1976) in the same hospital. He studied the effect of the combination of tobramycin and lincomycin in a 24 hours course. Apparently the addition of tobramycin to the regimen had no effect on the incidence of postoperative infections caused by aerobes.

The patients treated by, Stokes ef al. (1974), are prepared by means of conventional mechanical cleansing with additional neomycin. One group of patients received twice a day systemic lincomycin and tobra or gentamicin. The control group received placebos on the day of operation. In the test group $1 \%$ postoperative wound sepsis was noticed while in the control group $9 \%$ of the paticnts de. veloped a wound infection. No anaerobic micro-organisms could be cultured in the antibiotic treated group.

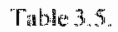

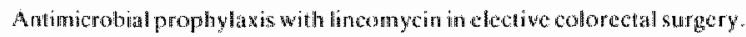

\begin{tabular}{|c|c|c|c|c|c|c|c|}
\hline \multirow{2}{*}{ Reference } & \multicolumn{2}{|c|}{ Testgrands } & \multicolumn{2}{|c|}{ Controlgrowp } & \multirow[b]{2}{*}{ 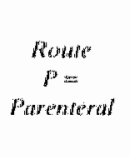 } & \multirow[b]{2}{*}{$\begin{array}{c}\text { Pantem } \\
n=\end{array}$} & \multirow{2}{*}{ Sigfificancer } \\
\hline & Antibionic & $\begin{array}{c}\text { Jroidence } \\
\text { Woundsepse } \\
(\%)\end{array}$ & Antibionic & $\begin{array}{c}\text { Ancridence } \\
\text { Wonowdsepsis } \\
(\%)\end{array}$ & & & \\
\hline Koighley $T^{\prime}$ & Lincomyciry & $4 / 33(12)$ & - & $11 / 29(38)$ & $p$ & 62 & $s$ \\
\hline Downing 76 & Lincomycin & $4 / 33(12)$ & $\ldots$ & $11 / 2 y(38)$ & P & 62 & $\mathrm{~S}$ \\
\hline $\begin{array}{l}\text { Alexandor } 76 \\
\text { Wiltians }\end{array}$ & $\begin{array}{l}\text { Lincomycin } \\
\text { Tobramyein }\end{array}$ & $6 / 33(18)$ & - & $1 / 29(45)$ & $\mathbb{3}$ & 62 & $\mathrm{~s}$ \\
\hline Stokes: 74 & $\begin{array}{l}\text { Lincomycin } \\
\text { Tobramyein } \\
\text { or Gentamicin }\end{array}$ & $1 / 85(1)$ & - & $890(9)$ & $p$ & 175 & $\$$ \\
\hline Foathers 77 & $\begin{array}{l}\text { Lincomycin } \\
\text { Gentanicin }\end{array}$ & $0 / 14(0)$ & - & $12 / 25(48)$ & $\mathrm{p}$ & $30)$ & $s$ \\
\hline Ulitich 'st & $\begin{array}{l}\text { Clindamycin } \\
\text { Kanamycin }\end{array}$ & $2 / 25(8)$ & - & $\| 624(66)$ & p & 45 & $\mathrm{~s}$ \\
\hline
\end{tabular}


Feathers ef al. (1977), reponted the results of a prospective tral comparing systemic prophylactic use of lincomycin and gentamicin daring 5 perioperative days. A reduction from $48 \%$ to $0 \%$ occurred in the postoperative wound sepsis. However, two patients developed a psendomembranous colitis of whom 1 died. Ulrich (1981), described a series of 49 patients in his thesis. Two out of 25 patients developed a postoperative wound infection after a 24 hours systemic clindamycin and kanamycin prophylaxis, while $66 \%$ of the 24 controls had a mixed aerobic-anaerobic infection.

Although lincomycin, alone or in combination with other antimicrobial drugs, has shown to be an effective prophylactic drug in elective collorectal surgery, the use of it should be reconsidered because of the high association with pseudomembranous colitis. Pseudomembranous colitis is a severe necrotizing inflammation of the large bowel and is considered as one of the most serious side effects of antibiotics. The relationship between linco- and clindanycin and pseudomembranous colitis is well established (Tedesco et al., 1974). Until 1977 the aetiology was unknown but it has now been recognized that pseudomembranous colitis is in fact an infection caused by toxigenic strains of $\mathrm{Cl}$. difficile (Rifkin et al., 1977).

\subsubsection{Aminoglycosides.}

Aminoglycosides, particularly neomycin and kanamycin have been widely used as prophylaxis for colorectal surgery. These drugs are effective against aerobes including $E$. coli and Ps. aeroginosa, but they have no effect on the anaerobic flora and on faecal streptococci Aminoglycosides are poorly absorbed from the gastrointestinal tract and are nephrotoxic and ototoxic. They may interact with anaesthetic agents and muscle relaxants, to give prolonged neuromuscular blockade (Pittinger et al, , 1970).

As might be expected from the known antibiotic sensitivities of the major faecal pathogens, oral aminoglycosides as a single agent have not been efficacious in reducing the overall incidence of septic complications associated with colorectal operations. (Washington et al., 1974; Wapnick et al. (1979). Aminoglycosides control the aerobes but they fail to control the anaerobes and their use results in a shift of the species of bacteria associated with septic complications but not in a reliable reduction of their incidence.

Data from recent controlled trials with neomycin and kanamycin are summarized in Table 3.6. Data about the use of gentamicin and tobramycin are mentioned in Tables 3.5 and 3.7 and discussed in paragraphs 3.3.2.1 and 3.3.2.3. Washington ef al. (1974), demonstrated again the uselessness of neomycin as a prophylactic antimicrobial drug in elective colorectal surgery. In well controlled trial the wound sepsis rate in the neomycin group was $41 \%$ and in the placebo group $43 \%$ after 48 hours perioperatively orally administered neomycin. Remarkable is that only one patient in the neomycin group and five patients in the placebogroup developed an aerobic sepsis.

Tallste 3 .

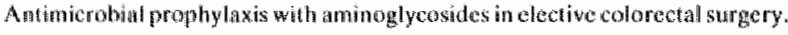

\begin{tabular}{|c|c|c|c|c|c|c|c|}
\hline \multirow{2}{*}{ Reforentere } & \multicolumn{2}{|c|}{ Tastigromp } & \multicolumn{2}{|c|}{ Contralgroup } & \multirow{2}{*}{$\begin{array}{c}\text { Ronte } \\
E= \\
\text { srateral }\end{array}$} & \multirow{2}{*}{$\begin{array}{c}\text { Patients } \\
n=\end{array}$} & \multirow{2}{*}{ Significantecte } \\
\hline & Antribiati: & 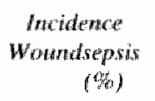 & Annibionic & $\begin{array}{c}\text { Whoidence } \\
\text { Wowndsephis } \\
\text { (\%) }\end{array}$ & & & \\
\hline Washingtron 7 & 74 Noomycin & $28 / 68 \quad(41)$ & - & $2763 \quad(43)$ & $\mathrm{E}$ & $13 \|$ & NS \\
\hline Nichols "7n & $\begin{array}{l}\text { Neamycin } \\
\text { Erythromygcin }\end{array}$ & $0 / 10(0)$ & - & $310(30)$ & $E$ & 20 & NS \\
\hline Farmer "75 & $\begin{array}{l}\text { Neomycin } \\
\text { Erythromyein }\end{array}$ & $474(5)$ & - & $8 / 23 \quad(35)$ & $E$ & 97 & $S$ \\
\hline Claske 77 & $\begin{array}{l}\text { Neconnycin } \\
\text { Enythromycin }\end{array}$ & $5 / 56(9)$ & - & $21460(35)$ & $\mathrm{E}$ & 116 & $s$ \\
\hline Vargigsto '78 & $\begin{array}{l}\text { Neominycin } \\
\text { Eryihrombycin }\end{array}$ & $3 / 30(10)$ & Neomycin & $4 / 32(13)$ & $E$ & 62 & NS \\
\hline Wapnick "79 & $\begin{array}{l}\text { Kanamycin } \\
\text { Erythromyein }\end{array}$ & $1 / 28(4)$ & Kanlataycin & $10 / 23 \quad(43)$ & $E$ & 51 & $\$$ \\
\hline Solnevitors 76 & $\begin{array}{l}\text { Neomyen } \\
\text { Bataticin }\end{array}$ & $7 / 50 \quad(14)$ & - & $28158 \quad(48)$ & $\mathrm{E}$ & 108 & $S$ \\
\hline Stathlknecht 7 & $\begin{array}{l}70 \text { Neomycin } \\
\text { Bacituricen }\end{array}$ & $741(17)$ & - & $24445 \quad(53)$ & $E$ & 86 & $\mathrm{~s}$ \\
\hline Jürgensen & $\begin{array}{l}\text { Neomycin } \\
\text { Baciltacin }\end{array}$ & $18 / 1001(18)$ & Teiracyctine & $10 / 115(9)$ & $\mathrm{E}$ & 216 & NS \\
\hline
\end{tabular}


The combination neomycin and erythromycin is very widely used in the U.S.A. and it is for this reason that particularly the results are mostly published in the American literature. The majority of the anaerobic micro-organisms in the large bowel are sensitive for erythromycin. Erythromycin is well absorbed from the bowel but erythromycin-base is incompletely absorbed from the gastrointestinal tract. Nichols ef al. (1973), described a small series of 20 patients. The antibiotic group received preoperatively neomycin and erythromycin-base orally for 19 hours. None of the treated patients and $30 \%$ of the place bo group developed a postoperative wound infection.

Significance was not reached due to the small series. A similar study was performed by Farmer (1975) in 97 patients with colonic cancer. After conventional mechanical cleansing 74 patients received neomycin and erythromycin orally and 23 patients a placebo. Postoperative wound infections occurred in $5 \%$ of the treated and in $35 \%$ of the placebo group.

In a well controlled multicenter trial of Clarke et al. (1977), an overall rate of directly related septic complications was noticed of $43 \%$ in the placebo group and of $9 \%$ in the antibiotic group. The antibiotic testgroup received orally neomycin and erythromycin-base on the last preoperative day. All patients underwent a conventional mechanical cleansing of the large bowel. The wound infection rate was reduced significantly from 35 to $9 \%$. Postoperative pus cultures were not performed. The study of, Vargish et al. (1978) revealed no statistical significance in postoperative septic complications after neomycin / erythromycin prophylaxis in the test group and neomycin in the controlgroup. Sixty $\%$ of the wound infections in this study were caused by micromorganisms different from those found in the colonic microflora. However, this study was not well controlled for the intra- and postoperative course. In all these studies the oral antimicrobials were given on the day before operation.

The combined oral use of relatively large amounts of erythromycin and kanamycin for 2 days prior to elective colon surgery resulted in a significant reduction of postoperative wound infections as compared with that in patients who received kanamycin alone from 43 to $8 \%$ (Wapnick et al., (1979).

Bacitracin is an antibiotic drug active against anaerobic bacteria and widely used in Germany. Schneiders ef al. (1976) prepared their patients before elective colorectal operations by means of mechanical cleansing and additional neomycin and bacitracin orally administered at 4 preoperative days. With this preparation the postoperative wound sepsis rate reduced signficantly from $48 \%$ to $14 \%$. Similar results were reported by Stahlknecht et al. $(1979), 17 \%$ wound infection in the test group compared to $53 \%$ in the control group in a series of 86 patients.

This prophylactic regimen was compared with a 6 days perioperative use of tetracycline by Iorgensen and Weile (1974) in a large controlled series of 216 patients. They found no statistically significant difference in postoperative septic complications between the two groups.

\subsubsection{Metronidazole.}

Metronidazole is an antimicrobial with bactericidal activity specific for anaerobes (especially Bacteroides species). Aerobes are not affected. In combination with aminoglycosides this drug is frequently used as antibiotic prophyllaxis in colorectal surgery. Data from recent controlled prospective trialls are summarized in Table 3.7.

Goldring et al. (1975) reported a series of 50 patients. Two out of 25 patients prepared by means of mechanical cleansing and 3 days oral metronidazole and kanamycin administered prior to operation developed a superficial aerobic wound infection. In the control group the wound infection rate was $44 \%$, and all of the infections were caused by mixed infections of aerobic and anaerobic microorganisms. The same antibiotic prophylactic regimen was used by Gillespie and McNaught (1981). The postoperative wound sepsis rate was reduced from $46 \%$ in the control group to $12 \%$ in the treated group. A highly significant reduction. Half of the wound infections in the antibiotic group were caused by staphylococci, no anaerobes were isolated. Almost all the wound infections in the control group were mixed aerobic/anaerobic infections.

Two comparable studics, with an oral administration of neomycin and metronidazole 48 hours before surgery were described by Keighley et al. (1978) and Matheson et al. (1978). In both studies the wound sepsis rate was reduced significantly and no anaerobes were isolated from infected wounds in the treated patients. However, almost all septic complications in the placebo group were caused by mixed aerobic/anaerobic infections. Other septic complications such as anastomotic break down, septicaemia, and the duration of the hospital stay were reduced significantly after antibiotic prophylaxis with neomycin and metronidazole. 
Table 3.7

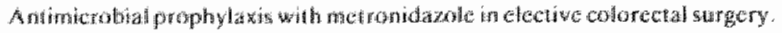

\begin{tabular}{|c|c|c|c|c|c|c|c|}
\hline \multirow{2}{*}{ Reforence } & \multicolumn{2}{|c|}{ Turstgratop } & \multicolumn{2}{|c|}{ Conarofgroup } & \multirow[b]{2}{*}{$\begin{array}{c}\text { Roure } \\
E= \\
\text { Enseral } \\
P= \\
\text { Parenteral }\end{array}$} & \multirow{2}{*}{$\begin{array}{c}\text { Pandents } \\
n=\end{array}$} & \multirow{2}{*}{ Shignifacdace } \\
\hline & Anthionstic & $\begin{array}{c}\text { Inadence } \\
\text { Woundepsis } \\
\text { (ry) }\end{array}$ & Anwbutotic & 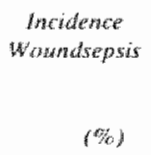 & & & \\
\hline Goldring 75 & $\begin{array}{l}\text { Actronid carole } \\
\text { Kanamycin }\end{array}$ & $2 / 25(8)$ & $\cdots$ & $11 / 25(44)$ & $E$ & 50 & $S$ \\
\hline Gillospie "7x & $\begin{array}{l}\text { Menronidiazele: } \\
\text { Kantamycinn }\end{array}$ & $4 / 34(12)$ & - & $17 / 37(46)$ & $E$ & 71 & $S$ \\
\hline Matheson $7 \%$ & 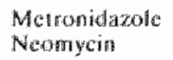 & $9 / 1(18)$ & سـ & $25159(42)$ & $\mathbb{E}$ & $\| 10$ & $S$ \\
\hline Keightey "78 & $\begin{array}{l}\text { Metronidarate } \\
\text { Nemongen }\end{array}$ & $0 / 30(30)$ & - & $2033761)$ & $f=$ & 63 & $S$ \\
\hline Willis 77 & $\begin{array}{l}\text { Mothoridazolè } \\
\text { Oentarnic irs }\end{array}$ & $4 / 27(15)$ & Contamicin & $11 / 19(58)$ & $E / P^{n}$ & 46 & $S$ \\
\hline If faugen 79 & Metrontarale & $2 / 7(12)$ & - & $82 \square(38)$ & $\mathbf{E}$ & 38 & $S$ \\
\hline Eykyn 718 & Marronidazolo & $13 / 44(30)$ & 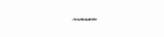 & $25 / 39(64)$ & $\mathrm{P}$ & 83 & $\mathrm{~s}$ \\
\hline Brsisso 78 & $\begin{array}{l}\text { Merongdazole } \\
\text { Neonycin } \\
\text { Cephablain }\end{array}$ & $2 / 39(5)$ & $\begin{array}{l}\text { Enythromycin } \\
\text { Noomycin } \\
\text { Cophalothin }\end{array}$ & $1040(25)$ & EP & 79 & $\$$ \\
\hline
\end{tabular}

Due to the increasing awareness of the importance of non-sporing anaerobes as a major cause of sepsis after surgery of the gastrointestinal tract a number of authors (Leigh, 1975; Keighley et al., 1976; Willis eral., 1977; Matheson et al. 1978) reported studies with metronidazole alone.

In a small randomized trial the effect of metronidazole on anaerobic postoperative infections was tested by Willis er al (1977). All patients received systemic gentamicin at premedication. One group was treated with metronidazole for 7 days, which was started 24 hours before surgery. A control group received placebo"s for 7 days.

Fiffy-eight \% of the control group developed a mixed acrobic/anacrobic wound infection while $15 \%$ in the metronidazole treated group developed a superficial acrobe wound sepsis. Willis stated that the anaerobic bacteria were far the most important in postoperative septic complications and that the gentamicin could be omitted. Hagen et al. (1979) confimed this statement in a study with 38 patients; $12 \%$ of these patients developed an aerobic superficial wound sepsis after 48 hours oral metronidazole prophylaxis. In $38 \%$ of the patients in the control group mixed acrobic/anaerobic infections was noticed. A remarkable high incidence of wound sepsis was seen by Eykyn et al. (1979) in patients receiving a 24 hours systemic prophylaxis with metronidazole. In the metronidazole group 7 superficial aerobic and 6 deep mixed aerobictanacrobic wound infections were seen (30\%). In the control group the incidence was $69 \% ; 20 / 25$ were deep mixed aerobic/anaerobic and $5 / 25$ were superficial aerobic and aerobic/anacrobic mixed infections. A very high rate of clinical anastomosis break down was reported in this study: $28 \%$ in the antibiotic - and $18 \%$ in the placebogroup.

In a Canadian study (Brass et al., 1978) the combinations neomycin/erythromycin and neomycin/ metronidazole were compared. Both groups received oral neomycin and systemic cephalothin during a 24 hours perioperative period. In one group metronidazole was given orally on the last 2 preoperative days, while the control group received erythromycin for one day. The two groups showed a significant difference in postoperative wound infections. Five $\%$ in the metronidazole group and $25 \%$ in the erythromycin group. The wound infections in the metroniclazole group were caused by staphylococci whereas colonic florit was cultured from the infected wounds in the erythromycin group. Although the results suggest that metronidazole did reduce the postoperative sepsis rate, a definite conclusion is not possible because of the differences in prophylactic regimens.

\subsubsection{Cephalosporins.}

Controlled trials of systemic cephalosporin prophylaxis for elective colorectal surgery have yielded somewhat variable results. The results of recent trials are summarized in Table 3.8.

In an older study by Polk and Lopez-Mayor (1969) the prophylactic use of cephaloridine for various 


\begin{tabular}{|c|c|c|c|c|c|c|c|}
\hline \multirow{2}{*}{ Worterater } & \multicolumn{2}{|c|}{ Tesgroup } & \multicolumn{2}{|c|}{ Controlgroup } & \multirow[b]{2}{*}{$\begin{array}{c}\text { Rowte } \\
P= \\
\text { Parephatial } \\
E= \\
\text { Enveral }\end{array}$} & \multirow[b]{2}{*}{$\begin{array}{c}\text { Parpesents } \\
n=\end{array}$} & \multirow{2}{*}{ Significome? } \\
\hline & Amitionicio & $\begin{array}{c}\text { Procidence } \\
\text { Woundspess } \\
\text { (\%) }\end{array}$ & Ambiontc & 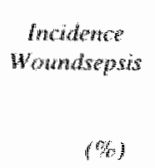 & & & \\
\hline Evans 73 & Cophaloridine & $14 / 5127)$ & - & $20 / 46(43)$ & $p^{s}$ & 7 & NS \\
\hline Kjellgren '77 & Ceptazolun & $1057 \quad(18)$ & - & $24 / 49(49)$ & $\mathbb{p}^{x}$ & 106 & $s$ \\
\hline Bundon 77 & Cephatothin & $1846(39)$ & - & $24 / 27(51)$ & $\mathrm{p}$ & a & $\mathrm{NS}$ \\
\hline Stand 74 & Cephatoinan & $516(31)$ & Cefamindole & $618(33)$ & $\mathrm{P}$ & 34 & NS \\
\hline Conds: 79 & $\begin{array}{l}\text { Cephalothin } \\
\text { Neomycin } \\
\text { Erythronyein }\end{array}$ & $20467 \times 3$ & Coppinalothin & $7 / 26(6)$ & $\mathrm{PE}$ & 193 & NS \\
\hline Stone 76 & $\begin{array}{l}\text { Cefazolin } \\
\text { Neomycim } \\
\text { Erythromycin }\end{array}$ & $61116(6)$ & $\begin{array}{l}\text { Neomycin } \\
\text { Erythromycin }\end{array}$ & $7 / 43(16)$ & $P A E$ & 144 & NS \\
\hline Jostandt si & $\begin{array}{l}\text { Cofotaxime } \\
\text { Paramosnycin }\end{array}$ & $2 / 31(6)$ & Paramonnycin & $8 / 29(28)$ & $\mathrm{P} / \mathrm{E}$ & 60 & $\mathrm{~s}$ \\
\hline Motfman sil & $\begin{array}{l}\text { Cefoxitin } \\
\text { Kunamycin: }\end{array}$ & $1333(3)$ & Kantamyen & $4 / 32(28)$ & PVIE & 65 & s \\
\hline
\end{tabular}

types of operations has been shown to reduce the postoperative septic complications. Evans and Pollack (1973) conducted a similar trial comparing cephaloridine to a placebo in various surgical procedures. Cephaloridine prophylaxis was associated with an overall reduction of septic complications among all types of abdominal surgery except elective colorectal operations. In colorectal procedures wound infections developed in 14 out of 51 cephaloridine treated patients (27\%) and in 20 out of 46 patients (43\%) receiving no antibiotics; this difference is not significant.

In the study of Kjellgran and Sellström (1977) a highly significant reduction in woundsepsis was noticed (from 49 to $18 \%$ ) after a systemic prophylaxis with cephalothin during a 4 day perioperative period. The cultures of the postoperative wound sepsis yielded $E$. coll in $70 \%$ of the cases, anaerobic cultures were not performed. No benefit from the systemic use of cephalothin was seen by Burdon $e t$ at. (1977). There was mo significant reduction in postoperative septic complications after a regimen of $2 \times 1 \mathrm{~g}$ nor of $2 \times 2 \mathrm{~g}$ cephalothin. It must be noticed that some patients in this study reccived neomycin and sulphonamides as well during the preoperative bowel preparation. Cefamandole, like cephalothin, active against the majority of aerobic intestinal bacteria and some species of anaerobic micro-organisms are also susceptible. But both drugs are not active against $P_{S}$. aeroginosa and $B$. fragilis. Slama ef al., (1979) reported high incidence of postoperative wound sepsis affer prophylitctic use of cefamondole (33\%) and cephatothin (31\%). Most of the infections were caused by resistent acrobic micro-organisms and B. fragilis. Condon and co-workers (1979) reported septic complication rate of $30 \%$ among patients receiving only systemic cephalothin for 24 hours. The preoperative large bowel preparation of the control group consisted of a mechanical cleansing, orally administered neonycin and erythromycin-base on the last preoperative day and 24 hours systemic cephalothin. In this group of patients the septic complication rate was $6 \%$, a significant difference. In the same article the results of an inquiry among. A merican surgeons was reported. The most favorite antimicrobial prophylaxis was orall neomycin and erythromycin-base combined with systemic cephalothin $(64 \%)$. Stone et al. (1976) measured the effect of cefazolin on septic complication rates after colorectal surgery. All patients in the study were given oral neomycin/erythromycin-base. Among patients also receiving intramuscular cefazolin for 24 hours, the incidence of wound infection was $6 \%$ compared with $16 \%$ among those received placebos. The lower septic complication rate in the cefazolin group suggest a useful role of cephalosporins as an adjuvent to oral antimicrobial prophylaxis. Recently Jostarndt $e$ t al. (1981) reported a study in a group of patients all prepared by means of whole gut irrigation with additional paramomycin in which one group received cefotaxime intravenously during 4 perioperative days, the control group received placebos. With this treatmemt the wound infection rate was reduced from 28 to $6 \%$. This was statistical significant. Other septic complications were not significantly reduced. Cefoxitin is a cephalosporin with also a bactericidal activity against anaerobic bacteria. In a study of Hoffmann el al. (1980) a reduction in postoperative 
septic complications was reported from $28 \%$ in the controll group to $3 \%$ in the cefoxitin group. A statistical significant reduction. All 65 patients were treated for 3 days with oral kanamycin. One group received systemic cefoxitin for at 24 hour period, the controls recenved placebos.

At this point it seems clear that cephalosporins, used as alone antimicrobial prophylaxis probably afe not very effective in reducing the risks of septic complications associated with operations on the colon and rectum. The use of cephalosporins as adjunct to oral antimicrobial agents in prophylaxis needs further investigation.

\subsubsection{Tetracyclimes.}

Tetracyclines have a broad spectrum of activity against colonic aerobes and anaerobes. However, both the colonic acrobes, particularly $E$. coli and the anaerobic micro-organisms develop resistance to these drugs relatively rapid (Klastersky et al., (1977). Tetracyclines administered orally are well absorbed, even from a parallysed gut, and have a good affinity to the mucosa. There is some direct intraluminal antibacterial effect of tetracyclines against the faecal flora, as well as establishment of tissue concentrations of the antibiotic at the time of operation. Tetracycline given at therapeutic doses inhibited only $40 \%$ of the $B$. fragilis organisms in vitro, whille erythromycin at the same concentration inhibited $92 \%$ of the organisms (Martin et al, (1972). Table 3.9 summarizes the data of controlled studies about prophylactic use of tet racychines in elective colorectal surgery.

Table 3

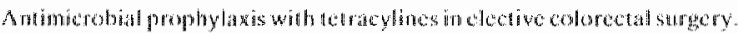

\begin{tabular}{|c|c|c|c|c|c|c|c|}
\hline \multirow{2}{*}{ Rejertane } & \multicolumn{2}{|c|}{ Terizgromer } & \multicolumn{2}{|c|}{ Combrolgronp } & \multirow[b]{2}{*}{ 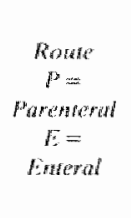 } & \multirow{2}{*}{$\begin{array}{c}\text { Puntionts } \\
n:=\end{array}$} & \multirow{2}{*}{ Stgunificancen } \\
\hline & Antibionta & 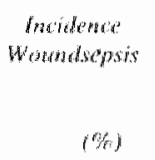 & Antribiontic & $\begin{array}{c}\text { Macialence } \\
\text { Wownatseysas }\end{array}$ & & & \\
\hline Wasthinten 'TA & $\begin{array}{l}\text { Totracylime } \\
\text { Nomyein }\end{array}$ & $365(5)$ & - & $27 / 63(43)$ & $\mathrm{E}$ & 128 & 5 \\
\hline Höjer '7s' & Doxycydina & $588(9)$ & -- & $25 / 60(42)$ & $\mathrm{E}$ & 1118 & S \\
\hline Nygantad "sing & Doxycyelline & $1 / 33(2)$ & -- & $849(16)$ & $P$ & 102 & $S$ \\
\hline Grüner "80 & $\begin{array}{l}\text { Doxycyditase } \\
\text { Thisidazole }\end{array}$ & $4 / 44(9)$ & Tutracyctine & $7 / 51(14)$ & $\mathrm{EP}$ & 95 & NS \\
\hline Vialded 80 & $\begin{array}{l}\text { Doxycycline } \\
\text { Tinidarele }\end{array}$ & $0 / 2 \Downarrow(0)$ & Tetracyeline & $1 / 21(5)$ & $\mathrm{Ep}$ & 42 & NS \\
\hline
\end{tabular}

Washington ef al. (1974) compared the oral administration of the combination tetracycline and neomycin with a placebo group, after a uniform mechanical cleansing of the gastrointestinal tract. A significant reduction in all septic complications was noticed. The wound sepsis rate decreased from $43 \%$ in the placebo group to $5 \%$ in the tetracycline / neomycin group.

All wound infections were caused by mixed acrobic/anaerobic infections. Höjer and Wetterfors (1978) compared oral doxycycline against a placebo in a very well controlled trial of 118 patients. Doxycycline was given 6 hours prior to operation and was continued for 5 days. A significant reduction of septic complications from 45 to $12 \%$ was seen. The reduction in wound infections from $42 \%$ in the placebo group to $9 \%$ in the doxycycline group was statistically highly significant. More deep wound infections were seen in the placebo group. A similar study was reported by Nygaard and Hognestad (1980). The difference was in the method of administration of drugs. In this study the antibiotics were given intravenously at the same time intervals. Half of this group of 102 patients suffered from ulcerative colitis or Crohn's disease. A significant reduction was seen from $16 \%$ in the control group to $2 \%$ in the doxycycline group. Remarkable is the very low percentage of wound infections in the untreated group. No difference in the infection rate was noticed between patients with Crohn's disease or ulcerative colitis and other colonic disexses. Intraperitoneal administration of doxycycline resulted in no further reduction of septic complications. In a multicentre trial Grüner ef al. (1980) investigated the possibility that additional administration of an anti-anaerobic drug, tinidazole, would further reduce the postoperative septic complications after colorectal surgery with 
doxycycline prophylaxis. All 95 patients received orally doxycycline on the last preoperative day and intravenously doxycycline in the postoperative period for 72 hours. On the day prior to operation one group received oral tinidazole. The control group received placebos. Supperation of the wound accurred in $9 \%$ of the tinidazole group and $14 \%$ of the placebo cases. Two patients in the control group developed a Bacteroides fragilis septicaemia. The data are not statistically different.

A similar study was performed by Viddel and Semb (1980). The only difference in the two studies was that tetracycline was given intravenously for a period of 5 days. "The results were almost identical. The addition of tinidazole caused no further reduction of the postoperative septic complications.

The question if oral antimicrobial prophylaxis is preferable to a systemic regimen in elective colorectal surgery has not been widely investigated.

Keighley et al. (1979) compared a systemic 24 hours perioperative use of metronidazole and kanamycin with the oral administration of the same drugs. The oral intake was started 3 days prior to operation, however, the metronidazole was withdrawn 36 hours before the operation. Postoperative sepsis occurred in $6.5 \%$ of those given antimicrobials systemically, compared with $36 \%$ of those given oral prophylaxis. 15 out of 17 infections in patients who received antimicrobials orally were due to kanamycin resistant bacteria present in the colon at operation. The increasing incidence of antibiotic resistant coliforms after oral antimicrobials may either be due to a longer exposure to the drugs or to the fact that there are kanamycin resistant aerobes in the hospital. The authors mentioned an increase of kanamycin resistant $E$. coli from 11 to $34 \%$ in a couple of years. The same study was reported by Aeberhard et al. (1980). They found no significant difference in the occurance of postoperative sepsis between the two groups. In both studies the conclusion was made that shortterm parenteral application is the safer method of antibiotic prophylaxis in colotectal surgery and is to be preferred to oral antimicrobial bowel preparation. However, the study is flawed by the fact that metronidazole was withdrawn 36 hours preoperatively from the patients undergoing oral preparation and that the systemic administration of drugs in this study was an optimal timing schedule in contrast to the long 3 day oral treatment.

\subsubsection{Topical application of antibiotics}

Topical antibiotics have been advocated to minimize sepsis in abdominal wounds. The topical use antibiotics offer the theoretic advartages of immediate effect, low systemic dosage and of providing a much higher concentration of antibiotics than could be achieved systemically. However, topical antimicrobials will not influence intra-abdominal abscess formation or septicaemia. Furthermore, topical antibiotic therapy is associated with an increasing incidence of skin sensitization, bacterial resistance and environmental pollution with an antibiotic drug (Hughes, 1970).

During the past three decades a number of investigators have studied the possible protective effect of irrigation or powdering the surgical wound with topical antibiotics or antiseptics. Many climical studies have been carried out on the use of topical antibiotics. Most of these studies do not meet criteria of scientific acceptability with controls, randomization and prospectivity. The published trials have included some cases in which drainage or systemic antibiotics have been used in addition to a topical agent. Unless really large numbers are used to assess the many variations of treatment, it is difficult to find 2 strictly comparable groups (Bates et al. 1974). There are no clinical, controlled series that compare topical antibiotics with systemic antibiotics, so that no position on this controversy can be taken. Bacteriological studies of incised organs, subcuteneous fat and pus showed that the majority of wound infections arose from endogenous sources (Pollack, 1975). In a high percentage of wound infections in colorectall surgery the peroperative prepared intraluminal cultures contained bacteria later found in cultures of the wound (Andersen et al., 1972).

There are just 3 prospective randomised studies available considering the use of topical antibiotics in elective colorectal surgery. (Table 3.10). Evans et al. (1974) found a significant decrease of wound in. fections after topical use of cephaloridine in 43 elective colorectal operations. Two consecutive really identical controlled triple blind trials showed that topical ampicillin offers a significant reduction in the frequency of wound infections after operations for cancer of the colon and rectum (Andersen et al., 1972). The same good results with topical ampicillin in colorectal surgery were reported by Nash and Hugh (1967) in a poorly controlled trial. 


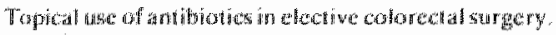

\begin{tabular}{|c|c|c|c|c|c|c|}
\hline \multirow{2}{*}{ Reflerentice } & \multicolumn{2}{|c|}{ Testeratips } & \multicolumn{2}{|c|}{ Combrolgritap: } & \multirow{2}{*}{ Parients } & \multirow{2}{*}{ Significance } \\
\hline & Antibionic & $\begin{array}{c}\text { Inciddence } \\
\text { Howndsepsis } \\
(\%)\end{array}$ & Antribum & $\begin{array}{c}\text { Iptidistace } \\
\text { Woundsepsis } \\
\text { (ow) }\end{array}$ & & \\
\hline Nowh ared litugh "67 & 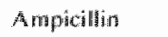 & $1(3)$ & . & $14(41)$ & 70 & $s$ \\
\hline Anderomon 72 & Artupicillin & $3(25)$ & - & $22(18)$ & 240 & $s$ \\
\hline Evalno 74 & Ceplatuloridine & $7(30)$ & - & $14(74)$ & 43 & $S$ \\
\hline
\end{tabular}

In different well controlled experimental studies good results were mentioned using topical kanamycin (Spier, 1964), penicillin (Casten er al. 1964) and combinations of neomycin/bacitricin, neomycin/ bacitricin/polymyxin (Glotzer el al., 1964). Moylon (1980) and Halasz (1977) postulated in review articles that topical antibiotics have been shown to be effective prophylactive agents in reducing wound infections in clean contaminated cases. The risk of development of superinfection and antibiotic resistant bacteria as well as organ-toxicity is minimal, when given in one single dose.

Antibacterial substances may be applied to the wound at the time of operation which suggests that it is not prophylaxis but an early treatment.

The adjunct of topical antibiotic drugs looks valuable in the treatment of clean - contaminated, contaminated wounds and in high risk patients. A suggestion which should be proven in good controlled, prospective, randomized, double blind trials.

\subsubsection{Chemotherapeutic agents}

Problems of considerable concern with the widespread use of antibiotics are the selection and the emergence of resistant microbial organisms. The theoretical advantage of chemotherapeutic agents over antibiotic treatment is, that it is effective against all bacteria and resistance to it is unlikely to develop.

Povidone-iodine, an antiseptic agent formed from a complex of polyvinyl pyrrolidone and iodine, has been demonstrated to possess a broad spectrum of bacterial activity with little capacity for tissue damage. The suggestion that povidone-iodine will cause secondary sepsis (Pollock and Evans, 1975) was not confirmed by Gilmore (1977). Peritoneal irrigation with povidone-iodine causes a short rise of serum iodine and P. B.I. In contrast T3 and T4 values remained unchanged (Sindelar and Mason 1977; A rangoet al. 1979).

In a vitro study Jones et al. (1975) compared the effectiveness of a neomycin-erythromycin solution and a povidone iodine solution against acrobic and anacrobic bacteria. After 20 minutes exposure to the antibiotic solution the aerobic count was reduced $1.24 \operatorname{logs}$. There was no reduction in anacrobes. After a 10 minutes exposure to povidone-iodine, no aerobic growth was seen and the total anacrobic concentration was reduced by 4 logs.

Results of experimental studies have demonstrated the efficacy of intraperitoneal installation of povidone-iodine in treating peritonitis from intraperitoneal bacterial contamination (Gilmore er al., 1977, 1978). Povidone-iodine solution instilled in proximal and distal segment after resection of the colon in dogs resulted in elimination of aerobes. The growth of anaerobes was reduced by 3 logs. At reexploration there was no significant difference between the treated group and in control group, in peri-anastomotic reaction, anastomotic dehisence, bursting pressure of the anastomosis and survival (Jones et al. 1975; Gilmore et al. 1978).

The results of clinical studies with povidone-iodine have been variable. These inconsistences may be explained, at least in part, by variations in the groups of patients studied and in surgical technique. The overall levels of wound sepsis in these studies vary widely. A factor of particular importance may be the control of bleeding in the wound, as povidone-iodine is absorbed by red blood cells, and inadequate haemostasis is likely to result in inactivation of the antiseptic applied in the wound. The infection rate was reduced by about one half when povidone-iodine was sprayed on the wound before closure after an emergency appendectomie (Gilmore ef al., (1979). These positive results could not be confirmed by other studies (Stokes et al., 1977; Pollock et al. 1978). Foster et al. (1981) compared the topical use of cephaloridine, saline and povidone-iodine in high risk operations 
(ileocollorectal surgery or operations upon obese patients). The rate of major wound sepsis in those protected by topical cephaloridine was statistical significant lower $(3.8 \%)$ compared with $13.2 \%$ in the saline irrigated-and $16.7 \%$ in the povidone-iodine group. After abdominal operations a wound infection rate of $8.1 \%$ was found in patients receiving systemic antibiotics compared to $42 \%$ in untreated patients and $39.5 \%$ in patients treated with topical povidone-iodine (Gallard et al. (1977). The study of Walsh et al. (1981) failed to demonstrate an overall reduction in postoperative wound sepsis, although a significant reduction in sepsis was found in certain subgroups such as female patients and patients receiving subcutaneous heparine. The postoperative stay in the hospital in patients with wound infections was decreased in patients treated with povidone-iodine. A significant reduction in postoperative wound infection rate was reported by Gray and Lee (1981).

They found $9.9 \%$ wound infections in the treated and $24.4 \%$ in the control group. Identical figures were given by Gilmore and Sanderson (1975). Eight point six \% wound infections in the treated group compared with $24 \%$ in the untreated group. In high risk operations (small bowel resections, large bowel resections and peritonitis), however, $71 \%$ of the wounds in the control group became infected, compared to $13 \%$ in the povidone-iodine group. Patients in a treatment group with intraperitoneal povidone-iodine irrigation, added to a antibiotic prophylaxis, had significantly fewer intra-abdominal abscess formation compared to a saline group (Sindelar, 1979)

Arango et al. (1979) described a technique for intra-operative segmental preparation of the large bowel with a $10 \%$ povidone-iodine solution, after a conventional mechanical cleansing. In a group of 25 patients no postoperative septic complications were seen. Ninety $\%$ of the bowel segments injected with povidone-iodine demonstrated no aerobic growth of bacteria.

Other chemotherapeutic agents were not used on large scale in clinical studies. Chlorhexioline (Crosfil et al., (1969) and noxythiolin (Bircl et al. 1971); both failed to reduce infection when instilled into the abdomimal wound prior to closure.

\subsubsection{Influence of mechanical cleansing and antibiotics on the colonic microflora}

Most studies of intestinal microflora following conventional mechanical cleansing by means of low or non residue diets, purgatives and enemas has considered the stool. Tyson and Spaulding (1959) found that mechanical cleansing decreased the concentrations of faecal bacteria from $10^{8}-10^{9}$ to $10^{6}$ $10^{7}$ organisms per gram of stool. However, 12 to 18 hours later bacterial concentrations had returned to pretreatment levels. Gorbach et al. (1970) showed that most micro-organisms in the stool declined in numbers immediately after massive infusions of fluid into the small bowel. They also found that after 18 hours the microbial counts were the same as, or higher than, pretreatment levels. Following cathartic-induced diarrhea, Levison and Kaye (1969) observed decreases in colliforms or enterococci in some patients but other faecal micro-orgamisms were unaffected. Bornside et al. (1966) found that a 72 hours conventional mechanical cleansing did not change the concentration of any faccal micro-organism. In a study of Nichols ef al. (1971) the effect of conventional mechanical cleansing on the microflora of the ileum, colon and stool was compared with those of untreated patients. A reduced concentration of coliforms in the ileums, colons and stools of four of six patients, was found, but there was essentially no change in the other major aerobic and anaerobic components of the intestinal microflora.

Vigorous preoperative cleansing causes marked reduction in the mass of faccal material in the large bowel, which facilitates handling of the colon at operation and also lessens the total number of micro-organisms within the lumen. However, the concentration of bacteria remaining in the colonic content is not significantly altered by wigorous mechanical cleansing. Thus spillage of any colonic contents in patients who had mechanical cleansing without antibiotics presents a significant potentiall for infection since the bacterial content per weight of faeces is unchanged.

A profound impact on the colonic flora has been reported in studies concerning the influence of parenteral and oral antibiotics on the microflora of the large bowel. Oral administration of antibiotics which are poorly absorbed in the upper gastrointestinal tract generally has the greatest effect on the faecal flora. Parenteral administration of antibiotics, however, may also alter the faecal flora because of biliary or colonic excretion. An antibiotic that is active against some of the intestinal organisms and is excreted at a sufficiently high concentration in the faeces may suppress or eliminate 
those organisms, or may exent a selective pressure in favour of the emergence of an antibiotic resistant population.

A comparison of stool specimen from patients and voluntears treated with short term oral neomycin and erythromycin base and a control group treated with placebo's showed that the drugs produced at decrease approximately of $10^{3}$ C.F.U./ml in mean bacterial concentrations of both aerobes and anaerobes. No patients developed persisting diarrhea of clinical evidence or colitis postoperatively. Examination of the first postoperative stool demonstrated no increase in recovery of staphylococe, neomycin resistant Gram-negative bacilli or fungi in the antibiotic treated patients compared to those who received placebos (Nichols er al., 1973; Clarke ef al., 1977; Bartlett ef at. 1978). The influence of oral karamycin and metronidazole on the colonic microflora was investigated by Gillespic and McNaught (1978). The stool specimens of patients who received placebos were unaffected, while the number of the acrobes as well as the anaerobes was significantly decreased by a 3 days antibiotic regimen.

Onlly E, coli $\left(10^{5} \mathrm{C} . \mathrm{F} . \mathrm{U} . / \mathrm{ml}\right)$ and B. fragilis $\left(10^{8} \mathrm{C} . \mathrm{F} . \mathrm{U} . / \mathrm{ml}\right)$ showed a significant decrease after a 48 hours oral treatment with neomycin and metronidazole (Arabi et al, 1978). Most of the other colonic micro-organisms were not significantly reduced. Brass et al. (1978) compared the difference between aneomycin/erythromycin prophylactic regimen with a noomycin/metronidazole regimen. Neomycin and erythromycin were administered on the day before operation, while metronidazole was given for two days prior to operation.

Bacteriologic studies of faeces and colon content during operation revealed no significant difference in the reduction of aerobic bacteria between the two groups. There was, however, a significantly greater reduction in the anaerobic bacteria in the faeces and colonic contents of patients receiving metronidazole. During operation, in $87 \%$ of the metronidazole patients no anaerobes could be isolated anymore, while this was $37 \%$ in the erythromycin group. However, the study is flawed by the fact that both antibiotic regimens were not identical.

After a 4 clay oral preoperative treatment with neomycin and bacitracin a significant decrease of $E$. coli, Bacteriodes, Clostridia and Proteus was found in $80 \%$ of the patients. But the amount of Klebsiella stayed the same or increased. Eighty-six \% of the investigated patients showed an increase of candida (Schneiders et al., 1976). Clindamycin orally given for 3 days together with a mechanicall cleansing of the gastrointestinal tract showed a reduction of anaerobic micro-organisms in the stool of healthy individuals of about 6 logarithms. Faecal streptococci were sensitive to clindamycin but were replaced in stools by clindamycin resistant enterococci. In $50 \%$ of the volunteers yeats were isolated from clindamycin treated volunteers (Bornside et al., 1969).

The reduction of the microflora after a two week elemental diet regimen reported by Winitz $e t a l$. (1970) could only partly confirmed by Arabi et al. (1978), who found only a light decrease of $E$. coli after 5 days nutrition with Vivonex. However, further studies failed to demonstrate these reductions in the colonic microflora after the use of an elemental diet (Glotzer et al., 1973; Russel, 1975; Schiessel et al. 1978).

The influence on the microflora of the gastrointestinal tract after whole gut irrigation with and without administration of antimicrobial drugs will be discussed later. 


\section{Chapter 4:}

\section{Considerations and aims of the studies}

The preoperative management of patients admitted for elective colorectal surgery and the prevention of intections in these patients after surgery have been matters of great concern to surgeons for many years. Much controversy still exists on questions about the most effectiwe method of preoperative bowel preparation and the prophylactic use of antibiotics. In the surgical department, St. Annadal Hospital of the University of Limburg, a conventional cleansing procedure was used. Antibiotic prophylaxis was more varied as no uniform regimen was followed. In 1978 seven different antibiotics were used for prophylaxis, whereas, in addition 13 antimicrobial agents were used for topical appplication. This diversity and the fact that the conventional method of mechanical cleansing was not satisfactory in every respect, prompted us to embark upon a series of studies in which whole gut irrigation as an alternative method for preoperative mechanical cleansing was evaluated and different antibiotic prophylactic regimens were compared. The studies were designed to provide an answer to the following questions:

Is whole gut irrigation alone or combined with an oral antibiotic prophylaxis more effective in preoperative bowel cleansing and the prevention of infections as the conventional methods with use of antibiotics;

Is further improvement of the method of whole gut irrigation possible by the prior administration of an osmotic cathartic;

Should antimicrobial prophylaxis cover either the aerobic microbial bowel flora, the anaerobic microbial bowell flora, or both;

Should antimicrobial prophylaxis aim primarily at a decrease of the degree of contamination by reducing the bowel flora or is an adequate tissue level during and directly after surgery of greater importance;

To what extend - in time and degree - do the different methods of large bowel preparation and the prophylactic use of antibiotics affect the bowel microflora and the Colonization Resistance of the gastrointestinal tract. 


\section{Chapter 5: \\ Whole Gut Irrigation}

\subsection{Introduction}

The degree of emptiness of the bowels is one of the most significant factors effecting the outcome of colorectal surgery. Removal of the bowel contents by mechanical cleansing prior to operation has been generally accepted and is seldomly disputed. The conventional method of mechanical clean sing achieved by dietary restrictions, the administration of purgatives and enemas takes $2-5$ days to perform and is not without drawbacks. This method is frequently unsuccessful and warying degrees of dehydration, starvation and physical exhaustion were seen. So the need exists for an alternative effective method to remove the bowel contents. The orthograde irrigation of the gastrointestinal tract is probably such a method.

The concept of volumogenic diarrhea produced by rapid ingestion of saline is not new. Dillard et al. (1965) showed that after a critical volume the fluid load is handled by faster transit, due to stimulated peristalsis, rather than further increase of the intestinal volume. The mean bowel transit time is reported to be approximately $25 \mathrm{~min}$., with a gut wolume of $1800 \mathrm{ml}$ (Love et $a l$., 1973). The colon is able to increase its absorption to approximately $3000 \mathrm{ml} /$ day, so volumes in excess of this delivered from the small intestine will produce diarrhea (Love et al., 1968; Phillips and Giller, 1973).

These findings were used by Hewitt et al. (1973) and Crapp et al. (1975) to introduce the method of whole gut irrigation as an alternative way of cleansing the gastrointestinal tract before elective colorectal surgery, endoscopic examination and radiologic studies. Furthermore, whole gut irrigation has been proposed for the elimation of as ingested blood, especially when the patient is suffering from cirrhosis, to prevent post haemorhagic encephalopathy (Champault and Patel, 1977; Hollander et al, 1980). Encouraging results with this method (Bartelsman et al., 1977; Stock et al., 1977; Hollander et al., 1978; Chung et al., 1979; Taat et al. 1981), and disappointing experience with conventional methods of mechanical cleansing prompted us to explore the usefulness of this technique.

\subsection{Method and Materials}

From May 1978 to June 1979100 whole gut irrigations were performed, at the University of Lim. burg, surgical department St. Annadal Hospital in Maastricht, in patients admitted for elective largc bowel surgery or colonoscopic examinations.

Obstruction of the gastrointestinal tract and a toxic megacolon were considered as absolute contra indications. Large bowel stenosis of more than $50 \%$ of the colonic diameter, congestive heart failure and renal insufficiency were relative contra indications. In case of congestive heart failure, furosemide $40 \mathrm{mg}$ was given before beginning whole gut irrigation.

In the study the following parameters were examined; body weight variation, duration of the procedure and the amounts of irrigation fluid used. Furthermore, metabolic disturbances, the vacuity of the colon at operation and the complications of this cleansing procedure were studied. Unless indicated otherwilse all these parameters were investigated in 100 patients.

The procedure of whole gut irrigation took place at the day of colonoscopy or in the afternoon before operation. Prior to the irrigation a nasogastric tube (Charićre 14-16) was placed in the stomach or duodenum of the starved patient. The position of the tube in the stomach was controlled with a stethoscope. The tube was well fixed in order to maintain its position. Placing a nasogastric tube nearby the Treitz ligament was made possible by using a guide wire and $x$-ray transillumination.

The patient was seated on a well padded commode which was placed above an automatically fushed-and air conditioned toilet. In order to pass time something to read and a radio-and/or televisionset was available (Fig. 5.1).

The irrigation fluid was deliwered by a roller pump (Watson-Marlow Flow inducer MHRE 22) to at 


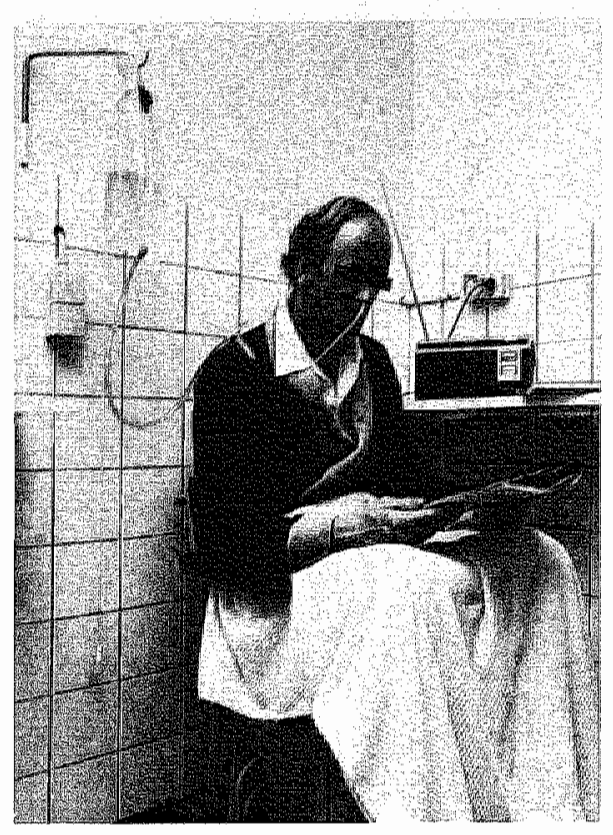

Fig. 5.. 1 .

Method of Whole Gut Irrigation.

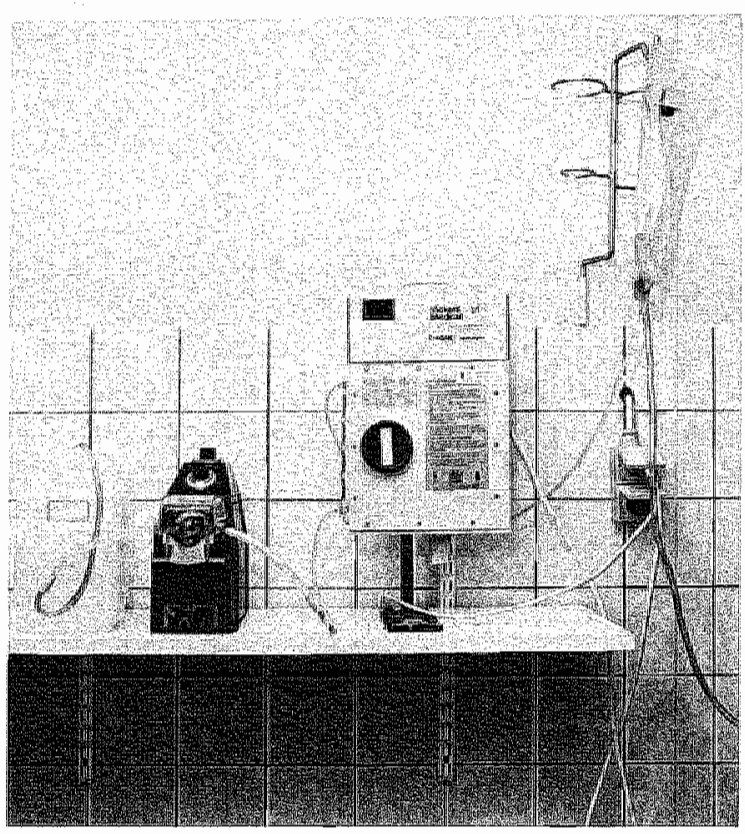

Fig. 5.2.

thermoheather (Vickers Treonic H.150) which warmed the irrigation fluid to $37^{\circ} \mathrm{C}$. A plastic bag, as used on the department of radiology for barium enemas of the large bowel, was used as an "overflow valve". The warmed isotonic irrigation fluid, was introduced via the nasogastric tube at a constant rate of $50-75 \mathrm{ml}$ per minute (Fig. 5.2). A minimum flow rate of $30 \mathrm{ml} / \mathrm{min}$. is desirable because a lower rate increases the absorption of the fluid from the bowel, and less irrigant will be delivered to the lower gut in order to produce a volumogenic diarrhea. The composition of the irrigation fluid used was as advised by Hewitt et al. (1973) (Table 5.3).

To prevent the symptoms of nausea, vomiting and distension metoclopramide $10 \mathrm{mg}$ i.m. or i.v. was given to all patients prior to the irrigation and was repeated during the lavage procedure when necessary.

\section{Table 5.3.}

Composition of the irrigation lluid (Hewilt et al., 1973).

\begin{tabular}{|c|c|c|c|}
\hline Supplemes & 1010 & I water & \\
\hline Grams & & Maeq. & \\
\hline $\mathrm{NaCl}$ & 6.14 & $\mathrm{Na}^{+}$ & 138 \\
\hline $\mathrm{KOl}$ & 0.75 & $\mathrm{~K}^{+}$ & 10 \\
\hline $\mathrm{NaHCO}^{3}$ & 2.94 & $\mathrm{Cl}^{-1}$ & 113 \\
\hline & & $\mathrm{HCO}_{3}$ & 35 \\
\hline
\end{tabular}

Osmolarity 275 mosm $/ \mathrm{kg}$.

$\mathrm{pH}=8.3$

In patients with a colostomy a double system was used: a nasogastric tube in the stomach and a Foley catheter (Charriere 22-24), via the colostomy bag in the afferent loop of the colon. The effluent from the proximal end was removed via a long tube fixed on the colostomy bag, while the effluent of the distal part disappeared via the physiological pathway. In this way, the proximal and distal part of the colon could irrigate at the same time (Fig. 5.4 ). 


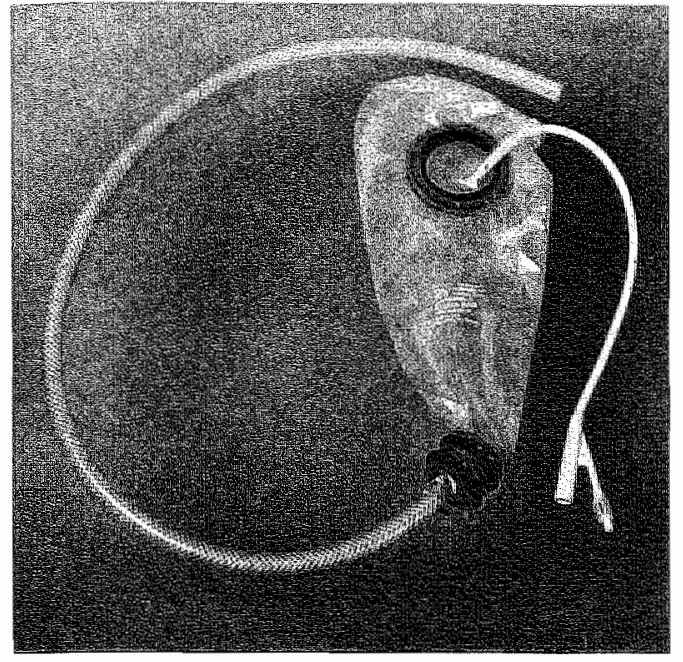

Fig. 5.4

Method to irrigate patients with a colostomy.

\subsubsection{Patients}

In this series the results of 55 men and 45 women were evaluated. "Their age varied from 16 to 81 years. Almost $60 \%$ of the patients were 50 to 70 years of age, and only 15 were older than 70 .

Their mean age was 59.3 for men and 51.6 for women. The age distribution for the series is shown in Fig. 5.5. The indications for performing whole gut irrigations are listed in Tab\#e 5.6.

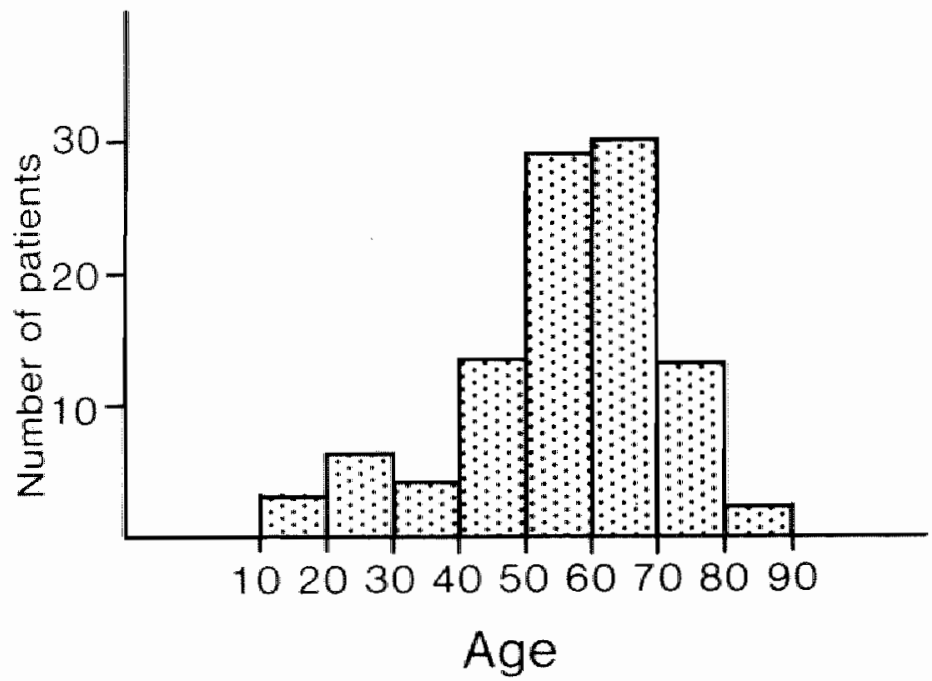

Fig. 5.5 .

Age distribution of 100 patiemts. 
Table 5.6.

Indications for whole gut imigation.

Carcinoma of the rectum and left colon

Carcinoma of the right and tramswerse colon

Diverticular disease of the sigmoid

Colostomy closure

Colonoscopy

Crohn's disease:

Carcinoma of the stornach 2

Polyposiscoli 4

Carcinoid 1

Closture Hartmann procedure

Total

\subsection{Results}

\subsubsection{Duration of the irrigation and amounts of irrigation fluids used}

The first bowel motion was usually passed $20-40 \mathrm{~min}$. from the start of the irrigation. The lavage was continued till the effluent rectally passed became completely clear.

The mean duration of the procedure was $3.0 \pm 1.0$ hours. The fastest whole gut irrigation was performed in 1.75 hours, while the most complicated one took 7 hours. In this case the lavage had to be interrupted several times because of vomiting and physical exhaustion of the patient.

The average amounts of irrigation fluid used was $14.4 \pm 4.4$ liters. The amount of irrigant used was at least 2.5 liters and at most 25 liters.

\subsubsection{Bodyweight variation}

In 75 of the 100 patients the change in bodyweight was scored. As expected the body weight of most patients increased. The mean increase was $2.0 \pm 1.4 \mathrm{~kg}$. "This body weight gain was found in $55 \%$ of the patients. The maximal weight gain in one patient due to the irrigation was $7.5 \mathrm{~kg}$ (Table 5.7). This patient was in good general condition but it took 80 minutes before the first defaecation started. The next morning his body weight was still $1.2 \mathrm{~kg}$. above his normal weight.

In most patients, however, the bodyweight was normalized within 24 hours due to fluid loss from the intestinall tract immediately after the irrigation, and due to an increased diuresis.

Table 5.7.

Bondy weight variation after whole gut irrigation.

\begin{tabular}{|c|c|c|}
\hline $\begin{array}{l}\text { Nr. of patients } \\
\text { hosing weight }\end{array}$ & $\begin{array}{l}\text { Nr. of parients } \\
\text { swying thesanne }\end{array}$ & $\begin{array}{l}\text { Nr. of parients } \\
\text { saining merighr }\end{array}$ \\
\hline $\begin{array}{l}1(10,5 \mathrm{~kg}) \\
1(-1.6 \mathrm{k})\end{array}$ & 4 & $\begin{array}{r}2(+0.5 \mathrm{~kg}) \\
10(+1.0 \mathrm{~kg}) \\
18(+1.5 \mathrm{~kg}) \\
15(+2.0 \mathrm{~kg}) \\
8(+2.5 \mathrm{~kg}) \\
3(+3.0 \mathrm{~kg}) \\
5(+3.5 \mathrm{~kg}) \\
4(+4.0 \mathrm{~kg}) \\
1(+5.0 \mathrm{~kg}) \\
2(+5.5 \mathrm{~kg}) \\
1(+7.5 \mathrm{~kg})\end{array}$ \\
\hline
\end{tabular}




\subsubsection{Metabolic disturbances}

The serum levels of sodium, potassium, chloride, ureum and kreatinine measured before and immediately after whole gut irrigation are summarized in Table 5.8. Two statistical significant changes can be observed. The increase in the serum level of sodium $(\mathrm{p}, 0.01)$ is most likely explained by an increased absorption from the gut, while the decrease of ureum $(p, 0.01)$ in the serum is due to haemodilution. The haemodilution can be explained by the distribution of sodium and water in the extracellular sectors. However, the statistical differences are of no clinical importance, because both changes are within physiological limits.

Table 5.8 .

Average electrolyte changes in serum.

\begin{tabular}{llllll}
\hline & $\begin{array}{l}\text { Sodium } \\
\text { mmol. } \pm S D\end{array}$ & $\begin{array}{l}\text { Potassium } \\
\text { mmol } \pm S D\end{array}$ & $\begin{array}{l}\text { Choride } \\
\text { mmol. } \pm S D\end{array}$ & $\begin{array}{l}\text { Urewm } \\
\text { mmol. } \pm S D\end{array}$ & $\begin{array}{l}\text { kreatinne } \\
\text { mmol. } \pm S D\end{array}$ \\
\hline Before irrigation & $137,7^{*} \pm 3,0$ & $4.3 \pm 0,46$ & $103,4 \pm 3,5$ & $5,3^{* *} \pm 1.8$ & $82.0 \pm 19.0$ \\
Afterirrigation & $139,1^{*} \pm 3,3$ & $4.2 \pm 0,48$ & $103,2 \pm 3,2$ & $4.0^{* *} \pm 1.6$ & $77.2 \pm 16.9$ \\
\hline
\end{tabular}

$* p=0,01 ; \quad * * 0,01$.

\subsubsection{Vacuity}

The vacuity of the colon at time of operation or colonoscopy was observed in 75 patients. A preparation was considered as very good if no visible facces or faecal substances remained, even in the diverticules. Good if in places some small stercoraceous deposits remained that did not hinder the surgical procedure or the endoscopic examination, and poor if stools were found afterwards in relatively profuse quantities. The results obtained are shown in Table 5.9. The high incidence of very good and good results of $86 \%$ highlights one of the great advantages of this technique: it allows the colon to be cleaned completely in less than 4 hours. In 10 instances, however, a incomplete satisfactory result was obtained. In all these cases the patient was suffering from a stcnotic pathologic process.

Table 5.9.

Vacuity after whole gut irrigation; $n=75$

Vacuity

Cleanliness Nrof oationts $\quad$ go

\begin{tabular}{lrr} 
Very good & 57 & 76 \\
Good & 8 & 10 \\
Poor & 10 & 14 \\
\hline Total & 75 & 100
\end{tabular}

\subsubsection{Complications}

Vomiting, nausea and abdominal distention were the complications most frequently seen. Approximately one third of all patients complained about abdominal distension, became nauseated or vomiting was seen. These symptoms disappeared in most cases after an injection of an anti-emetic drug i.e. metoclopramide $10 \mathrm{mg}$ i.v., reduction of the flow rate or temporary interruption of the procedure. In only six cases the lavage had to be interrupted due to persistent vomiting or physical exhaustion. The operation the next day had to be postponed. Vomiting was less frequent when the nasogastric tube was placed close to the Treitz ligament, or at least distal to the pylorus.

In the few patients with renal - or cardiac failure who underwent a whole gut irrigation no scrious complications were encountered.

The only two serious complications during or after whole gut irrigation will be described. 


\section{Conse 1}

A 64 year old man was suffering from a diverticular discase of the sigmoid colon. In the afternoon before the operation an uncomplicated whole gut irrigation was performed, within 3 hours with 15 liters of irrigation fluid. One and a half hour after the irrigation procedure was finished he complained of abdominal pain and was nauseated.

Physical examination revealed abdominal tenderness and absence of bowel sounds. On the upright plain abdominal $x$-ray free wir was seen under the diafragn. The same afternoon a laparotomy was performed and a free perforaton of a diverticula in the sigmoid to the abdominal cavity was found. A resection of the sigmoid and a Harmanm procedure were pertormed. The postoperative course was only complicated by a wound sepsis. Two months latier the patient was reoperated and the colonic continuily was restored.

\section{Cage 2}

A 58-year old, previously healthy man underwent a low anterior resection to remowe an ade nocarcinoma of the rectosigmoid. One day before operation whols gut irrigation was performed, during which $15 \mathrm{~L}$ was introduced. Erythromycim base $(1 \mathrm{~g} / \mathrm{l})$ and neomycin $(1 \mathrm{~g} / \mathrm{l})$ were added to the last $10 \mathrm{~L}$ of the irrigation fluid. No parenteral aniibiotics were administered. The postoperated course was uneventful and the patient discharged on the eleventh postoperative day. On the twenty-third postoperative day he was readmitted in poor general condition, passing watery stools, with 7.10 bowel movements per day, dehydrated and with severe abdominal cramps. Physical examinations revealed abdominal distension, nomal bowel sounds and slight abdominal tenderness. At proctosignoidoscopy, inllamed mucosa with grey/white coloured pseudomembranes was seen, extending from the anus upwards. In spitc of treatment with total parenteral nutrition, cholestyramine and vancomycin, the patient developed hyperpyrexia, increasing abdominal distension and tenderness. On plain abdominal x-ray films, signs of a toxic megacolon with thickened irregular mucosal folds and contour defects resembling "thumb printing" were seen. To prevent inpending perforation, decompression was performed by means of three bllow out colostomiss and a terminal ileostomy. After this operation, his colitis improved. However, the patient developed multiple organ failure and died on the forty-fourth postoperative day. Although the cultures for Clostridium difficile were negative, and essay for the presence of toxin was not avalable, the death of this patient was most probably caused by a psetudomenbranous colitis after whole gut irrigation with additional erythromycin base and neomycin(Weidemateral, 1980).

\subsection{Discussion}

With the method of whole gut irrigation no dietary restrictions are required until the day of preparation. Food is withheld for a minimum of 5 hours before the beginning of the whole gut irrigation because nutrients especially glucose and aminoacids, increase the rate of absorption of sodium and water from the duodenum and je junum (Sladen and Dawson, 1969; Sladen and Dawson, $1969^{\text {by). }}$

The principle of whole gut irrigation is that most of the irrigation fluid is unabsorbed. The resultant increased intraltuminal volume stimulates peristalsis throughout the bowel, and thus irrigation fluid and small intestinal fluid is used to clean the colon and rectum of solid faeces. The normal colon diarrhea is achieved by presenting the small bowel with a large volume of fluid. After a critical volume, the flow of fluid in the small bowel increases with increasing volume of perfusate (Dillard et al. 1965). This because the colon is able to increase its absorption to approximately $3000 \mathrm{ml} / \mathrm{day}$ (Phillips and Giller, 1973). Volumes in excess of this will produce diarrhea. Untill the absorptive capacities of the small bowel are overcome there will be appreciable movement of sodium and water from the intestinal lumen into the circulation, which is an important theoretical complication in patients who are unable to readily excrete a salt and water load.

In this study, no clinical important electrolyte changes occurred in the serum due to the whole gut irrigation. A significant rise of serum sodium was seen because sodium is actively absorbed (against an elcctrochemical gradient) by the intestinal mucosa. The decrease of serum ureum may be caused by the increase of the circulating volume. The serum electrolyte changes, found in this study are in cor* respondence with figures reported by others (Skucas et al., 1976; Marti and Pouret 1977; Hollender eral., 1978; Tate al, 1981). In all these studies an isotonic irrigation fluid was used, as described by Hewitt er al., (1973). Kujat et al., (1981) noticed a hyperchloraemic metabolic acidosis after whole gut irrigation with $0.9 \%$ saline solution. The changes in serum electrolytes and water resorption de* pends on the composition of the irrigation fluid.

The body weight gain of $2.0 \pm 1.4 \mathrm{~kg}$ in our material is within the range found by others. The body weight gain due to fluid retention varies between $0.75 \mathrm{~kg}$ (Hollender et al., 1978) to 2.3 $\mathrm{kg}$ (Skucas et 
al, 1976). The fluid retention depends on the rate of irrigation and the osmolarity of the fluid. The more hyperosmolar the irrigation fluid is less water resorption occurs. The body weight gain is partly explained by an increase of the circulating volume due to water resorption and partly by an amount of irrigation fluid within the intestinal tract. Hollender et al. (1978) reported an increase of the circulating volume of $5-20 \%$ mainly caused by an increase of the plasma volume. In most patients the body weight gain is normalized within 24 hours (Ackermann and Akovbiantz, 1978. Kiene er al. 1979; Kujat el al., 1981). This is mainly caused by an increased diuresis during and after whole gut ir"rigation (Champault and Patel, 1977; Kujat etal, 1981).

Whole gut irrigation method proved to be a surprisingly well tolerated procedure, producing far less discomfort than the administration of laxatives and enemas. Paticnts who experienced both conventional cleansing and whole gut irrigation, 75-80\% prefer lavage (Crapp ef al., 1975; Levy k al. 1976: Chung ef al., 1979; Downing etal., 1979; Speclman ef al. 1981). Amost one third of the patients complained about nausea or vomited. The irrigation was abandoned in only 6 patients due to persistent vomiting or mental exhaustion, and the operation the next day had to be postponed. These failures were due to gastric retention of fluid and unrelated to colonic obstruction. The incidence of failure may be minimized by not overloading the stomach with a to rapid rate of infusion at the beginning of whole gut irigation. The passage of the nasogastric tube seemed to be the most uncomfortable event in the whole course of preparation. This finding was also reported by others (Downing 6 al., 1979; Speelman et al. 1981). Furthermore, especially for elderly patients the $3-4$ hours immobilization above the commode was to long. But an old fashioned cholera bed or a specially constructed bed can be used as an altornative method (Welvaart and Hoogstraten, 1980). After this series of 100 pat tents our experience is extended to over 250 pationts.

Quite contrary to popular belief, the whole gut irrigation method proved to be a rapid, economic, effective and surprisingly well tolerated procedure of cleansing the bowel of patients who atre not obstructed. Certainly it produces far less discomfort than the administration of laxatives and enemas, with at least equal if not superior clinicall results. The lavage method of bowel cleansing has other advantages besides being easier to take; the preoperative hospitalization can be reduced because the whole gut irrigation take hours instead of days. Instead of starvation and dehydration, some prehydration can be attained by means of lavage. Furthermore, a retarded beginning of postoperative bowel function without symptoms of ileus is reported (Ackermann and Akovbiantz, 1978) giving the colonic anastomosis a longer time for healing. Disadvantages of this preparation are the possibilities of overloading the circulation, the need for constant supervision and sometimes a relative discomfort for the patient. 


\section{Bacteriological and clinical evaluation of three methods of large bowel preparation before elective colorectal surgery.}

\subsection{Introduction}

Conventional mechanical cleansing alone does not reduce the concentration of resident microorganisms neither in the colonic lumen nor in the colonic mucosa. It does reduce, however, the total number of bacteria and has been thought to lower wound infection risk.

Preoperative oral administration of antibiotics has shown to reduce the bacteriall concentrations of the colonic microflora, faecal - as well as mucosal flora, and lower the rate the postoperative septic complications.

As reported in chapter 5 whole gut irrigation has been shown to be a very effective method of mechanical cleansing of the large bowel before elective colorectal surgery. However, a number of questions remained to be answered:

How effective is whole gut irrigation in reducing the faecal and mucosal colonic microflora?

Whole gut irrigation decreases peroperative faecal spilling; is it therefore justifiable to omit the prophylactic use of antibiotics?

Is the oral administration of antibiotics more effective in reducing the colonic microflora when combined with whole gut irrigation, than in combination with a conventional cleansing method?

Does whole gut irrigation with or without additional administration of orally administered antibiotics further reduce the postoperative septic complications compared to the conventional method.

To answer these questions a prospective, randomized, trial was embarked upon comparing whole gut irrigation with the conventional method of mechanical cleansing.

\subsection{Methods and materials}

Between 1979 and 1980 , a prospective, randomized investigation of 60 paticnts admitted for elective colonic and rectal surgery was carried out on the department of surgery at the St. Annadal Hospital, the University of Limburg. All patients with primarily surgical disorders of the coton and rectum, were examined for suitability of entering into the study. Patients operated for an appendectomy and restoration of a loop-colostomy were excluded. In the former the (elective) operation is crsentially mon contaminating and in the latter group the patients are colonized with a different colonic microflora, which already contaminates the field of operation. The patients admitted to the study had to fulfill the following criteria:

Absence of obstructive symptoms anywhere in the alimentary tract.

Radiologically less than $50 \%$ of terminal encroachment when a colonic lesion was demonstrated.

No signs and symptoms, clinical or radiological, of perforation of the gastro-intestinal tract.

Patients should not have received antibiotics 10 days before operation. 
Patients admitted to the study were allocated at random to one of groups by the sequential selection of coded envelopes containing the complete instructions for the preoperative bowel preparation. The order of assigment was randomized using a table of random numbers. The groups received one of the following three methods of preoperative bowel preparation (Table 6.1).

Table 6.1.

Preopenative large bowel propartion regunens

\begin{tabular}{|c|c|c|c|}
\hline & $\begin{array}{l}\text { Day- } \\
\text { (3 days befores operationt }\end{array}$ & $\begin{array}{l}\text { Day-2 } \\
\text { (2 ans before operation) }\end{array}$ & $\begin{array}{l}\text { Day-1 } \\
\text { (1 day before operation) }\end{array}$ \\
\hline $\begin{array}{l}\text { GROUP } \\
\text { (CONV.) }\end{array}$ & $\begin{array}{l}\text { - low residuediet } \\
\text { - sennosid }(x-\text { prep }\end{array}$ & $\begin{array}{l}\text { - Iow residuediet } \\
\text { - sernosid (x-Prep } R) \\
\text { - water enema } \\
\text { 11.00, } 4.00 \text { p.m.. } \\
\text { 10.00 p.m. }\end{array}$ & 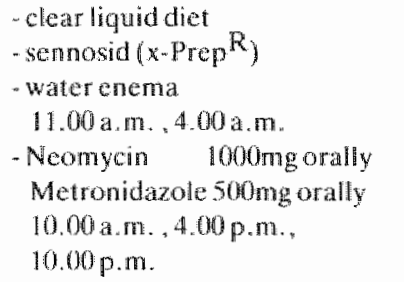 \\
\hline $\begin{array}{l}\text { GIROUP } \\
\text { (W.O.I.) }\end{array}$ & & & $\begin{array}{l}\text { - Whole Gut Irrigation } \\
\text { 2.60 p.m. }\end{array}$ \\
\hline $\begin{array}{l}\text { GROUP } \\
(W \cdot G \cdot 1 . A B)\end{array}$ & & & 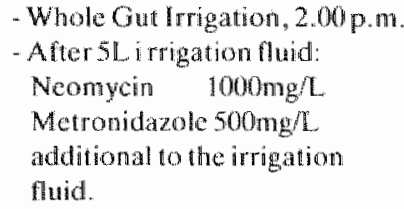 \\
\hline
\end{tabular}

\section{Conventional method}

The conventional method (CONV) existed of a low residue diet and the administration of the oral laxative sennosid ( $x$-Prep $R$ ) on day -3 . On day-2 water enemas, three times daily, were added to the regimen On day-1 the patient was placed on clear fluds and both oral laxative and enemas were given. The enema at $10.00 \mathrm{p} . \mathrm{m}$. was omitted. On this last preoperative day the patients in this group received $1 \mathrm{~g}$ neomycin and $0,5 \mathrm{~g}$ metronidazole three times a day by mouth

\section{Whole Gut Irrigation}

The second group of patients was prepared on the afternoon before the operation by means of whole gut irrigation (W.G.I.) as described in chapter 5.

\section{Whole Gut lrrigation + Antibiotics}

Pattionts in the last group underwent the same whole gut irrigation, however, after the first 5 liters of irrigation fluid $1 \mathrm{~g} / \mathrm{l}$ ncomycin and $0.5 \mathrm{~g} / \mathrm{l}$ metronidazole were administered to the irrigation fluid (W.G.I. + AB).

\subsubsection{Pre-and peroperative evaluation methods}

Bacteriological parameters; pre- and peroperative, quantitative aerobic- and anaerobic cultures were taken from the faeces before treatment, immediately after the bowel preparation and from biopsics of the entire thick ness of the colonic wall of the resected part of the colon. The latter investigations were performed because it seemed relevant to determine the density of acrobic and anaerobic bacteria in the colonic mucosa, since this may be regarded as a potential source of contaminating bacteriaduring a colorectal operation.

Serum levels of metronidazole were measured in the perioperative period. In the group prepared by metns of the conventional method the blood samples were taken before treatment on day 3 at 11.00 p.m. and at time of the premedication on the day of operation. In patients who underwent a whole gut irrigation with additional neomycin and metronidazole in the irrigation fluid the samples were 
taken before, immediateley after irrigation, at $11.00 \mathrm{p} . \mathrm{m}$. and at time of the premedication. Furthermore, metronidazole levels were measured in the last faecal samples obtained after the last cnema and in the clear rectal effuent after whole gut irrigation.

\subsubsection{Operative procedures}

Although maximum latifude in technical details for conducting the colon operation were felt to be desirable, certain restricting were imposed to reduce variables. All patients were operated, on the day after the bowel preparation had been finished, by residents supervised by attending surgeons or by one of those surgeons themselves. All anastomoses were performed in two layers (the inner with continuous catgut and the outer with inverting interrupted silk) except for low anteriot resections which were usually performed with one layer of inverting, interrupted sillk sutures or in case of very low anterior resections the circular stapling instrument was used. The decision to use a proximal diverting colostomy was left to the judgement of the individual surgeon. No caecostomies were performed. When no proximal diverting colostomy was performed a dilatation of the anus was usual. The abdominal cavity was washed with saline after the anastomosis was performed. Wound closure was done in two different manners; the abdominal wall was either closed with interrupted vycryl in two layers or in one layer with a double continuous vyeryl 2 stitch. The skin was always closed with interrupted nylon. In this series no delayed primary suture of the skin was done. After colonic resections drains were not used as a routine procedure. When drains were used after colonic resection this were always closed suction drains and brought out through seperate stab wounds. Neither in colonic operations nor after abdominal perineal resections of the rectum were non suction-or open Penrose drains used. After abdomino-perineal resection of the rectum the proctectomy space was always closed as a primary procedure over two closed suction drains. (Sump-drains), brought out through separate stab wounds. Drains in the subcutaneous tisswe were never used.

\subsubsection{Postoperative evaluation methods}

To evaluate the postoperative course the following parameters were recorded. Wound infections and other septic complications such as septicaemia, anastomotic dehiscence, peritonitis and intraabdominal abscesses.

The patients' wounds were inspected by the same person on the third, seventh and tenth postoperative day, as well as after four weeks, for evidence of infection. For the assessment of postoperative wound infection, the criteria for wound infections are summarized in Table 6.2. Only wounds in category 1 and 2 were recognized as wound infections, while wounds in category 3 and 4 were considered as no wound infections.

Table 6.2.

Wound scoring

Categary Criferia

1.

Pus visible in the wound.

A culture, positive or not is unimportant.

2 .

Erythema, swelling or excessive pain or

tenderness in the wound and fever.

No pus is visible.

A positive culture support the diagnosis.

3.

Local pus formation around the stitches.

The surgical wound heals per primam.

4.

No signs of sepsis. The wound heals per

primam.

Positive blood cultures related to other causes of septicaemia (pulmonary-or urinary tract) were not considered as septicaemia due to the colonic operation. Three blood cultures were taken at regular intervals when clinical signs of septicaemia occurred. Intra-abdominal or pelvic abscess was defined 
either by a spontaneous discharge from a palpable mass or by a collection of pus requiring surgical drainage. Data on an anastomotic breakdown we re obtained from evidence of a leak on signoidoscopy, from radiological examination, from clinical evidence of a faecal fistula or of peritonitis requiring a second operation, or as a result of autopsy. Only dehiscences of the amastomosis with clinical consequences were reconded. A postoperative contrast enema in order to find a radiological leakage was not performed routinely after colonic resection and primary anastomosis.

Duration of hospital stay was used as an indication of the rate of healing, and was defined as the number of days from the date of operation to the date of discharge.

\subsubsection{Microbiological methods and techniques}

\subsubsection{Specimen collection}

Proper collection and transportation of clinical specimens are critical factors in the recovery of obligate anaerobes (Finegold and Rosenblatt 1973). The sample of discharge or exudate should be collected trom the deep, active region of infection, to prevent surface contamination and aeration of the specimen. Whenever possible, tissue samples or fluid aspirates are collected rather than swabbed specimens. As with aerobic specimens, the material on swabs must be processed rapidly to prevent drying and to preserve viability. Specimens should immediately be placed in an anaerobic environment for transport to the laboratory.

The most simple technique is collection by needle aspiration using an 18 gauge needle. Prior to needle aspiration, the involved atea should be cleansed with an antiseptic solution to prevent surface contamination. After aspuration the needle on the aspirating syringe is bent or corked with a rubber top after all air bubbles within the specimen have been expelled.

In casc of lack of material to aspirate the swab technique can be used. The swabbed specimen should be placed immediately into a sterilized reduced solidified transport medium (Port-a-Cul of Becton). After the swab has been inserted into the glass tube, a fitted rubber stopper should be applied immediately.

The sampling techniques used in this study will be reviewed.

The faccal samples were collected in the following way: The patient was seated on a toilet chair and the facces samples are collected in a sterile bottle, fixed to the chair, flushed with $\mathrm{CO}_{2}$. In case of conventional bowel preparation the last faeces sample was obtained after the last enema. In patients prepared by means of whole gut irrigation, with or without additional antibiotics, the first faeces and the clear rectal effluent at the end of the preparation were cultured in the same way (Fig. 6.3). In case of solid faces the bottle was closed with a rubber cork and transported in this way. The rectal cffucnt after whole gut irrigation was clear liquid and could be aspirated from the bottle through a rubber diaphragm.

During operation a ring of the proximal and distal end of the resected part of the colon was cut. Fat on the scrosa was removed, and the biopsies were directly transported after resection in a sterile anacrobic transport tube. A sterile screw capped the tube filled with cabon dioxide and $\mathrm{H}_{2} \mathrm{~S}$ absorbent, to provide anerobiosis, and silicagel in onder to withdraw humidity. A piece of tissue of the entire thickness of the colonic wall, weighing $1 \mathrm{gram}$ was ascptically removed from the specimen with sterile scissors in the anaerobic glovebox. The tissue sample was homogonized with $1 \mathrm{ml}$ of sterile saline solution in a tissue grinder (Tenbroecke grinder).

Wound exudate or pus was obtained by the aspiration technique or in case of lack of material with the swab technique. Free abdominal fluid or pus were obtained in the same way. All specimens for bacteriological investigations were transported immediately to the department of microbiology and within 30 min. introduced into an anaerobic glove box (Anaerobic Work Chamber Bench GMPVAC) and processed. 


\subsubsection{Isolation and idlentification}

By using a turrax mixer one part of faeces of tissue homogenate was thoroughly mixed with 9 parts of Pre Reduced Anaerobic sterilized (PRAS) diluent (saline + $0.05 \%$ cysteine $\mathrm{HCl}$ ). The homogenates were serially diluted tenfold $\left(10^{1}-10^{11}\right)$. Am aliquot of $0.1 \mathrm{ml}$ of each diluent was spread over the surface of the agar plates. The dilutions $10^{1}-10^{7}$ on $5 \%$ sheepblood agar (Oxoid CM 55) and Mac Conkey agar (Oxoid $\mathrm{CM} 7$ ) were incubated for 48 hours under atmosferic conditions at $37^{\circ} \mathrm{C}$ before counting the colonies. For the $10^{4}-10^{11}$ dilutions a modified Wensinck medium, (Fieldes extract (Oxoid SR 46) instead of whole blood), was used.(Wensinck and Ruseler-v. Emden, 1971). These were incubated for 72 hours before counting the colonies. Counting was repeated after 7 days of incubations. Selective media for $\mathrm{Cl}$. difficile (Cycloserine, cepoxitine, fructose agar) and for yeasts (Sabouraud-dextrose agar (Oxoid CM 41) with 1\% chloramphenicol) and PRAS, brain heart infusion broth (Oxoid CM 225) with additional vitamin $\mathrm{K}$ and hemine were inoculated with the $10^{\mathrm{i}}$ dilution and checked for growth during one week. The Sabouraund plates were incubated under acrobic conditions.

Pus was processed for isolation of aerobic micro-organisms and identified according to generally accepted bacteriological procedures. For isolation of obligate anaerobic bacteria pus was processed according to the Wadswoth Anaerobic Bacteriological Manual (Sutter ef al, 1975) and isolates were identified on bases of morphology, biochemical reactions (Minitek system), antibiotic resistance and analysis of volatile fatty acids by gas chromatography (Packard model 433). The concentration of micro-organisms is expressed as the logarithm to the base ten of Colony Forming Units per $\mathrm{ml}$ (C.F.U. / mll) of fluid, bowel content or gram faeces or tissue.

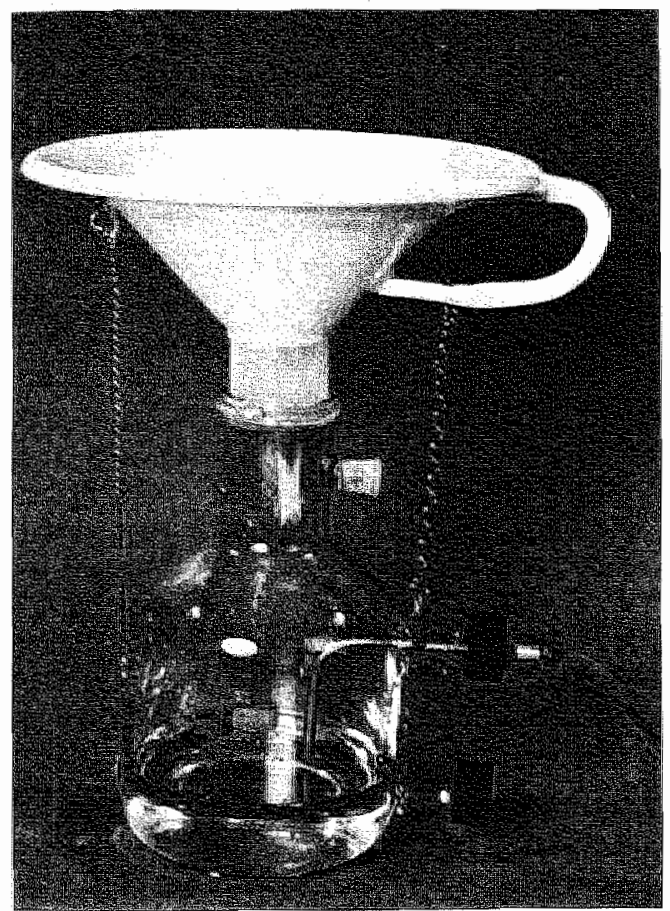

Fig. 6.3.

Method 10 collect faecal Samples.

\subsubsection{Levels of metronidazole in serum and fareces}

The levels of metronidazole in serum in the perioperative period as well as the metronidazole levels in the faeces before and after large bowel preparation were measured by means of High Performance Liquid Chromatography (Spectra-physics SP 3500 B). The HPLC system consisted of a Spectra Physics SP 3500 B pump equipped with a Rheodyne injector. Absorbtion at $320 \mathrm{~mm}$ was monitored with a Schoeffel SF 770/GM 770 spectrophotometer. 
A Lichrosorb RP-8 column (particle stze $5 \mu \mathrm{m} ; 150 \mathrm{~mm} \times 4,6 \mathrm{~mm}$ I.D., Chrompack, Middelburg. The Netherlands) was used in combination with a quad column (ODS, pellicular material; $100 \mathrm{~mm}$ $2,1, I . D$.) to extend lifetime of the analytical column. The mobile phase was $25 \%$ v/v methanol in bidistilled water. The preparation of the serum samples consisted of a deproteinisation. $125 \mu$ serum was added to 400 ul methanol and centrifuged for 4 minutes at $20.000 \mathrm{~g}$. Aliquots of $10 \mu$ of the supernatant were injected. The detection limit was less than $1 \mu \mathrm{g}$ and the standard deviation of the reproducibility was less than $10 \%$.

\subsubsection{Statistical evaluation}

The significance of differences was assessed by chi-schuare test analysis or by the student-test. Unless indicated otherwise these methods were used throughout all studies.

\subsection{Results}

\subsubsection{Patient population}

The patient characteristics of the 60 patients in the three different groups are summarized in Table 6.4. The three groups were well matched for sex distribution, preoperative hospital stay, duration of the operation, intra-operative complications and the use of suction drains. Although, age distribution, number of paticnts over 60 years of age, and duration of the operation were different in the three groups, statistically significant difference was not achieved for these parameters. The vacuity of the colon at operation was better in both irrigated groups compared to the group prepared by means of the conventional cleansing method. The different diagnoses and types of colonic operation were similarly distributed between the three groups, however, in the conventionally prepared group only 2 patients underwent an abdominoperineal resection of the rectum for a rectum carcinoma (Table 6.5 and 6.6).

Table 6.4 .

Comparison of patients characteristics

\begin{tabular}{|c|c|c|c|}
\hline & $\begin{array}{l}\text { Group } \\
\text { CONV. }\end{array}$ & $\begin{array}{l}\text { Group } \\
\text { W.G.I. }\end{array}$ & $\begin{array}{l}\text { Group } \\
W . G .+A B\end{array}$ \\
\hline Patients $n=$ & 21 & 20 & 19 \\
\hline Matle & 9 & 14 & 10 \\
\hline Fiemale & 12 & 6 & 9 \\
\hline Age & $68.9 \pm 10.8$ & $60.6 \pm 13.9$ & $56.7 \pm 16.3$ \\
\hline Range & $50-87$ & $28-80$ & $16-75$ \\
\hline $\begin{array}{l}\text { Preoperative hospital } \\
\text { stay (days) }\end{array}$ & $7.9 \pm 3.6$ & $9.0 \pm 5.6$ & $6.8 \pm 4.8$ \\
\hline Operation time (min.) & $140 \pm 37$ & $157 \pm 79$ & $187 \pm 74$ \\
\hline Range & $90-225$ & $60-420$ & $70-390$ \\
\hline \multicolumn{4}{|l|}{ Vacuity: } \\
\hline Verygood $(\%)$ & $9(43)$ & $14(70)$ & $14(74)$ \\
\hline Good $(\%)$ & $7(33)$ & $3(15)$ & $4(21)$ \\
\hline Bad $(\%)$ & $5(24)$ & $3(15)$ & $\|(5)$ \\
\hline \multicolumn{4}{|c|}{ Intraoperative complications: } \\
\hline Faecal spilling & 2 & 3 & 2 \\
\hline Excessive blood loss & 0 & 1 & 1 \\
\hline Other & 0 & 0 & 1 \\
\hline \multicolumn{4}{|l|}{ Drain location: } \\
\hline Abdominal & 6 & 5 & 3 \\
\hline Perineal & 2 & 5 & 5 \\
\hline
\end{tabular}


Table 6.5 .

Comparison of the diagnoses

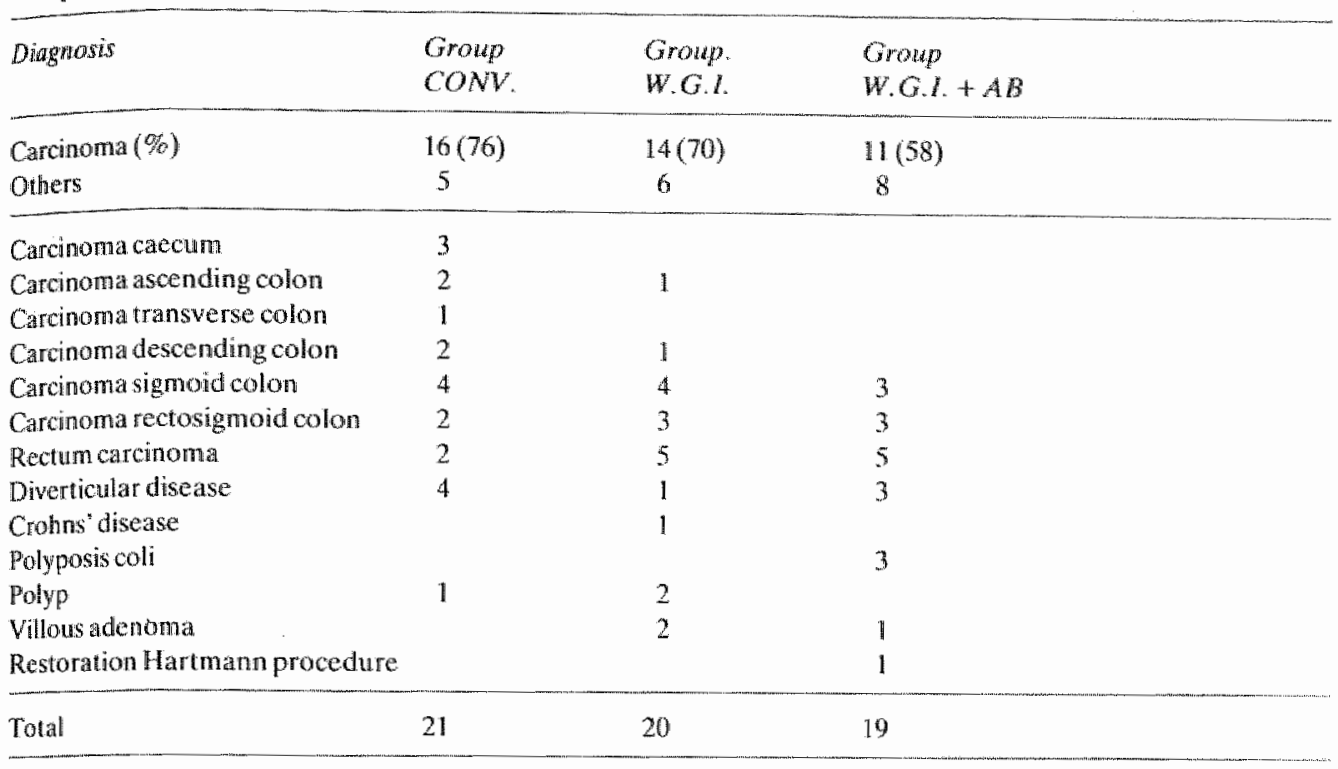

Table 6.6.

Comparison of the operations

\begin{tabular}{llll}
\hline Operations & Group & Group & Group \\
& CONV. & W.G.I. & W.G.L +AB \\
\hline
\end{tabular}

\section{Abdominoperineal}

resection

Low anterior resection

Sigmond colectomy

Left hemicolectomy

Right themicolectomy

Resection transwerse-

colon

Subtotal colectomy

Colotomy

Hartmann procedure

Restoration Hartmann

procedure

$\begin{array}{lll}2 & 5 & 5 \\ 2 & 5 & 4 \\ 8 & 4 & 5 \\ 2 & 2 & \\ 5 & & \\ 1 & & 4 \\ 1 & 1 & 1\end{array}$

Total $21 \quad 20 \quad 19$

\subsubsection{Bacteriological results}

\subsubsection{Reduction of aerobic and anaerobic faecal microflora}

The pre- and post treatment faeces were quantitatively cultured, and the total aerobes, coliforms, bacteriodes, and anaerobes were measured in order that the three groups could be compared. To evaluate our aerobic - and anaerobic method of culturing faecal flora, the faeces of 4 healthy individuals was cultured. The results of these cultures arc noted in Table 6.7 and compared with the results of Wensinck (1975). The results of the quantitative aerobic and anaerobic bacteriological cultures of the faecal specimens (obtained before - and immediately after preparation) expressed as average per group \pm S.D., are shown in Figs. 6.8 and 6.10 and Tablles 6.9 and 6.11 . 
Table 6.7 .

Evaluation of the aerobic and anacrobic culture method on Wensinck plates in healthy individuals

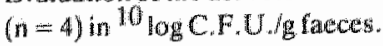

\begin{tabular}{lrc} 
& Presentsudy & Wensinck 1975 \\
\hline Acrobic & $7.52 \pm 0.70$ & $7.79 \pm 0.78$ \\
Anaciobic & $11.15 \pm 0.38$ & $10.95 \pm 0.37$ \\
\hline
\end{tabular}

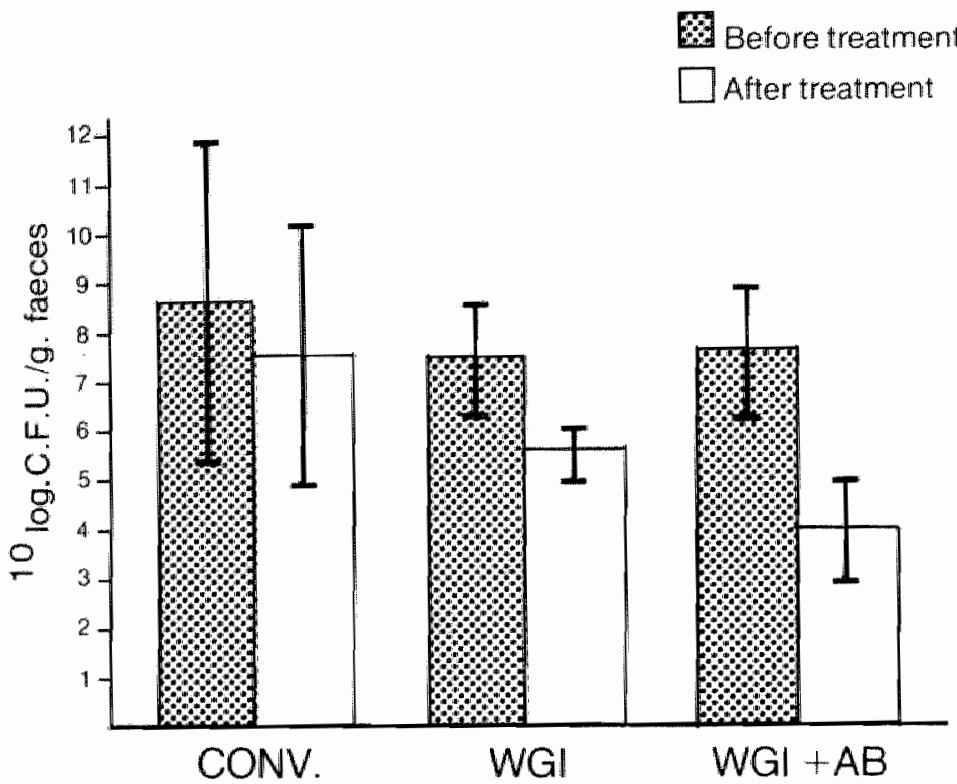

Fig. 6.8 .

Reduction of the acrobic faecal microflora \pm S.D.

Table 6.9.

Reduction of the aterobic facal micro-flora $\left({ }^{10} \log\right.$ C.F. U. /g faeces \pm S.D) due to three different types of preoperative preparation of the large bowel.

\begin{tabular}{lcll} 
& CONV & W.G.I. & W.G.I. AB \\
\hline Before treatment & $8.75 \pm 3.30$ & $7.65 \pm 1.19$ & $7.76 \pm 1.35$ \\
Affer treatment & $7.57 \pm 2.62$ & $5.60 \pm 0.63$ & $4.15 \pm 1.06$ \\
Reduction & $1.15 \pm 2.45 \mathrm{~A}$ & $2.04 \pm 1.10^{*}$ & $3.70 \pm 1.48^{*} \mathrm{~A}$
\end{tabular}

$* p=0.004$

$s_{p}=0.01$

In both irrigated groups the pre-treatment faecal counts for aerobes and anaerobes tended to be lower, although not significantly, than those of the conventionally treated group. This is probably due to the unavoidable dilution by the irrigation fluid. Ditution and more effective removal of bacteria explain the lower counts after treatment in group W.G.I. compared to group CONV, although this difference was not statistically significant. A marked further reduction in aerobic and anaerobic counts occurred when antibiotics were added to the irrigation fluid. Highly significant differences were seen between group W.G.I. + AB and group CONV but especially between group W.G.I. + $A B$ and group W. G.I. (Table 6.9 and 6.11). 


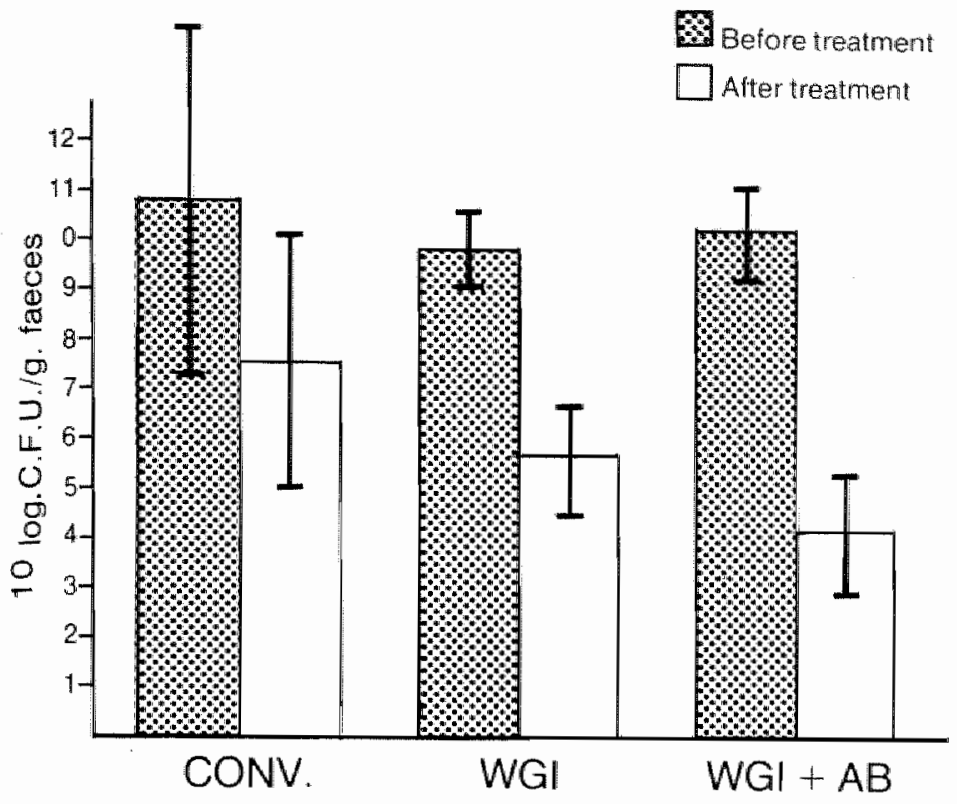

Fig. 6.10.

Reduction of the anaerobic faecal microflora \pm S.D.

Table 6.11.

Reduction of the anaerobic faecal micro-flora $(10 \log$ C.F.U./g faeces \pm S.D.) due to three different types of preoperative preparation of the large bowel.

\begin{tabular}{lccc} 
& CONV & W.G.I. & W.G.I..$+ A B$ \\
\hline Before treatment & $10.92 \pm 3.52$ & $9.70 \pm 0.78$ & $10.22 \pm 0.90$ \\
Aftertreatment & $8.80 \pm 2.60$ & $6.90 \pm 1.13$ & $5.23 \pm 1.16$ \\
Reduction & $2.23 \pm 2.89 \circ$ & $2.80 \pm 1.38^{\mathrm{ut}}$ & $5.09 \pm 1.64^{\circ} \mathrm{A}$ \\
\hline
\end{tabular}

$\mathrm{*} p=0.001$

$\Delta p=0.01$

No significant differences were seen in cultures on candida before and after bowel preparation in either group. Furthermore, $\mathrm{Cl}$. difficile was not identified in any of the facees samples during the bowel preparation. In the postoperative period no signs of bacterial overgrowth by pathogenic micro-organism were remarked.

\subsubsection{Aerobic and anaerobic bacteria counts in the biopsies}

The cultures of the resected part of the collon, the results of which are shown in Fig. 6.12 and Table 6.13, showed a rather large variation in counts as shown by the greater S.D. Although the samples were standarized on a weight basis, the composition of the samples with regard to the amount of mucosal tissue probably varied, and explains the variation. However, the results clearly indicated that the most important factor in reducing the mucosal flora is the presence of antibiotics. Compared with group W.G.I., both the group W.G.I. + AB and group CONV patients showed a significant reduction in aerobic and anaerobic bacterial counts. Since the concentration of the antibiotics at the mucosal site is quite different in these two groups (see paragraph 6.3.2.3.), the data suggests that once an effective antibiotic concentration is reached a further increase in concentration does not further reduce the mucosal flora. 


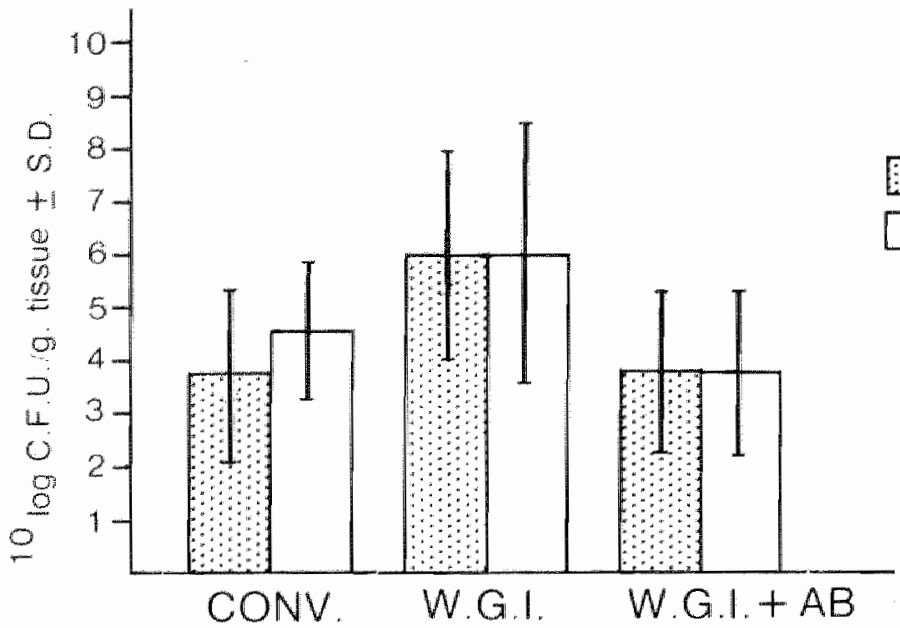

Fig. 6. 12 .

Aerobic and araterobic cultures of the biopsies of the resected part of the colon $\left({ }^{10} \log\right.$. C.F.U./g tissue \pm S.D.).

Table 6.13 .

Acrobic and araterobic cultures of the biopsies $\left({ }^{10} \log\right.$ C.F.U.g tisstue \pm S. D. $)$

\begin{tabular}{llll} 
& CONV. & W.G.I. & W.G.I. AB \\
Acrobic culture & $3.70 \pm 1.62^{*}$ & $6.02 \pm 1.98^{* A}$ & $3.73 \pm 1.52^{\mathrm{A}}$ \\
Anacrobic cuilure & $4.54 \pm 1.30^{* *}$ & $6.03 \pm 2.45^{* *}$ & $3.72 \pm 1.56^{*} \mathrm{AL}$ \\
\hline
\end{tabular}

* $p=0.009 \quad p=0.003$

$A_{p}=0.008 \quad \therefore \Delta p=0.001$

\subsubsection{Levels of metronidazole in serum and faeces}

Metronidazole, in contrast to neomycin, is readily absorbed from the intestinal tract. To establish the serum levels of metronidazole obtained in the two groups that received antibiotics during their preoperative preparation, blood samples were taken at the previously stated points of time and assayed for metronidazole. The results are shown in Fig. 6.14 and Table 6.15.

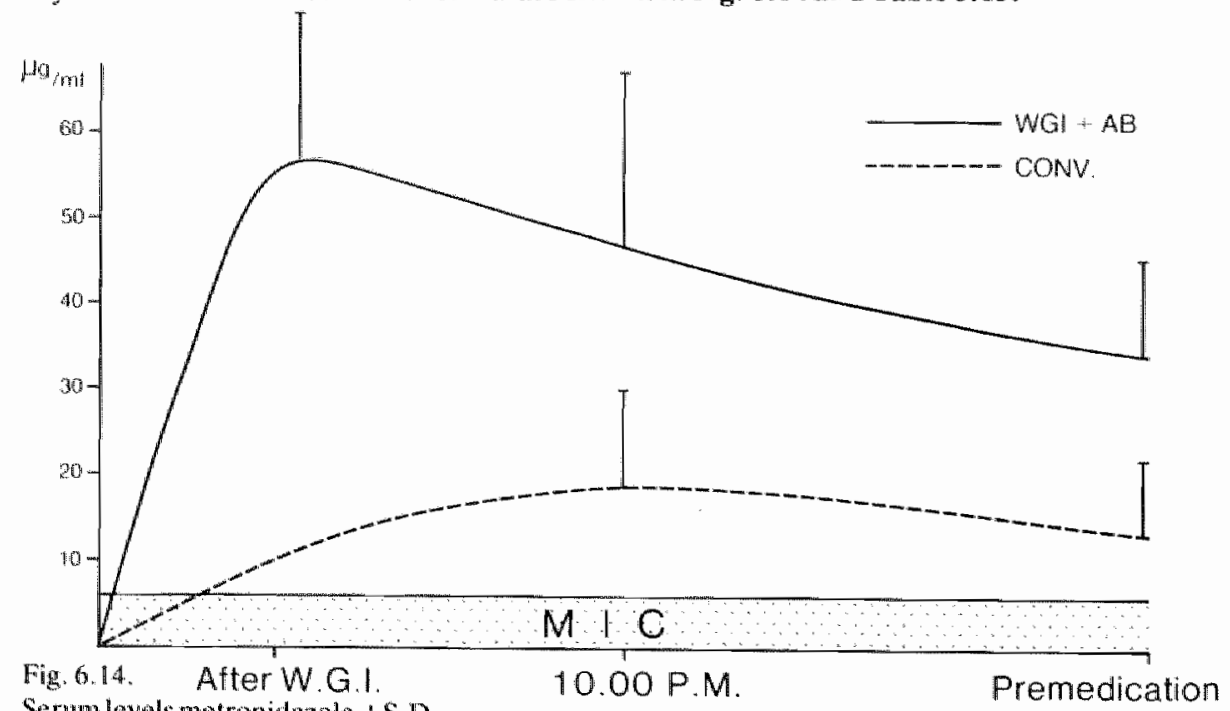

Serum levels metronidazole + S.D. 
Serum levels of metronidarole ( $\mathrm{gg} / \mathrm{ml} \pm \mathrm{S} \mathrm{D}$.$) .$

\begin{tabular}{lcccc} 
& Conrol & AflerW.G.I. & 10.00 p.m. & Premedication \\
\hline CONV. & 0 & - & $18.5 \pm 10.4$ & $13.8 \pm 8.7$ \\
W.G.I. AB & 0 & $55.7 \pm 17.8$ & $48.2 \pm 20.3$ & $34.4 \pm 11.3$ \\
\hline
\end{tabular}

In both groups metronidazole reached serum lewels during the preparation period and at time of operation well above the awerage M.I.C. values of anaerobic bacteria for this antimicrobial drug. The M.I.C. of metronidazole for most of the colonic obligate anaerobes is $2-6 \mu \mathrm{g} / \mathrm{ml}$. (Sutter and Finegold, 1975). The differences in serum lewels observed between the two antibiotic treated groups is due to the differences in dosage, the total amount of metronidazole administered to group W.G. I. $+\mathrm{AB}$ being in average 3 times higher than that given to group CONV. Due to these large amounts of metronidazole in group W.G.I. + AB high serum levels were observed immediately after the trrigation was finislled.

Metronidazole does not achieve significant levels within the colon (Willis et al., 1977) but may do so in patients with diarrhea (George et al., 1977). This statement could be conformed in our own experiments. In group CONV metronidazole in the faeces after the last enema could not be detected in 16 out of 20 patients, while the mean level was under the M.I.C. of most anacrobic bacteria. The metronidazole level was $131 \pm 53 \mathrm{mcg} / \mathrm{ml}$. in the clear rectal effluent in group W.G.l. + AB. A highly significant difference between both groups was reached ( $\mathrm{P} \times 0.01$ ).

\subsection{Clinical results}

\subsubsection{Wound infections}

The data concerning wound sepsis in the three different groups are summarized in Table 6.16. All the abdominal as well as the perineal wounds of the 5 patients in group W.G.I. who underwent an abdominoperineal resection of the rectum for a rectum carcinoma became infected. These wound infections were serious deep infections with purtrid smelling pus. "The cultures of the pus revealed all mixed aerobic/anaerobic colonic bacteria. Five out of 15 patients ( $33 \%$ ) who underwent an elective colonic operation developed a wound sepsis. Furthermore, four of these patients developed other more serious septic complications. From the pus of all these wounds, both aerobic as anaerobic colonic micro-organisms were cultured, except in one patient. In this patient no anaerobic cultures were done.

In the conventionally prepared group only 2 patients were operated upon for a rectum carcinoma. In one of these patients the perineal wound became infected with a $E$. coll. In patients who underwent an elective operation of the rest of the colon $2(10 \%)$ developed a wound sepsis. In one patient a beta-haemolytic Streptococcus, group A was cultured from an erysipilas like wound infection. The other patient developed a serious deep wound infection, from which mixed acrobic / anacrobic colonic micro-organisms were isollated, after a right hemicolectomy. 
Drisease
Woundsepsis

$A=$ Abdominal Aerobic

$P=$ Perineal
Pus culures

Anderabic
W. G.II.

1. Recturncatcinoma

2. Rectum carcinomat

3. Rectumitareinomati

4. Rectum carcinoma

5. Recium catrinoma

6. Carcinoma sigmoid

7. Carcinoma tectosigmoid

8. Carcinoma descen dingrolon

9. Adenomatous polyp cacoum

10. Cincinomatectosigmoid

Low anterior resection

\section{CONV.}

11. Recum carcinoma

12. Diverlicular discane

13. Garcinoma hepatic Aloxure

\section{W. C.I. + A H}

14. Rectum carethoma

15. Rectum carcinoma resection resection resection resection rescction

rescction

Harmann

procedure

Colotomy resection

right: rescetion
Abdomino perineal

Abdomino perineal

Abdominoperineal $A, B^{3}$

Abolominoperineal A.P

Abdominoperineal A,P

Sigmoid colectomy

A

A

A.

A

A

E.coli

$\mathrm{A}, \mathrm{P}$

Abdomino perineal

Sigmoind collectomy

Hemi colectomy

A A

Abdomino perimeal

Abdominoperincal p rescction
B. fraglis

Fuso bacteria

Enterococci B. fragilis

Str. faecalls B. fragilis

Ei. coli

roteus

E.coli

proteus

Str. faccalis

Proteus

klebsialla

E. coli

B. Fragilis

Clostridium

E. coli

Protens

E. coli

Str. faccalis

E. coli

Sir. faccalis

Noiculured

B. fragilis

B. fragilis

S. atreus

E. coli

Proteus

Klebsialla

B. fremillis

E. coli

Str. hacmolytica

E. coli

B. fragilis

Str. fatecalis

Satureus

Santeus

Str. facedis

E. coli

Proteus.

The best results were seen in group W.G.I. + AB. Just 2 out of 5 perineal wounds after abdominoperincal tesection of the rectum became infected. One was due to an exogenous infection with $S$.aureus, while the other was amixed acrobic infection of $E$. coli and Proteus. No anaerobic micro-organisms were cultured from the pus of these superficial perineal infections. The postoperative hospital stay was not significantly influenced by these mild infections. None of the 15 other pathents in this group developed a wound infection after an elective colonic operation.

In summary: (Fig. 6.17) $50 \%$ of the patients in group W. G.I. developed a wound infection after elective colorectal sutgery while these percentages in group CONV. and in group W.G.I. + AB were $14 \%$ and $10 \%$ respectively. The incidence of postoperative wound infection in group CONV $(p=0.04)$ as well as in group W.G.I. + AB $(p=0.03)$ were significantly less compared to group W.G.I. No significant difference in incidence of wound sepsis in both groups prepared with additional antibiotics was seen. Further analysis showed that the uneven distribution of the ab- 
Table 6.17.

Comparison of the incidence of postoperative wound infection after elective colon and rectum surgery.

\begin{tabular}{lcccccc}
\hline & & \multicolumn{2}{c}{ Colon } & \multicolumn{2}{c}{ Colon + Rectum } \\
\hline & $\begin{array}{c}\text { Operations } \\
n\end{array}$ & \multicolumn{2}{c}{ Woundinfections } & Operations & Woundinfections \\
& $n$ & $\%$ & $n$ & $n$ & $\%$ \\
\hline CONV. & 19 & 2 & 18 & 21 & 3 & 14 \\
W.G.I. & 15 & 5 & 33 & 20 & 10 & 50 \\
W.G.I. + AB & 14 & 0 & - & 19 & 2 & 10 \\
\hline
\end{tabular}

dominoperineal resection of the rectum between the groups markedly influenced the results. Omitting these operations the incidences of wound infections in group W.G.I., in group CONV. and in group W.G.I. + AB were respectively $33 \%, 10 \%$ and zero.

\subsubsection{Intra-abdominal sepsis}

The incidence of intra-abdominal sepsis is visualized in Fig. 6.18. In group W.G.I. + AB no other septic complication other than superficial wound infections in the patients undergoing an abdominoperineal resection of the rectum were seen. In group CONV three patients (14\%) developed an intra-abdominal sepsis, of which two patients died. One case of peritonitis was caused by leakage of an anastomosis. Short case histories of these three patients will be given.

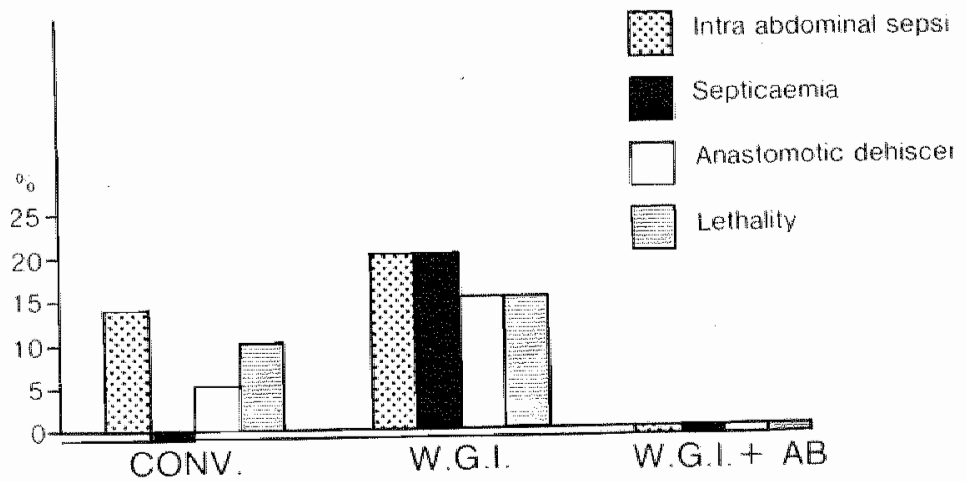

Fig. 6. 18 .

Comparison of septic complications except wound infections after elective colorectal surgery.

\section{Case 1.}

In a 66 year old previously healthy woman an abdominoperineal resection of the rectum was performed for at carcinoma of the reetum. The vacuity of the bowel was poor, but mo intra-abdominal gross falecal spilling accurred. The operation was performed in 135 minutes without complications. On the fifth postoperative day the patient had to be reoperated for a peritonitis. The cultures of the intra-abdominal fluid revealed only ancrobes: $\mathbb{E}$. coli and $P$. mirabilis. The day after this daparotomy the patient died suddenly duc to a massive lung cmbolism despite anticoagulant the rapy.

Case 2.

A 74 year old, diabetic, obese, woman underwent a right hemicolectomy for a Dukes $D$ adenocarcinoma of the caecum. The vacuity of the large bowel after conventional preparation was good, and no faccal spilling occurred. On the 9 th postoperative day she had to be reoperated for a secondary peritonitis. The ilcocolostomy was intact. The cultures of the intra-abdominal fluid revealed an aerobic/anaerobic mixed infection with Klebsiella and $B$. fragilis. She died on the 30 th post-operative day of multiple organ failure due to a septic shock.

Case 3.

For long standing complaints of diverticular disease a resection of the sigmoid colon was performed in an otherwise bealthy 51 year old woman. The wacuity of the bowel was good and no gross faecal spilling ocurred. No 
proximal colostomy was made. On the tenth postoperative day a large aerobic intra-abdominal abscess had to be drained. The cultures showed a mixed infection of E. coll, faecal Streptococci, and P. mirabilis. No anaerobes could be cultured.

In addition to a high incidence of wound infections in group W. G.I., a high rate of other serious septic complications was seen in this group of patients. $20 \%$ of the patients prepared by whole gut irrigation alone developed a peritonitis or an intra-abdominal abscess. Three out of four of these cases of secondary peritonitis were caused by a dehiscence of the anastomosis, two of these patients had a burst abdomen and 2 patients finally died. Short case histories of these 4 seriously ill patients will be given.

\section{Case 4.}

A previously healthy man of 51 was operated for a large adenomatous polyp in the caecum, which could not be re* moved with the coloscope. A polypectomy was performed via a caecotomy. The vacuity of the colon was very grood after whole gut irrigation. On the sixth postoperative day he had to be reoperated for a secondary peritonitis due to a leakage of the suture line. An exteriosation of the caecum was performed. The cultures of the intraabdominal pus revealed a mixed aerobic/ anaerobic infection with $E$. coli, $P$. mirabilis and $B$. fragilis. After this second operation the postoperative course was complicated by an intra-abdominal abscess and a burst abdomen which both made reoperation necessary. An enterocutaneous fistula closed spontaneously after 7 weeks total parenteral nutrition.

\section{Case 5.}

A 70 year old man with a carcinoma of the descending colon developed an acute abdomen on the evening after whole gut irrigation. A laparotomy was done the same evening and a perforation of a diverticula in the sigmoid colon was found, causing spilling of clear fluid into the abdominal cavity. A Hartmann procedure was performed after a resection of the sigmoid colon. The postoperative course was complicated by a serious wound infection and a peritonitis both caused by mixed aerobic/anaerobic micro-organisms ( $E$. coli, faecal streptococci and $B$. fragilis).

\section{Case 6.}

A 74 year old man was operated for a carcinoma of the rectosigmoid. After a whole gut irrigation a clean colon was obtained and a low anterior resection with a loop colostomy was perforned without complications in 3 thours. On the sixth postoperative day he had to be reoperated for a generalized peritonitis caused by an anastomotic dehiscence. Only aerobic cultures from the intra-abdominal pus were performed. A mixed aerobic colonic flora of E. coli and faecal streptocci were cultured. After this operation the patient developed and E. coli sepsis and died finally on a multiple organ failure due to al septic shock.

\section{Case 7.}

A low anterior resection with loop colostomy was performed for an Dukes C adenocarcinoma of the rectosigmoid in a 71 year old lady. The operation was uncomplicated and took 180 minutes. The vacuity of the colon was very good after whole gut irrigation. The patient developed a mixed ae robic/anaerobic wound infection and a secondary peritonitis on the fifth postoperative day which was caused by at rupture of the anastomosis. The cultures from the intra-abdominal fluid revetiled an infection with $P$. mirabilis, faceal streptococci, $B$. fragilis and $P e p r o s$ trephococcus. A Hartmann procedure was performed. In the postoperative phase she developed an aerobic sepsis with $P$. mirabilis and Klebsiella and died finally on a respiratory distress syndrome.

\subsubsection{Septicaemia}

Four pationts in group W.G.I. (20\%) develloped a septicaemia in the postoperative course. All the blood cultures revealed aerobic colonic micro-organisms. Anaerobic bacteria could not be isolated from the blood. Three calse histories are already described (case 4,6 and 7 in paragraph 6.4.2.). The last patient in group W. G.I. with a septicaemia had the following case history.

\section{Case 8.}

A 75 year old man underwent a very low anterior resection for a carcinoma of the rectosigmoid. The vacuity of the colon was very good after W.G.I. At the end of the operation which took 6 hours a loop colostomy was performed. He developed a wound infection and on the 9 th postoperative day he was reoperated for a burst abdomen "The anastomosis was intact. After this operation he developed a high output enterocutaneous fistula and later an acrobic sepsis with positive blood cultures for $E$. coli and faecal streptococci. No anaerobes could be cul- 
tured. A serious bronchopneumonia deteriorated further his clinicil condition and he finally died on the 29 th postoperative day. At autopsy no clinical dehiscence of the anastomosis was found.

No patient in group CONV nor in group W.G.I. + AB developed a septicaema in the postoperative course (Fig. 6.18).

\subsubsection{Anastomotic dehiscence}

In group CONV. just 1 patient developed an anastomotic breakdown (case 3). Dehiscence of the colonic anastomosis occurred in 3 patients in group W.G.I. (15\%) (Case 4, 6, 7 described in paragraph 6.4.2.). In group W.G.I. AB no rupturing of the anastomotic suture line was seen (Fig. 6.18).

\subsubsection{Lethality}

In group CONV, one patient died in septic shock after a generalized peritonitis (case 2) and another due to a massive longembolism the day after a relaparotony for a secondary peritonitis (case 1). Three patients who underwent an elective colonic operation in group W. G.I. died in consequence of serious postoperative septic complications (15\%) (Case 6,7 and 8). Postoperative lethality in this group was $10 \%$. No patient died in group W.G.I. + AB in the first 30 postoperative days (Fig. 6.18).

\subsubsection{Other postoperative infective complications}

Other postoperative infective complications, chiefly involving the respiratory and urinary tract, occurred in 20 patients in group W.G.I. in 6 patients in group CONV and in 7 patients in group W. G.I. $+A B$. As a matter of fact these data did not achieve significance between the groups receiving antibiotics, but was statistical significant $(p=0.02)$ when group CONV or group W.G.I. $+A B$ is compared with group W.G.I.

The fact that less patients receiving antibiotics were recorded as having postoperative infections not dibectly related to the operations may be a favourable effect of drug administration. However, this observation may represent an artefact of selection.

\subsubsection{Postoperative hospital stay}

The duration of postoperative hospital stay was used as an indicator of the rate of healing, and was defined as the number of days from the date of operation to the date of discharge. The mean overall postoperative thospitalization stay is summarized in Table 6.19.

Table 6.19.

Mospital stay

\begin{tabular}{lcccc}
\hline Group & \multicolumn{2}{c}{ Nowowndinfections } & \multicolumn{2}{c}{ Wound infections } \\
\hline & Colon & Colon + Rectum & Colon & Colont Recum \\
\hline CONW. & $21.0 \pm 10.0$ & $20.1 \pm 10.4$ & $36.0 \pm 29.6$ & $29.3 \pm 23.9$ \\
W.G.1. & $19.7 \pm 16.3$ & $19.7 \pm 16.3$ & $34.4 \pm 11.8$ & $37.4 \pm 16.5^{*}$ \\
W.G.I. $+\mathrm{AB}$ & $23.7 \pm 26.4$ & $23.2 \pm 24.6$ & - & $19.3 \pm 3.7^{*}$ \\
\hline
\end{tabular}

${ }^{*} P_{6} 0.01$

When no septic complications occurred the postoperative hospital stay was identical in either group. Wher a wound infection took place in group CONV as well as in group W.G.I. the postoperative hospital stay was prolonged by two weeks. The postoperative hospital stay in group W.G.I. AB was not influenced by the postoperative wound infections of the perineum after an abdominoperineal excision of the rectum. Only the difference in postoperative hospital stay between group W.G.I. and group W.G.I. AB achieved statistical significance in cases of wound in- 
fection ( $p=0.01)$. The hospital stay wn the case of a septic complication as well as in the case of an uncventful postoperative course was ratherlong. The indications for these long stays were social rather than surgical in most patients. In our country it is difficult to dehospitalize elderly patients because of a lack of homes for them.

\subsection{Discussion}

Preoperative bowel preparation aims the removal of faceal mass and the elimination or reduction of the resident flora. Theoretically, a decrease in the intra-fuminal colonic flora would reduce the level of potential bacterial contamination with its inherent consequences to the anastomosis, peritoneal cavity and cutaneous wound. Conventional methods of mechanical cleansing did not show a reduction of the resident collon flora (Nichols et al., 1972; A rabi elal., 1978). The enteral administration of non - or poorly absorbed antibiotics, however, caused a remarkable reduction of the faecal flora at the time of operation. Clark et al. (1977) and Bartlett et al. (1978) reported a decrease in as well the aerobic as the anaerobic flora of 5 logs after administration of neomycin and erythromycin base. Arabi et al. (1978) described an acrobic reduction of the faecal flora of 5 logs while the anaerobic flora was reduced by 8 logs after a conventional bowel preparation with orally administered neomycin and metronidazole. The aerobic faecal reductions of $1.1 \mathrm{log}$ and anaerobic reduction of 2.2 logs in group CONV were less than found by others. This difference can be explained by the fact that the post treatment specimen were obtained after the last cnema and not during operation via the aspiration technique. The antibiotics had less time to achieve the reduction.

An acrobic faecal reduction of less than $1 . \mathrm{log}$. and an anaerobic faecal reduction of $1 \mathrm{log}$. after a mechanical cleansing procedure by whole gut irrigation was found by Hirt et al. (1977). Huk et al. (1980) found no bacterial reduction neither acrobic nor anacrobic after whole gut irrigation. The same results were found by Stock et al. (1977), while Hollender and co-worker 1980 found a total bacterial reduction of $2-5$ logs in 16 patients and no bacterial reductions in 5 patients after whole gut irrigation. The aerobic faecal reduction of 2 logs. and the anacrobic faccal reduction of $2.8 \mathrm{logs}$. in group W.G.I, were in contrast with the faecal reduction found by others. In all these studies however, less irrigation fludd was used. The reduction in this study is probably more influenced by a greater dilutative factor due lo larger amounts of irrigation fluid. In any case the colonic flora is hardly influenced by whole gut irrigation alone. Impressive faecal reductions after an irrigation procedure with additional administration of enteral antibiotics were reported in the literature.

Huk ef al. (1980) found an aerobic reduction of $4.6 \mathrm{logs}$ and an anaerobic reduction of $5.6 \mathrm{logs}$ after whole gut irrigation with additional neomycin, clindamycin and bacitracin added to the irrigation fluid. Hollender et al. (1980) reported an acrobic reduction of 4 logs and an anaerobic reduction of at least $5 \operatorname{logs}$ after W. O.I. with additional neomycin and metronidazole. In nearly $50 \%$ of the 47 patients a complete sterilization was obtained after W.G.l. and at time of operation $65 \%$ free isolates were found. Stock of al. (1977) reported a reduction of $1 \mathrm{log}$ acrobic and 2 logs anacrobic after W.G. I. with saline and neomycin.

These large acrobic and anaerobic faecal reductions were also found in group W.G.1. \# AB. An acrobic faccal reduction of $3.7 \mathrm{logs}$. and an anaerobic faecal reduction of 5.0 logs. were found immediately after the lawage. It can be assumed that these reductions should be much higher when the needle aspiration technique was used at time of operation.

The comparison of the acrobic - and anaerobic bacterial treductions in the faeces in the three different groups showed a significant difference in bacterial reductions between group W.G.I. $+\mathrm{AB}$ and both other groups. These differences could partly be explained by the better mechanical cleansing procedure, by a dilutative factor and by the rapid action of neomycin and especially of metronidazole. The differences in bacterial reductions between group CONV and group W. G.I. did not achieve statistical significant values. This may be caused by the better mechanical cleansing and a dilutative factor in group W.G.I. and the relative short time the antibiotics in group CONV had time to act.

Vargish et al. (1978) cultured $10^{4}=10^{5}$ aerobic and anaerobic micro-organisms from mucosal biopsies taken from unprepared large bowels. After bowel preparation with different regimens of antimicrobial prophylaxis 25 out of 91 biopsies were sterile while 6 patients had the same amount of micro- 
organisms in the biopsies as found in the specimens from unprepared colons. The key to this contradiction lies in the variability of enteric organisms harboured by each patient. Not all micro-organisms in the gastro-intestinal tract were sensitive to the orally administered antibiotics used in their in their study.

The cultures of the biopsies, of the entire thickness of the colonic wall in group CONV as well as in group W.G.I. + AB did not show a statistical significant difference. The equall amount of aerobic bacteria $\left(10^{3}\right.$ per gram tissue) in both group CONV and group W.G.I. + AB suggest that the low dose of neomycin is as effective as the large quantities used in the irrigated group. Concerming the anaerobic micro-organisms in the colonic biopsies these figures for group W.G.I. + AB and group CONV were respectively, $10^{3.7}$ and $10^{4.5}$. These results, suggesting that the quantity of antimicrobial drugs is not very important when they were given in a sufficiently high dose. The amounts of aerobic and anaerobic bacteria cultured from the biopsies in group W. G. I. (aerobic as well as anaerobic, 10 C.F.U./g tissue) were equal or larger than cultured from the rectal effinent after irrigation. In the 1619 hours period between irrigation and operation the colonic flora had the opportunity to increase or stabilize. In the three groups of patients just 4 patients, equally divided in both antibiotic groups showed sterile cultures of the biopsies. The difference in results, compared to those of Vargish er al. could be explained by different bacteriological culture techniques.

As contrasted with neomycin, which is hardly absorbed from the gastro-intestinal tract, metronidazole is very well absorbed from the small intestine. When orally administered in a dosage of $500 \mathrm{mg}$ the same serum levels were achieved as in a intravenous administration (Houghton et al. 1978). Metronidazole is distributed in virtually all tissues and body fluids in concenctrations which do not differ markedly from the corresponding serum levels. Metronidazole has a drug elimination half life of 6-8 hours (Urtasan ef al., 1978). Metronidazole is being distributed into the intestinal tract mainly by secretion through the gut wall (Ings, 1973) but does never achieve levels in the collon above the Minimum Inhibitory Concentration (Whelan, 1969).

At time of operation a sufficient high serum level was reached in both group CONV and group W.G.I. + AB, in any way far above the M.I.C. The difference between serum levels of metronidazole at time of operation are significantly different $(\mathrm{p}=0.01)$. Only in group W.G.I. $+\mathrm{AB}$ a serum level of over 10 times the M.I.C. was achieved. Whether it is necessary or desirable to exceed the M.1.C. by a factor 10 or more is questionable (Eykyn and Philips, 1976).

In the faeces of the conventionally treated group hardly any metronidazole could be detected, certainly levels were below the M.I.C. In the clear rectal effluent in group W.G.I. + AB, however, levels of $131 \pm 53 \mu \mathrm{g} / \mathrm{ml}$ were found. This finding confirms the statement of George et al. (1977) who reported an increase of facees levels of metronidazole in case of diarrhea or in patients whose colonic flora has been partially eliminated by prior anti-microbial therapy. Metronidazole does not influence the anaerobic flora in volunteers, however, administered together with an aminoglycoside a profound effect on the anaerobic flora was found (Arabi et al., 1979). Whether the high faeces levels. of metronidazole in group W.G.I. + AB are responsible for the anacrobic reduction during irrigation, or that this is due to a better mechanical cleansing together with a synergistic action with neomycin is not clear. The last statement is the most likely because no difference was found in the anaerobic cultures of the biopsies.

The dosage of antibiotics in this study were chosen arbitrarily and no clear attention was being paid to the pharmakokinetics of the drug. It seems likely that the schedule of group W.G.I. + AB was more than adequate and that in the future it will be possible to reduce the dosage. Theoretically the chance exists of bacterial overgrowth or resistance. The high dose, short duration regimen, was selected to maximize the effect on the faecal flora for a sufficiently short period to prevent overgrowth of new resistant forms. Keighley et al. (1979) reported an $E$. coli resistancy for kanamycin of $34 \%$, resulting in a high incidence of postoperative septic complications. In this hospital kanamycin was used on a large used routinely. When an antibiotic drug was used on a large scale it had to be reconsidered if that particular antibiotic drug was shown to develop resistance in vivo.

Goldring et al. (1975) reported an incidence of wound sepsis of $8 \%$ after a conventional mechanical cleansing procedure and a 3 days oral antimicrobial prophylactic regimen with kanamycin and met- 
ronidazole. A similar preoperative large bowel preparation was used by Gillespie and Mc. Naught (1978). The postoperative wound sepsis rate was $12 \%$. Two comparable studies with enteral admimistration of neomycin and meironidazole were described by Keighley et al. (1978) and Matheson et al. (1978). The incidences of wound sepsis were respectively $18 \%$ and $30 \%$. The rates of wound infection in group CONV $(14 \%)$ as well as in group W. G.I. + AB (10\%) were in agreement with the results found by others. Howcver the results were flawed by the fact that in group CONV just two patients undenwent an abdominoperineal resection of the rectum while in group W. G.I. + $A B, 5$ patients underwent this operation. Omitting the operations in which the rectum was resected $10 \%$ of the patients in group CONV developed a wound infection after an elective collonic resection while in group W.G.I. + AB neither wound infection nor another serious septic complication was seen. The very thigh incidence of septic complications in group W.G. I, were in agreement with results from control groups in the literature in which after a conventional mechanical cleansing procedure or after whole gut irrigation placebos were administered instead of antibiotics.

The incidence of septic complications in group W.G.I. was significantly higher than in group W.G.I. + $A B(p=0.01)$ while the incidence of septic complications did not significantly differ from group CONV $(p=0.08)$. This difference was not significant between both groups who received antibiotics preoperatively. Comparing the three groups for colonic operations, with respect to the onset of postoperative septic complications; the difference in the incidence of septic complications between group W.G.I. and group CONV and between group W.G.I. + AB and group CONV were not statistically significant, however this difference was highly significant between group W.G.I. and group W.G.I. + AB ( $p=0.007)$. In addition, what these statistical data did not show was the gravity of these septic complications. All the wound infections in group W.G.1. were deep infections involving the whole incision and the full thickness of the skin. Not only serious wound infections were seen in this group, other septic complications were also seen most frequently in this group. A remarkable fact was that from all the infected areas anaerobic colonic micro-organisms could be isolated. In group CONV just one mixed aerobic/anaerobic infection was seen in an old, obese, diabetic lady with a peritonitis (case 2 ). In the other cases only aerobic colonic micro-organisms could be isolated. In group W.G.I. + AB only two mild infections of the perineal wound were seen. One was an cxogenous infection with $S$. aureus while the other was caused by a mixed aerobic flora of $P$. mirabilis and E. coli. The postoperative hospital stay was significantly prolonged in the case of a septic complication in group W.G.I. compared to both other groups, not only due to the wound infections but more due to the accompaning other serious complications in 5 out of 6 patients in this group. An analysis of the results of this trial showed no correlation between the aerobic and anaerobic faecal reductions due to the different types of bowel preparation and the postoperative septic complications. Furthermore, no correlation was found between the amount of aerobic and anacrobic mucosal micro-organisms cultured from the biopsies and the incidence of postoperative septic complications The only correlation was found between the serum level of metronidazole att time of operation and the incidence of postoperative septic complications. In case the group of patients with al septic complication the serum level at time of operation was $10.6 \pm 4.5 \mu \mathrm{g} / \mathrm{m} /$ while this level was $23.7 \pm 14.2 \mu \mathrm{g} / \mathrm{mul}$ when no septic complication occurred. This difference was highly significant $(p=0 .(001)$. This finding suggests that a scrum level which exced the M. I. C. by a factor 10 or more is questionable.

The cultures from the pus of the septic complications showed once more that an important role is played by the anaerobic colonic micro-organisms in the incidence and gravity of postoperative septic complications after elective colorectal surgery. Almost all serious deep wound infections and other more serious septic complications were caused by mixed infections with aerobic and anaerobic colonic bacteria. An antibiotic prophylaxis regimen with metronidazole in group CONV, as well as in group W.G.I. \& $A B$ extirminated the anaerobic infections almost completely. The excellent results in group W. G. I. + AB could be explained by a decrease of the aerobic and anaerobic faceal and mucosal flora, making the chance of faecal spilling as small as possible, in combination with a high serum level of metronidazole at the time of contamination.

The method of whole gut irrigation is an excellent method of preoperative large bowel preparation, making the chance of faecal spilling as small as possible. However, this method of mechanical cleansing without concomitant administration of antimicrobial drugs has been shown to be associated 
with a significantly increased risk of wound sepsis and other more serious septic complications compared with antibiotic treated patients. Further reliance on mechanical cleansing for preoperative preparation for elective colorectal surgery appears to be ethically unwarranted.

The final conclusions in this study are that from the three investigated methods of preoperative large bowel preparations, the method of whole gut irrigations with additional $0.5 \mathrm{~g} / \mathrm{l}$ metronidazole and $\lg /$ neomycin to the irrigation fluid, is the method of choice, and that in the use of antimicrobial prophylaxis in elective colorectal surgery the presence of an appropriate serum level of an antimicrobial drug at the time of surgery is the most important factor in preventing postoperative septic complications. 


\section{Hours systemic antimicrobial prophylaxis with gentamicin and metronidazole or with metronidazole alone in elective surgery of the colon after mechanical bowel preparation with mannitol and whole gut irrigation.}

\subsection{Introduction.}

The results from the first study investigating large bowel preparation before elective colorectal surgery did indicate that there is good evidence that patients infected with aerobic colonic microm. organisms do not fare as badly as those infected with anaerobes. The relative failure of antibiotics directed against the aerobic flora to prevent infection (Washington et al, 1974; Wapnick et al., 1979) suggest that the aerobic flora alone is not the prime bacteriologic requirement for the development of postoperative septic complications. The results of the previously described series suggest that synergysm between anaerobic micro-organisms and aerobic organisms is necessary to produce an infection in the wound or abdominal cavity. Removal of the anaerobes alone may therefore be all that is required to reduce sepsis and treatment with antibiotics effective against Gram negative aerobic bacteria may be unnecessary. Furthermore, as shown in chapter 6 , we believe that in the use of antimicrobial prophylaxis in elective colorectal surgery the presence of an appropriate drug circulating in the patients' blood at time of surgery is more important than the preoperative reduction of the colonic aerobic and anaerobic flora.

Disadvantages of whole gut irrigation are the possibility of a fluid overload and, in elderly patients, the lavage can be exhausting. Mannitol is an osmotic cathartic which is hardly absorbed from the gastrointestinal tract and attracks fluid from the circulation into the lumen of the bowel and prevents in this way fluid retention (Donovan et al., 1980; Davis et al., 1980). Mannitol produces little physiologic disturbances and when used in combination with whole gut irrigation it will probably reduce the fluid retention and decrease the duration of the whole procedure of mechanical cleansing (Minervini et al, 1980; Taat et al., 1981).

The incidence of postoperative wound sepsis after abdominoperineal excision of the rectum is higher than after elective surgery of the rest of the large bowel. The clinical results in the first trial were influenced by a disproportional distribution of this operation over the three groups. The abdominoperineal excision of the rectum should therefore be considered as an separate entity in the elective colorectal surgery, and is not included in the present study.

These considerations caused us to embark upon a prospective, randomized trial in which a 24 hours systemic administration of gentamicin and metronidazole was compared with metronidazole alone as an antibiotic prophylaxis for elective surgery of the colon after mechanical preoperative large bowel preparation with mannitol and whole gut irrigation.

\subsection{Methods.}

Between 1980 and 1981 , a prospective, randomized, trial of 41 patients admitted for elective surgery of the colon was carried out. All patients with primarily surgical disorders of the colon, except appendectomy, restoration of a loop colostomy and carcinomas of the rectum which required an abdominoperineal excision of the rectum, were examined for suitability to enter into the study.

The criteria used for suitability are the same as in the previous study and are described in chapter 6 , paragraph 6.2. All patients who fulfilled the criteria were randomly divided into one of two groups. At admission the patients were assigned into one of these groups by the sequential selection of coded envelopes containing the complete instructions for the preoperative bowel preparation. The order of assignment was randomized using a table of randomized numbers. 
The mechanical bowel preparation was identical in either group. This cleansing procedure took place on the day before operation. Ten mg domperidon was given intramusculary, to the starved patient at $8.45 \mathrm{am}$, in order to prewent nauseat and vomiting. Furthermore, this drug speeds emptying of the stomach. At $9.00 \mathrm{a} . \mathrm{m}$. the patient started to drink a $1000 \mathrm{ml}$ cold $10 \%$ mannitol solution finshing within 1/2-2 hours. In order to improve the taste of the fluid some flavouring was added. After $30-45$ minutes a profuse osmotic diarrhea started. During and after the intake of mannitol the patient was allowed to drink clear fluids freely.

Thus far the whole procedure took place on the surgical ward. At 1.45 p.m. another dose of dom* peridon $10 \mathrm{mg} \mathrm{i.m}$. was given, and at $2.00 \mathrm{p} . \mathrm{m}$. whole gut irrigation was performed as previous described (chapter 5). After the whole gut irrigation was finished the patient was placed on a clear fluid diet till midnight.

The antibiotic prophylactic regimens in the two groups were different (Table 7.1). In group A, the 24 hours antibiotic prophylaxis consisted of gentamicin $80 \mathrm{mg} \mathrm{i.v.} \mathrm{and} \mathrm{metronidazole} 500 \mathrm{mg} \mathrm{i.v.} \mathrm{(in} \mathrm{a}$ solution of $100 \mathrm{ml}$ ), and was given at 8 hours interval starting on the day of operation at time of the premedication.

Table 7.1.

Preoperative large bowel preparation regimer
Day-1
Day 0
1 day before operation
day of operation

\section{Group A}

Gentamicin

Metronidazole

$8.45 \mathrm{am}$

$9.00-11.00 \mathrm{a} . \mathrm{m}$.

$11.00-1.45 \mathrm{p.m}$.
$1.45 \mathrm{pm}$.
$2.00 \mathrm{pm}$.
$0.00 \mathrm{am}$.

\section{Group B}

Metronidazole
The same schedule as Group $\mathrm{A}$ domperidon $10 \mathrm{ming}$ i. $\mathrm{m}$. $10 \%$ mannitol $1000 \%$.

Clear fluid domperidon $10 \mathrm{mg}$ i.m. Whole Gut Irrigation Clear fluid
Gentamicin $80 \mathrm{mg}$ i.v. Metronidazole $500 \mathrm{mg}$ i. $\mathrm{v}$. 8 hourly for 24 hours. Start at premedication
Metronidazole $500 \mathrm{mg}$ i. $\mathrm{x}$. 8 hourly for 24 hours.

The patients in group B received an eight hourly, 24 hours regimen with metronidazole $500 \mathrm{mg}$ alone administered on the same way at the same time as pattients ingroup $\mathrm{A}$.

For evaluation of the mechanical cleansing procedure the following parameters were used: duration of the procedure, amounts of irrigation fluid, body weight wariation, metabolic disturbances and the vacuity of the colon at time of operation. All the methods for operative procedures, specimen collection, microbiological techniques and statistical evallation were the same as described in chapter 6 .

\subsection{Pre-and peroperative evaluation methods.}

As parameters, for pre- and peroperative evaluation of the two different methods quantitative ac robic and anacrobic cultures were taken from the first faeces obtained after the start of oral intake of mannitol and from the clear rectal effluent after whole gut irrigation. Furthermore biopsies of the entire thickness of the resected part of the colon were taken. From these biopsies aerobic and anaerobic cultures were performed. Microbiological methods and techniques were identical to these described in chapter $6(6.2 .4)$. Serum levels of metronidazole and gentamicin were not determined.

\subsubsection{Postoperative evaluation methods.}

Wound infections and other septic complications such as septicaemia, anastomotic dehiscence, peritonitis and intra-abdominal abscess formation were noted as postoperative septic complications and served as a parameter for evaluation of the two different methods of bowell preparation. All the operation wounds were inspected by the atuthor at day 3,7 and 10 after operation for evidence of infection. Furthermore, an inspection of the wound took place four weeks after the operation. 
The criteria of wound sepsis as used in the previous study were abandonned. This schedule was rather complicated and the depth and the extensiveness of the wound infections were not scored. In the present study a wound infection was defined as a wound with the presence of pus. A discrimination was made between a superficial and a deep wound infection. A superficial wound infection was defined as an infection involving less than half of the abdominal incision and only a part of the subcutis, while in a deep wound infection the skin and subcutis were involved to the fascia of the abdominal wall. All the criteria for more serious postoperative septic complications were identical lo those described in chapter 6.

\subsection{Materials.}

The characteristics of the 41 patients in the two different groups are summarized in Table 7.2 . The two groups were well matched for sex, age, preoperative hospital stay, duration of the operation and intraoperative complications. In group A more suction drains were used in the intra-abdominal cavity. Although the mean age in both groups was not statistical different, in group $A 47.6 \%$ of the patients were older than 60 years of age while this percentage was $30 \%$ in group $B$. Concenning the different diagnoses in both groups, a more carcinomas $(62 \%)$ were seen in group A compared to group B (45\%) (Table 7.3.). In Table 7.4. the comparison was made of the different types of operations. Except for a doubling in the incidence of low anterior resections in group $A$ the different types of colonic operations we re similarly distributed.

Table 7.2.

Comparison of patients characteristics

\begin{tabular}{lcc}
\hline & $\begin{array}{c}\text { Group A } \\
\text { (Gentamicin/Metronidazole) }\end{array}$ & $\begin{array}{c}\text { Crolp B } \\
\text { (Metronidazole) }\end{array}$ \\
\hline Patients n $=$ & 21 & 20 \\
Male & 7 & 8 \\
Female & 14 & 12 \\
Age & $63.2 \pm 14.9$ & $55.7 \pm 13.9$ \\
Range & $31-90$ & $21-85$ \\
Preoperative hospital stay (days) & $6.0 \pm 4.8$ & $8.7 \pm 11.2$ \\
Operation time & $179.7 \pm 74.5$ & $164.7 \pm 44.1$ \\
Range (min) & $90-420$ & $90-240$ \\
Intra-operative complications & & \\
Faecal spilling & 2 & 0 \\
Perforation & 2 & 1 \\
Excessive blood loss & 1 & 0 \\
Others & 2 & 2 \\
Drain location & & \\
Abdominal & 8 & \\
\hline
\end{tabular}


Table 7.3 .

Comparison of the diagrnoses

\begin{tabular}{|c|c|c|}
\hline Diagnosis & $\begin{array}{l}\text { Group A } \\
\text { (Gemamicinimetronidazole) }\end{array}$ & $\begin{array}{l}\text { Group B } \\
\text { (Metronidaz olle) }\end{array}$ \\
\hline Carcinoma $(\%)$ & $13(62)$ & $9(45)$ \\
\hline Others & 8 & $\mathbb{1 1}$ \\
\hline Carcinoma caecum & 2 & $\mathbb{1}$ \\
\hline Carcinotna ascending colon & 1 & \\
\hline Carcinoma transversecolon & & 1 \\
\hline Carcinoma sigmoid colon & 4 & 7 \\
\hline Carcinoma rectosigmoid colon & 6 & \\
\hline Diverticular disease & 3 & 5 \\
\hline Crolnns" disease & & 1 \\
\hline Polyposis coli & & 1 \\
\hline Villous adenoma & & 1 \\
\hline Others & 5 & 3 \\
\hline Total & 21 & 20 \\
\hline
\end{tabular}

Talble 7.4.

Comparison of the operations

\begin{tabular}{lcc}
\hline Operations & Grotp A & Group B \\
& (Gentamicin/metronidazole) & (Metronidazole) \\
Lowanterior resection & 5 & 2 \\
Sigmoid colectomy & 9 & 11 \\
Left hemicolectomy & 4 & 1 \\
Right hemicolectomy & & 2 \\
lleocaccal resection & & 1 \\
Subtotal colectomy & 2 & 1 \\
Hartnann procedure & 21 & 1 \\
Resioration Hartmann proc. & 21 & 20 \\
Totul & &
\end{tabular}

\subsection{Results of mechanical bowel preparation.}

Drinking the mannitol solution was well tolerated by most of the patients. Only 2 patients com* planed of nausea and vomiting did not occur. Thirty to 40 min. after the start of the oral intake a profuse diarthea commenced. This was well tolerated by the patients. No haemodynamic disturbances due to the mannitol administration were seen. The whole gut irrigation performed on the afternoon after the mannitol intake had a mean duration of $101.5 \pm 20.3$ minutes, and 7.9 . \pm 2.1 . liters of irrigation fluid were necessary to obtain a clear rectal effluent. In this series the mean body weight values betore the start of mechanical cleansing and immediately after whole gut irrigation were $65.8 \pm 8.6 \mathrm{~kg}$ and $65.7 \pm 8.8 \mathrm{~kg}$, respectively. The changes in serum electrolytes, ureum kreatinino, haemoglobin, haematocrit and osmolality are summarized in Table 7.5. No statistical significant changes in these data were encountered, suggesting that this method of mechanical cleansing does not influence the circulating blood volume nor causes electrolyte shifts. Overall the wholle procedure was well tolerated by the patients and an interruption of the lavage was not necessary, (Table 7.6). Our oldest patient in this series, a lady of 90 years underwent the cleansing procedure whout any problem. The vacuity of the colonic lumen at time of operation was very satisfactory in $90 \%$ of the patients (Table 7.7). 
Table 7.5 Changes in different serum lewels and body weigh due to whole gut irrigation after previous $10 \%$ manmitol intake
orally.

\begin{tabular}{lrr} 
& \multicolumn{1}{l}{$\begin{array}{l}\text { Before } \\
\text { treameni }\end{array}$} & \multicolumn{1}{c}{$\begin{array}{l}\text { Afier } \\
\text { treansment }\end{array}$} \\
\hline Bodyweight & $65.8 \pm 8.6$ & $65.7 \pm 8.8$ \\
Potassium & $4.3 \pm 0.4$ & $4.4 \pm 0.4$ \\
Sodium & $140.5 \pm 12.5$ & $141.2 \pm 13.2$ \\
Chionide & $103.4 \pm 3.4$ & $104.0 \pm 3.0$ \\
Ureum & $4.6 \pm 1.5$ & $4.7 \pm 1.7$ \\
Kreatinine & $80.3 \pm 16.3$ & $84.3 \pm 19.7$ \\
Haemoglobin & $8.3 \pm 1.09$ & $8.4 \pm 1.2$ \\
Hatematocrit & $0.42 \pm 0.08$ & $0.42 \pm 0.07$ \\
Osmolality & $288.3 \pm 16.4$ & $292.3 \pm 16.7$ \\
\hline
\end{tabular}

Table 7.6.

Patients'assessment

\begin{tabular}{lcc}
\hline Arsessment & Nr. of potient & \% \\
\hline Good & 32 & 78 \\
Moderate & 4 & 10 \\
Poor & 5 & 12 \\
\hline Total & 41 & 100 \\
\hline
\end{tabular}

Table 7.7.

Vacuity

\begin{tabular}{lccc}
\hline Cleanliness & Nr. of patients & $\%$ \\
\hline Vorygood & 31 & 76 \\
Good & 6 & 14 \\
Poor & 4 & 10 \\
\hline Total & 41 & 100 \\
\hline
\end{tabular}

\subsection{Bacteriological results.}

\subsubsection{Reduction of aerobic - and anaerobic faecal microflora.}

The results of the quantitative aerobic and anaerobic cultures of the faeces before treatment and from the clear rectal effluent immediately after the whole gut irrigation are visualized in Fig. 7.8 and summarized in Table 7.9. The reduction of the aerobic colonic flora was 2.4 . logs. while this reduction was 3.4. logs. for the anaerobic flora. The difference in the quantities in aerobic and anacrobic faecal micro-organisms before and after mechanical cleansing were statistically significant, $p=0,02$. These reductions could be explained by a dilutative factor and partly by the good mechanical cleansing procedure itself.

No signs of overgrowth with pathogenic micro-organisms or yeasts were seen in this serics. Closmidium difficile was cultured in 4 patients in group A and in 5 in group B. These positive cultures were seen before as well as after the mechanical bowel preparation. 


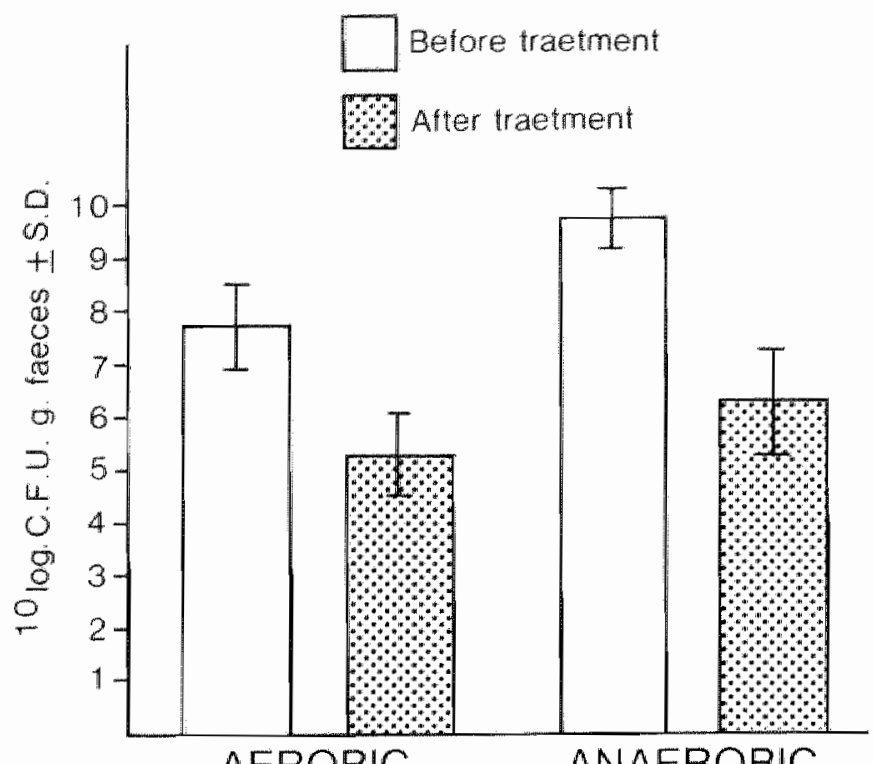

Figg. 7.8.

Aerobic and araerobic feacal reduction due to the mechanical cleansing by whole gut irrigation with previous administration of mannitol.

Truble 7.9.

Aerobic and anaerobic reduction of the faecal micro-flora ( $10 / \mathrm{og}$ C.F.U./g faeces). $\mathrm{n}=41$.

\begin{tabular}{llll}
\hline & $\begin{array}{l}\text { Before } \\
\text { reatment }\end{array}$ & $\begin{array}{l}\text { After } \\
\text { reatment }\end{array}$ & Reduction \\
\hline Acrobic & $7.68 \pm 0.75$ & $5.22 \pm 0.76$ & $2.42 \pm 1.05$ \\
\hline Anacrobic & $9.71 \pm 0.57$ & $6.24 \pm 1.01$ & $3.46 \pm 1.14$ \\
\hline
\end{tabular}

\subsubsection{Aerobic - and anaerobic bacteria counts in the biopsies.}

The cultures of the homogonized biopsies of the entire thickness of the colonic wall are visualized in Fig. 7.10 and summarized in Table 7.11. In group $\mathrm{A}$ as well as in group $\mathrm{B} 10^{4}$-10 ${ }^{5}$ aerobic colonic micro-organisms were cultured while the anaerobic cultures showed $10^{5} \mathrm{CFU}$ per gram tissue in both groups. The slight differences observed between the number of aerobie and the anaerobic microorganisms cultured from the biopsies of the colonic wall in both groups did not achieve statistical significance. 


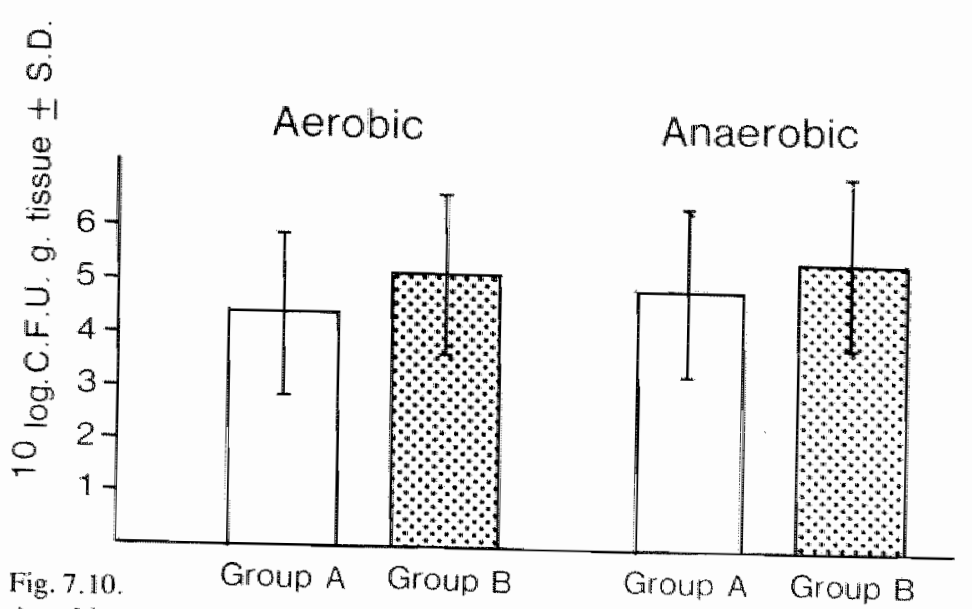

Aerobic and anaerobic cultures of the biopsies of the resected part of the collon $\left({ }^{10} \log\right.$, C.F.U./g tisstie \pm S.D. $)$.

Table 7.11.

Cultures of the biopsies ( $10 \log$ C.F.U.Jg tissue).

\begin{tabular}{lll} 
& Group A & Group B \\
\hline Aerobic culture & $4.43 \pm 1.56$ & $5.23 \pm 1.53$ \\
Anaerobic culture & $4.88 \pm 1.64$ & $5.49 \pm 1.62$ \\
\hline
\end{tabular}

\subsection{Clinical results.}

\subsubsection{Wound infections.}

The data concerning the wound sepsis in the two different groups are summarized in Table 7.112. Some striking and unexpected findings occurred in the postoperative course in group A as well as in group $B$.

First the high incidence of wound infections in both groups; $19 \%$ in group A and $25 \%$ in group $\mathrm{B}$. "This high incidence could not be explained by a prolonged operation time. In case of a wound infection in group A this time was slightly increased $(200 \pm 80 \mathrm{~min}$.) compared to the time in cases of an uneventful postoperative course (179 $\pm 74 \mathrm{~min}$.). In group $B$ this difference in operation time was not seen, $177 \pm 43 \mathrm{~min}$. in cases of a wound infection and $164 \pm 44$ when the wound healed without a septic complication. In group $\mathrm{A}$, however, 3 out of five patients developed a wound infection after a low anterior resection and in group B just rwo patients underwent this operation, without postoperative septic complications. It is well known that the incidence of septic complications is higher in the case of an anastomosis below the peritoneal reflection. The second remarkable finding was that no deep wound infections occurred in either group, and that no anaerobic micro-organisms were cultured from the infected wounds. From all the wounds, except one, an E. coli was isolated. in 4 cases this was the only bacteria which could be cultured, while the other 4 infections werc caused by a mixed culture of $E$. coll and faecal streptococci ( 3 cases) or, as in one case, by $E$. coll and a Klebsiclla strain. One patient in group B was discharged on the 8th postoperative day, with an uneventful course after a ileocaccal resection for a diverticulum of the caecum, but was readmitted on the 22 th day with a wound abscess. The culture of this abscess revealed a pure culture of $S$.aureus. No anaerobes could be isolated. Another late abscess occurred in a patient in group $A$. This was an $\mathrm{ex}_{\text {- }}$ tremely obese family doctor with a carcinoma of the caccum. After a right hemicolectomy the postoperative course was complicated by a superficial wound infection, a pneumonia and a longstanding paralytic ileus. However, on the 22 th postoperatve day he could be discharged in a good general condition. One week later he reported to us that he had drained a wound abscess by himself from which purtrid smelling pus was evacuated. Although we have no proof, because no material was obtained for culture, this abscess might have been caused by anaerobic bacteria. 
Table 7.12.

Postoperative woundsepsis

\begin{tabular}{|c|c|c|c|c|}
\hline \multirow[t]{2}{*}{ Disealse } & \multirow[t]{2}{*}{ Operation } & \multirow[t]{2}{*}{ Woundsepsis } & \multicolumn{2}{|c|}{ Pus cultures } \\
\hline & & & Aerobic & Anaerobic \\
\hline $\begin{array}{l}\text { Group A } \\
\text { Ca.rectosigmoid } \\
\text { colon }\end{array}$ & $\begin{array}{l}\text { Low anterior } \\
\text { resection }\end{array}$ & Superfiscial & $\begin{array}{l}\text { E. coli } \\
\text { Klebsiella }\end{array}$ & - \\
\hline $\begin{array}{l}\text { Ca. rectosigmoid } \\
\text { colon }\end{array}$ & $\begin{array}{l}\text { Low anterior } \\
\text { resection }\end{array}$ & Superfiscial & $\begin{array}{l}\text { E. coli } \\
\text { Str. faecalis }\end{array}$ & - \\
\hline Ca. caecum & Right hemicolectomy & Superfiscial & E. coli & - \\
\hline $\begin{array}{l}\text { Ca, rectosigmoid } \\
\text { colon }\end{array}$ & $\begin{array}{l}\text { Low anterior } \\
\text { resection }\end{array}$ & Superfiscial & E. coli & 一 \\
\hline $\begin{array}{l}\text { Giroup B } \\
\text { Diverticula catecum }\end{array}$ & Ileocaecal resection & Superfiscial & St.aureus & - \\
\hline Diverticular disease & Sigmoid colectomy & Superfiscial & E.coli & - \\
\hline Ca. caecum & Right hemicolectomy & Superfiscial & $\begin{array}{l}\text { E. coli } \\
\text { Str. faecalis }\end{array}$ & - \\
\hline Villows adenoma & Sigmoid colectomy & Superfiscial & E. coli & - \\
\hline Ca. transverse colon & Left bemicolectomy & Superfiscial & $\begin{array}{l}\text { E. coli } \\
\text { Str. faecalis }\end{array}$ & - \\
\hline
\end{tabular}

\subsubsection{Other septic complications.}

In constrast to the high incidence of superficial wound infections, a low incidence of the more serious postoperative septic complications was seen. Two patients had a complicated postoperative course. The short case histories of these two patients will be given.

\section{Case 1.}

A 77 year old woman with diverticular disease was operated in the past for a free perforation of a diverticulum. A sigmoid colectomy and a Hartmann procedure were performed. "The postoperative course after this first operation was complicated. However, she became suicidal after a couple of months because of her colostony. In spite wher moderatte general condition we decided to restore the Hartmann procedure. After a mechanical cleansing, and an antimicrobial prophylaxis with gentamicin and metronidazole the Hartmann procedure was restored in an uncomplicated operation within 195 minutes. On the fifth postoperative day she had to be reoperated because of a secondary peritonitis due to a complete anastomotic breakdown. A Hartmann procedure was performed again and the abdominal wall was closed with a marlex ganze. After a very complicated postoperative course she could be discharged in a moderatte general condition atter three months.

\section{Case 2.}

In a 79 year old, diabetic man with a carcinoma of the rectosigmoid a very low anterior resection was performed after at mechanical cleansing, resulting in a poor vacuity, and an antimicrobial prophylaxis with gentamicin and metronidazole. The operation which took 7 hours, was very difficult and was complicated by a iatrogenic perforation and faccal spilling. The anastomosis $4 \mathrm{~cm}$ from the anal ring was performed with a circular Stäpler instrument. The wound healed per primam. However, on the 20 th postoperative day a large intra-abdominal abscess had to be drained. The cultures revealed a mixed infection with $E$. coli and faecal streptococci, no anaerobes were cultured. After this operation the patient developed an $E$. coli septicaemia and died finally on a respiratory distress syndrome after a septic shock on the 46 the postoperative day. The autopsy revealed no anastomotic breakdown.

In addition to these two serious cases just one patient developed an anastomotic dehiscence after a very low anterior resection. The small dehiscence was palpable by rectal examination. The small dehiscence was treated conservatively and when the colostomy was restored three months later an uneventful postoperative course followed. No other cases of anastomotic breakdown, nor sep- 
ticaemia or intra-abdominal sepsis were noticed. The incidence of other septic complications not related with the operation, chiefly involwing respiratory and urinary infection, were not different in the two groups. None of the postoperative septic complications was caused by anaerobic microorganisms. The incidence of septic complications in both groups was not statistically different.

\subsubsection{Postoperative hospital stay.}

The influence of the septic complications on the postoperative hospital stay are summarized in liable 7.13. In cases of an uneventful postoperative course the hospital stay in group A was somewhat longer compared to group $B$. When a wound infection occurred the hospital stay was prolonged by 7 days in both groups. Only in group B did this prolongation achieved significance $(p=0.01)$. The long hospital stay in group A when no wound infection occurred, was because both serious complicattions took place in this group without a concomittant wound infection.

Table 7.13.

Hospital stay

\begin{tabular}{|c|c|c|c|c|}
\hline & \multicolumn{2}{|c|}{ Woundinfection } & \multicolumn{2}{|c|}{ Sepric complicarion } \\
\hline & Present & Absent & Present & Absent \\
\hline $\begin{array}{l}\text { Group A } \\
\text { Gentamicin + metronidazole }\end{array}$ & $30.6 \pm 9.0$ & $22.8 \pm 23.4$ & $48.4 \pm 324$ & $16.3 \pm 10.0$ \\
\hline $\begin{array}{l}\text { Group B } \\
\text { Metronidazole }\end{array}$ & $18.4 \pm 3.5^{*}$ & $12.4 \pm 3.1^{*}$ & $18.4 \pm 3.5$ & $12.4+3.1$ \\
\hline
\end{tabular}

${ }^{*} \mathrm{p}=0.01$

\subsection{Discussion.}

The mechanical cleansing by means of whole gut irrigation after previous administration of mannitol has proved to have many adwantages over the whole gut irrigation without this pretreatment. The time necessary to clean the colon, after preventive administration of mannitol, by whole gut irrigation $(101.5 \pm 20.3 \mathrm{~min}$.) was significantly shorter than the procedure without this osmotic cathartic $(180 \pm 60 \mathrm{~min}$. This difference was staristical significant $(\mathrm{p}, 0.01)$. Especially for elderly patients this is an improvement. The 1.5 hour sitting on the commode was well tolerated by the elderly people while the 3 hours sitting during whole gut irrigation without manmitol was to cxhausting.

The body weight gain of $2.0 \pm 1.4 \mathrm{~kg}$ seen in the previous study of whole gut irrigation (chapter 5 ) was prevented by the administration of mannitol, indicating that nofluid overload of the circulation occurred. The vacuity of the colon during operation after whole gut irrigation with or without administration of mannitol were identical. Furthermore, the metabolic disturbances never achicved clinical importance in either method of whole gut irrigation. Concerning the mechanical cleansing of the large bowel, similar benificial findings after an oral intake of $500 \mathrm{ml} 10 \%$ mannitol previous to whole gut irrigation were reported by others (Newstead el al., 1979; Mimervini et al., 1980; Donovan et al. 1980; Taat et al. 1981).

The aerobic and anacrobic reductions of the faecal flora due to this method of mechamical cleansing were mainly caused by a dilutative factor. The reductions of the faecal flora in the present group of patients did not differ significantly from those in group W.G.I. in the previous trial. The conclusion can be made that whole gut irrigation with or without the previous administration of $10 \%$ mannital did not influence the faceal flora during the mechanical cleansing procedure.

The amount of aerobic and anaerobic bacteria cultured from the biopsies both in group $\mathrm{A}$ and group $B$ were in agreement with those found by Vargish et al. (1977) in colonic nucosal biopsics from unprepared colons, although the biopsy and culture methods were different. In Fig. 7.14 the results of the cultures from the biopsies in both groups in this study are compared with those who received an orally administered antibiotic as prophylaxis in the previous trial. 


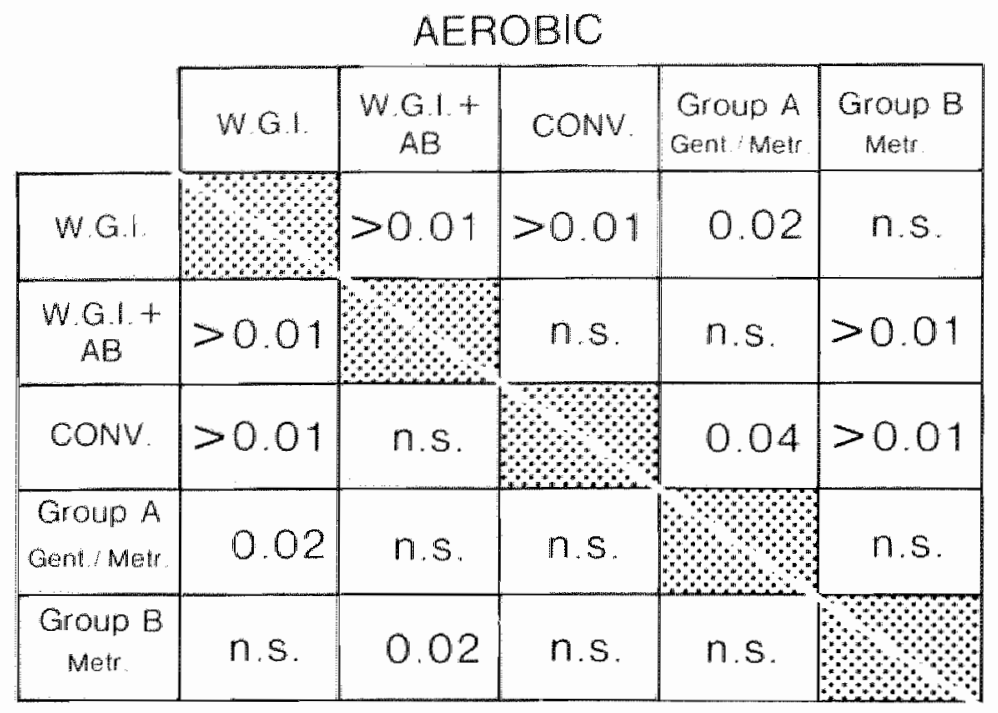

\section{ANAEROBIC}

Fig. 7.14.

Comparison of the biopsy cullures.

Each antibiotic prophylaxic regime containing an aminoglycoside and metronidazole caused a decrease of the number of bacteria cultured from the biopsics, irrespecting of the route of administration. However, the administration of metronidazole alone in group B did not influence the aerobic mucosal microflora while the anaerobic mucosal microflora was hardly reduced compared to group W.G.I. This indicates that a combination of an aminoglycoside and metronidazole is necessary to obtain a reduction of the mucosal microflora. Despite the relatively short time the antibiotics have to act in these systemic antibiotic regimes, no statistically significant differences were seen in the cultures of the biopsies. Since systemic and oral administration (with a low or a high dose regimen) have a similar reducing effect on the mucosal microflora, the most important factor in this decrease is good tissue perfusion.

One of the most striking facts in this study was that the anaerobic infective complications were completely eliminated after the systemic administration of metronidazole in both antimicrobial prophylactic regimens. The absence of activity of metronidazole against aerobic and facultative anaerobic bacteria and its remarkable efficiencey in reducing the incidence of serious post surgical sepsis clearly implies that the great majority of infections that complicate colonic surgery have an anacrobic aetiology, or at least require the participation of anacrobic micro-organisms. "The patients who did become infected with aerobic colonic micro-organisms or with exogenous pathogens did not fare as badly as those infected with anaerobes. The fact that all wound infections were of a superficial character again might be explained by the abscence of anaerobic micro-organisms. This supports the statement that in some way anaerobic bacteria work in synergysm with the aerobic organisms to produce serious deep wound infections and more serious septic complications such as intra-abdominal sepsis, septicaemia and dehiscence of the anastomosis. Just why the suppression of anacrobes should so significantly affect the frequency of wound infection remains unexplained as long as the synergystic mechanism in mixed infections is unknown.

Although all the wound infections in both groups were superficial, the incidence of these infections was relative high (19\% in group $\mathrm{A}$ and $25 \%$ in group $\mathrm{B}$ ). A striking fact was that from all these wound infections $E$. coli could be isolated. This $E$. coli was cultured alone or in a mixed infection with Klebsiella or with Enterococci. This remarkable high percentage of wound infections was also reported by Keighley ef al. (1981). They found despite antibiotic cover with cefoxitin or the combination of motronidazole and gentamicin, a rate of sepsis of $40 \%$ in 37 patients using mannitol alone, compared to $12.5 \%$ in 32 patients having whole gut irrigation. The cultures of the bowel content revealed an overgrowth of gas producing $E$. coli after a mechanical cleansing with oral $5 \%$ mannitol. 
Mannitol is a non absorbed oligosaccharide and the large concentration present in the colon are likely to be metabolized by faecal bacteria resulting in the production of explosive gas. This gas production must be responsible for the colonic explosions after bowel preparation with mannitol and the use of electrocauterization for polypectomies (Bond et al, 1976; Bigard et al., 1979). Taylor $e_{\text {al }}$ (1981) found that after oral mannitol bowel preparation high levels of explosive gases, hydrogen and methane, were produced and that the explosive risk after this form of bowel preparation is significantly greater than after whole gut irrigation or after mannitol with additional enteral administration of neomycin and metronidazole. It would be ideal if an alternative non-absorbable sugar which was not fermented by intestinal bacteria was available. Recently Davis et al. 1981 described an irrigation fluid with sodium sulfate as the predominant salt, in order to prevent electrolyte changes, and polyethylenyglycol as an alternative for mannitol.

Polyethylenyglycol (P.E.G.) is nonabsorbable and is not metabolized by colonic micnomomisms. Probably is the use of P.E.G. instead of mannitol may help to prevent the overgrowth of gasproducing strains of E. coli. However, little experience is known with this substance.

The final conclusions of this study are that a whole gut irrigation with previous oral administration of $10 \%$ mannitol is a more convenient method of mechanical cleansing than whole gut irrigation alone. However, the fermentation of mannitol by especially $E$. coli in the large bowel, causes an overgrowth of this micro-organism and as a consequence an increase in postoperative wound infections. The mechanical cleansing procedure of the large bowel using mannitol and whole gut irrigation should therefore be abandonned. Due to the fact that the incidence of postoperative wound infections did not differ significantly in both groups the administration of gentamicin in the antibiotic prophylactic regimen could be omitted. An antibiotic prophylaxis with metronidazolle alone will protect the patient from serious anacrobic postoperative septic complications. 


\section{Recolonization and Colonization Resistance of the large bowel after three methods of preoperative preparation of the gastro- intestinal tract}

\subsection{Introduction}

Antibiotics influence the intestinal flora, both commensales and potential pathogenic micro-organisms, primarily by direct selective action on the susceptible micro-organisms and thereby affecting the stability of their microflora. The effect of antibiotics depend upon the local concentration which is determined by the dose given, the route of administration, and the degree of drug absorption from the upper gastrointestinal tract. Oral administration of antibiotics that are poorly absorbed in the upper gastrointestinal tract generally has the greatest effect on the faecal flora. Parenteral administration of antibiotics, however, can also alter the faecal flora because of cxcretion by the liver in the bile or direct excretion in the gastrointestinal tract. An antibiotic agent that is active against certain species of the intestinal micro-organisms and is excreted at sufficiently high concentrations in the colon can suppress or eliminate those organisms. In addition each antibiotic exerts a selective pressure in favour of the emergence of an antibiotic resistant population.

From the outset of antibiotic therapy, the influence of antibiotics on the colonic microflora was recognized. Weinstein (1947) related that debilitated patients treated with penicillin or streptomycin had a decrease in the "threshold dose" necessary for the colonization of the gastrointestinal tract by pathogenic bacteria. In early experimental animal work similar findings are teported. The intestinal colonization with pathogenic bacteria, such as Salmonella typhimurium (Bohnhoff and Miller 1982) or Vibrio cholerae (Freter, 1955), was greatly facilitated by one oral dose of streptomycin. Recent experimental work confirmed these findings. Van der Waaij et al. (1974) found that in mice without antibiotic treatment, oral contamination doses of $10^{9}$ or more of potentially pathogenic bacteria were required for a "take", whereas minute doses of about 100 bacteria appeared to be sutficient to colonize in animals treated with oral antibiotics.

To describe the phenomenon that the normal microflora of the digestive tract protects man and animals against overgrowth with pathogenic micro-organisms, the concept of Colonizarion Resistance (C.R.) was introduced by v.d. Waaij et al. (1971). The experimental work on C.R. became possible when germfree mice became available; with these animals it is possible to colonize the gastro-intestinal tract with specific bacterial species. V.d. Waaij ef al. (1971) observed that germfrec mice kept in a germfree isolator and contaminated with the intestinal flora animals treated with certain antibiotics, showed a high level of C.R. The intestinal tract of these mice contained an exclusively anaerobic microflora. These anaerobes were responsible for the difference in the "threshold contamination dose for colonization", or C.R., between conventional and antibiotic treated mice (v.d.Waaif et at., 1974). Mice colonized with exclusively aerobic bacteria, isolated from conven. tional mice, had no resistance to colonization with pathogenic bacteria.

In animals the C.R. can be assessed by oral contamination with a known dose of a specific bacterial challenge strain. The number of days this strain is excreted in the faces and the concentration reached, are used as parameters. A low C. R. corresponds with a high concentration and a long period of excretion, in animals with a high $C . R$. the challenge strain will be excreted in low numbers and for a short period of time. Another parameter is the presence or absence of $\beta$. aspartylglycerine in the faeces. Welling and Groen (1978) reported the presence of - $\beta$-baspartylglycine in caecal contents of germfree mice and mice treated with bacitracin (which reduces the anaerobic microflora). B-aspartylglycine was not found in the caecal contents of control mice and 
mice treated with antibiotics which do not affect the anderobic microflora. It scems therefore that the presence of Haspartylglycine might be an indicator for a decreased level of $C$. $R$. The mechanism by which the anacrobic bacteria induce the C.R. is presumably by the production of Volatile Faty Acids by the anacrobic bacteria (Lee and Gemmel, 1972). A sufficient high concentraton of thesc volatile fatty acids probably prevents the colonization of the large bowel by many bacterial species. The Volatile Fatty Acids (V.F.A.) can be assayed in the faeces. The V.F.A. patern as determined by gaschromatography is a rather specific indicator for the presence of anaerobic bacteria.

As shown in the previous studies an antibiotic prophylaxis is essential in elective colorectal surgery. However, most antibiotics influence the stability of the normal colonic microflora and do affect more or less the C.R. By increasing the risk of bacterial colonization of the large bowel, a prophylaxis regimen might therefore actually enhance instead of diminish the possibility of postoperative infections.

As the influence of the large bowel preparation on the C.R. by direct challenge or contamination with potential pathogenic strains is not possible in patients we embarked upon a study with 21 heatlthy wolunteers. In this study the impact of three different types of preoperative large bowel preparation on the microbial flora and the C.R. of the gastrointestinal tract was studied including the time neccssary to reestablish this microflor

\subsection{Material and Methods}

\section{Volunteers}

Fifteen healthy volunteers, 10 males and 5 females, mean age 23.4 years, were at random devided into one of three groups (Fig. 8.1). An additional group of 6 volunteers was used in preliminary studies. In 3 volunteers, who did not underwent a large bowel preparation, the dosis needed for colonization was cxamined for 2 orally administered test strains of $E$. coli and $P$ s. aeroginosa in total numbers of $10^{9}, 10^{16 /}$ and $10^{11}$ C.F.U.

Table 8.1.

Preoperative large bowel preparation regime

\begin{tabular}{|c|c|c|c|}
\hline & Group W.C.I. & Growp W. G.I. $+A B$ & Group $M A N N+A B$ \\
\hline Bay 1 & $\begin{array}{l}9.00 \text { a.m. } \\
\text { Wholo Cout Itrigation }\end{array}$ & $\begin{array}{l}\text { 9.00 dt.m. } \\
\text { Whole Gut Irrigation } \\
\text { Metronidazole } 500 \mathrm{mg} / 1 \\
\text { Neomyen } 1000 \mathrm{mg} / 1 \\
\text { Claar liquid diet }\end{array}$ & $\begin{array}{l}9.00 \text { a.m. } 9.00 \text { - } 1100 \mathrm{a} \text {.m. } \\
\text { Mannitollo\% orally } \\
12.00 \text { a.m. } \\
\text { Whole Gut lrugation } \\
\text { Clear liquid diet }\end{array}$ \\
\hline Day 2 & & & $\begin{array}{l}9.00 \mathrm{a} . \mathrm{m} .4 .00 \mathrm{pm} \text {. } \\
\text { Gentamicin } 80 \mathrm{mg} \text { i. } \\
\text { Metronidazole } 500 \mathrm{mg} \text { orally }\end{array}$ \\
\hline
\end{tabular}

Three other volunteers underwent one of the large bowel preparations as scheduled in Fig. 8.1 , and were contaminated afterwards with the test strains in doses of $10^{7}, 10^{8}$ and $10^{9} \mathrm{C}$.F.U.

For all these studies a permission was obtained form the ethical committec of the hospital as well as from the medical faculty.

\section{Large Bowel Preparation}

The following three methods of large bowel preparation were used (Fig. 8.1).

Gronp W.G.I.

In this group of volunteds a whole gut irrigation was performed without administration of antibiories.

Group W.G.I. $+A B$

The sccond group was prepared by means of whole gut irrigation. After $5 \mathrm{~L}$ of irrigation fluid was in-

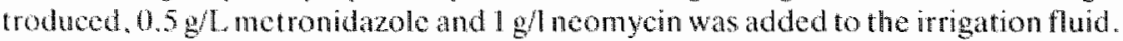


A whole gut irrigation with prior administration of $10 \%$ mannitol was performed in the last group of volunteers. The day after bowel preparation an antibiotic prophylactic regimen was given consisting

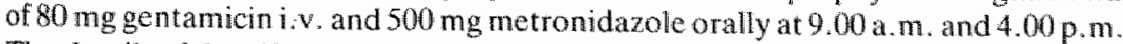

The details of the different methods of bowel preparation were described in the chapters 5,6 and 7 . After the bowel preparation the volunteers were allowed to drink clear fluids till 9.00 a. m. the next day.

\section{Bacterial strains and contaminating dose}

One E.coli and one Ps. aeroginosa strain were used to investigate the C.R. of the gastrointestinat tract before and after one of the large bowel preparations. Both strains were resistant to neomycin and gentamicin (M.I.C. $1 \mathrm{mg} / \mathrm{ml}$ ). One hour after the bowel preparation was finthed a contaninating dose of $10^{6} \mathrm{C}$. F.U. of the test strains, suspended in a glass of milk $(100 \mathrm{ml})$, was ad ministered to all volunteers. This dose was established in the preliminary studies.

\subsubsection{Evaluation methods during bowel preparation}

Quantitative and qualitative, aerobic and anaerobic cultures were taken from the faeces before treatment and every $30 \mathrm{~min}$. during the lavage procedure till the last culture from the clear rectal effluent at the end of the cleansing procedure.

In group Mann $+\mathrm{AB}$, mannitol levels in the rectal effluent were measured before and immediately after whole gut irrigation.

\subsubsection{Evaluation methods after bowel preparation}

During the first week after bowel preparation qualitative and quantitative aerobic and anacrobic cultures were taken from the faeces to investigate the composition of the microflora of the large bowel and the duration of the excretion of the neomycin and gentamicin resistant $E$. coli and $P_{s}$. aeroginosa. The second and following 4 weeks only aerobic cultures of the faeces were performed, unless the anaerobic flora had not yet recovered. "The aerobic cultures were continued monthly as long as the neomycin and gentamicin resistant strains were present in the faeces. The faccal samples were also analyzed for $\beta$-aspartylglycine and Volatile Fatty Acids (V.F.A.).

\subsubsection{Microbiological methods and techniques}

\subsubsection{Specimen collection}

Faecal samples obtained before treatment and in the first week after the bowel preparation werceolleeted and processed within 15 min. The faecal samples taken during the lavage procedure were collected in aterile bottle and asprated with a $60 \mathrm{ml}$ syringe. After all air bubbles within the specimen had been expelled the syringe was corked with a rubber top and immediately transported to the microbiology laboratory. On arrival at the laboratory all specimens were inmediately placed into in anaerobic glovebox and processed within $30 \mathrm{~min}$. The faecal specimens obtained in the second and following weeks were transported under aerobic conditions.

\subsubsection{Isolation and identification}

By using a turax mixer one part of facces was thoroughly mixed with 9 parts of Pre Reduced Anaerobic Sterilized (PRAS) diluent (saline $+0.05 \%$ cysteine $\mathrm{HCl}$ ). The homogonates were serially diluted tenfold $\left(10^{\prime}-10^{\prime \prime}\right)$ and an aliquot of $0.1 \mathrm{~m}$ of each dilution was spread over the surface of plates using a spiral plater (Spiral system model B).

The acrobic bacterial microflora was counted and isolated by plating the dilutions $10^{1}-10^{7}$ upon the following plates: $5 \%$ sheepblood agar (Oxoid CM 55); Endo agar (BBL 11199), Mac Conkcy (Oxoid CM 7) + Azide agar, 5\% sheepblood agar + nalidixine, polymyxine and neomycin (Oxoid SR 74) and Mannitol sall agar (Oxoid CH 85). For the isolation of yeasts a sabouraud dexerose agar (Oxoid CM 41) + chloramphenicol was used. The plates were incubated for 48 hours under atmospheric conditions at $37^{\circ} \mathrm{C}$ before counting the colonies. For the anaerobic bacteriology a modified Wen. sinck medium, in which whole blood was replaced by Fieldes extract (Oxoid SR 46), was used. "The dilutions $10^{4}-10^{11}$ were spread over this and the following plates: a Wensinck medium containing 
kamamycin and vancomycin, a Bacteroides-bile-esculine-agar and an Egg Yolk agar. A selective medium (cycloserine-cefoxitin-fructose agar) was used for the isolation of $\mathrm{Cl}$ difficile.

These plates were incubated anaerobically at $37^{\circ} \mathrm{C}$ and the colonies counted after 72 hours and $7 \mathrm{days}$ of incubation.

For the detection of anacrobic bacteria present in low counts the $10^{\prime}$ ditutions in PRAS were inoculated in brainheart infusion broth (Oxoid CM 225) with addtional vit. $K$ and hemine, and checked for growth during one week.

For the identification of obligate anaerobic bacteria the isolates were processed according to the Wadsworth Anaterobic Bacteriology Manual (Sutter et al., 1975), on the basis of morphology, biochemical reactions (Minitek system), antibiotic resistance and analysis of wolatile fatty acid by gas chromatography. The concentrations of micro-organisms are expressed as the logarithm to the base ten of Colony Forming Units per ml (C.F. U./ml) of faeces.

\subsubsection{Identification of beta-aspartylglycine}

By using a turax mixer one part of faeces was thoroughly mixed with 9 parts of water. The homogomized samples were centrifugated at $2.000 \mathrm{~g}$ for at least $30 \mathrm{~min}$. The supernatants were fricze dried at $-70^{\circ} \mathrm{C}$ and stored at $-25^{\circ} \mathrm{C}$ until transportation. The determination of $\beta$-aspartylglycine was performed by high-voltage paper electrophoresis at the Biochemical Laboratory, University of Groningen. High-voltage paper electrophoresis was performed at $\mathrm{pH} 3.5$ (pyridine/acetic acid water, $1: 10.89$ by volume) for one hour at $3.000 \mathrm{~V}$ with a self-made apparatus similar to the commercially-avalable Savant Model HVE 8034. Whatman 3 MM chromatography paper (46x57 cm) was used and samples of 5 to $50 \mu$ were applied $1.5 \mathrm{~cm}$ apart at a distance of $12 \mathrm{~cm}$ from the margin of the paper that is to be immersed in the anode buffer compartment. Generally, $80 \mu$ of a $25 \%$ solution of faecal supernatants was applied. Xylene Cyanol FF was added to a reference mixture of aminoacids as a colourmarker. After electrophoresis the paper was dried at $70-80^{\circ} \mathrm{C}$ for $10-15 \mathrm{~min}$, and sprayed with $0.2 \%$ ninhydrin in ethanol. Subsequent heating at $70-80^{\circ} \mathrm{C}$ resulted in purple spots for most of the peptide-like material, except for beta-aspartylglycine which shows up greyish. Additional heating at $110^{\circ} \mathrm{C}$ for $10 \mathrm{~min}$. gives a clear blue spot for $\beta$-apartylglycine (Welling 1974).

\subsubsection{Determination of Volatile Fatty Acids}

The Volatile Fattly Acids (V.F.A.) were measured in the faeces or rectal effluents by Gas Liquid Chronatography (G.L.C.). The G.L.C.-system consisted of a Packard Becker 433 Gaschromatograph cquipped with a dual column system and Flame Ionisation Detectors in conjunction with a digital processor. The glass columns ( $1 \mathrm{~m} \times 2 \mathrm{~mm}$ ) were packed with Carbopack-C $0.3 \%$, Carbowax $20 \mathrm{M} / 0.1 \% \mathrm{H}_{3} \mathrm{PO}_{4}$. The columns were conditioned overnight in the oven at $175^{\circ} \mathrm{C}$ with a carrier gas flow of $20 \mathrm{~m} / / \mathrm{min}$. The next day 7 , doses of $5 \mathrm{mcl}$ of $0.1 \% \mathrm{w} / \mathrm{v}$ formic acid in water were injected. Dur ing operation the injector temperature was $100^{\circ} \mathrm{C}$ and the detector temperature $200^{\circ} \mathrm{C}$. The oven temperature was programmed to $110^{\circ} \mathrm{C}-190^{\circ} \mathrm{C}$ with increments of $20^{\circ} \mathrm{C} / \mathrm{min}$. This temperature programme was statted $90 \mathrm{sec}$ after injection of the sample and the final temperature was hold for 5 min. Faces were diluted $1: 10$ in anacrobic dilution fluid and rectal effluents were used undiluted. These samples werc prepared for gaschromatography by applying $1.9 \mathrm{ml}$ of the sample with $0.1 \mathrm{~m} /$ of a 200 mmol. stock solution of heptonoic acid, which was used as an internal standard, on to $1 \mathrm{ml}$ of cationexchange resin ( $\mathrm{CG} 50 \mathrm{~W}-\mathrm{X}_{2}, 2004400$ mesh, hydrogen form, washed in water) packed on glasswool in a pasteur pipette. The sample was allowed to drain through the resin and the resin was than washed twice with $1 \mathrm{ml}$ of $0.1 \% \mathrm{v} / \mathrm{x}$ formic acid in water. All fluid draining from the pipette was collected in a test tube and $1 \mu$ directly injected into the gaschromatograph for analysis of V.F.A. The minimum detection level of each V.F.A. $\left(\mathrm{C}_{2}-\mathrm{C}_{6}\right)$ is $0.02 \mathrm{mmol} / \mathrm{l}$ and the variance in reproductibility of the method is $1.5 \%$. 


\subsection{Results}

\subsubsection{Reduction of the aerobic - and anaerobic faecal microflora}

The reductions of the aerobic and anaerobic faecal microflota caused by the three different types of large bowel preparation are summarized in Table $\mathbf{8 . 2}$ and 8.3. In both groups not receiving antibiotics during the irrigation procedure (W.G.I. and Mann $+A B$ ) a reduction of the aerobic faecal microflora of $2 \mathrm{logs}$ was achieved, while this reduction was 3 logs in the group W.G.I.+AB. AIthough a higher reduction of the aerobic microflora was seen in group W. G.I.+ AB, this difference in reduction of the aerobic faecal microflora did not achieve statistical significancy as compared to both other groups.

Table 8.2

Comparison of the reductions of the aerobic faecal microflora in volunteers, due to three different types of targe bowel preparation.

\begin{tabular}{lllll}
\hline Aerobic & $\begin{array}{l}\text { Before } \\
\text { treatment }\end{array}$ & $\begin{array}{l}\text { After } \\
\text { treamen }\end{array}$ & Reduction & $\begin{array}{l}\text { Reduction } \\
\text { Patients }\end{array}$ \\
\hline W.G.I. & $7.18 \pm 1.42$ & $5.10 \pm 0.69$ & $2.08 \pm 1.30$ & $2.04 \pm 1.10$ \\
\hline W.G.I. $+\mathrm{AB}$ & $7.40 \pm 0.58$ & $4.40 \pm 0.58$ & $2.99 \pm 0.74$ & $3.70 \pm 1.48$ \\
\hline MANN. + AB & $7.18 \pm 0.61$ & $4.98 \pm 0.85$ & $2.19 \pm 1.09$ & $2.42 \pm 1.05$ \\
\hline
\end{tabular}

Table 8.3.

Comparison of the reduction of the anaerobic faecal microflora in volunteers, due to three different types of large bowel preparation.

\begin{tabular}{lllll} 
Anaerabic & $\begin{array}{l}\text { Before } \\
\text { treamen }\end{array}$ & $\begin{array}{l}\text { Afier } \\
\text { treatment }\end{array}$ & Reduction & $\begin{array}{l}\text { Reduction } \\
\text { Patients }\end{array}$ \\
\hline W.G.I. & $10.43 \pm 0.52$ & $6.74 \pm 0.90$ & $3.69 \pm 0.94$ & $2.80 \pm 1.38$ \\
\hline W.G.I. $+\mathrm{AB}$ & $10.48 \pm 0.42$ & $6.01 \pm 0.54$ & $4.47 \pm 0.80$ & $5.09 \pm 1.64$ \\
\hline MANN $+\mathrm{AB}$ & $10.77 \pm 0.35$ & $6.03 \pm 0.35$ & $4.74 \pm 0.31$ & $3.46 \pm 1.14$ \\
\hline
\end{tabular}

The anaerobic faecal flora showed a reduction of $4-5 \mathrm{logs}$ in all three groups. The differences ob. served between the three groups were not statistically significant.

The reduction in both the aerobic and the anaerobic faccal microflora in each group can be partly explained by the good mechanical cleansing, but is mainly due to dilution. The oral administration of antibiotics in the volunteer group W.G.I. + AB did hardly influence the reductions of the faccal microflora during the irrigation procedure.

\subsubsection{Recolonization}

The quantitative and qualitative composition of the aserobic faecal microflora in the days following three types of bowel preparation are visualized in iig. 8.4. In all three groups of volunters a temporary increase in the numbers of aerobic colonic micro-organisms was seen as compared to the pretreatment counts. In group W.G.I. this "overgrowth" disappeared within wo days after the irrigittion. Despite a recuperation of the anaerobic microflora within 24 hours a disturbance in the syncrgism between the ae robic and anaerobic microflora must have caused this temporary overgrowth.

The short, high dose antibiotic regimen in group W. G.I. + AB had a considerable after-etfect on the: bowel-flora. The acrobic microflora in particular showed an "overgrowth", increasing in numbers during the first three days and followed by a gradually decline. It took over one week before normal 

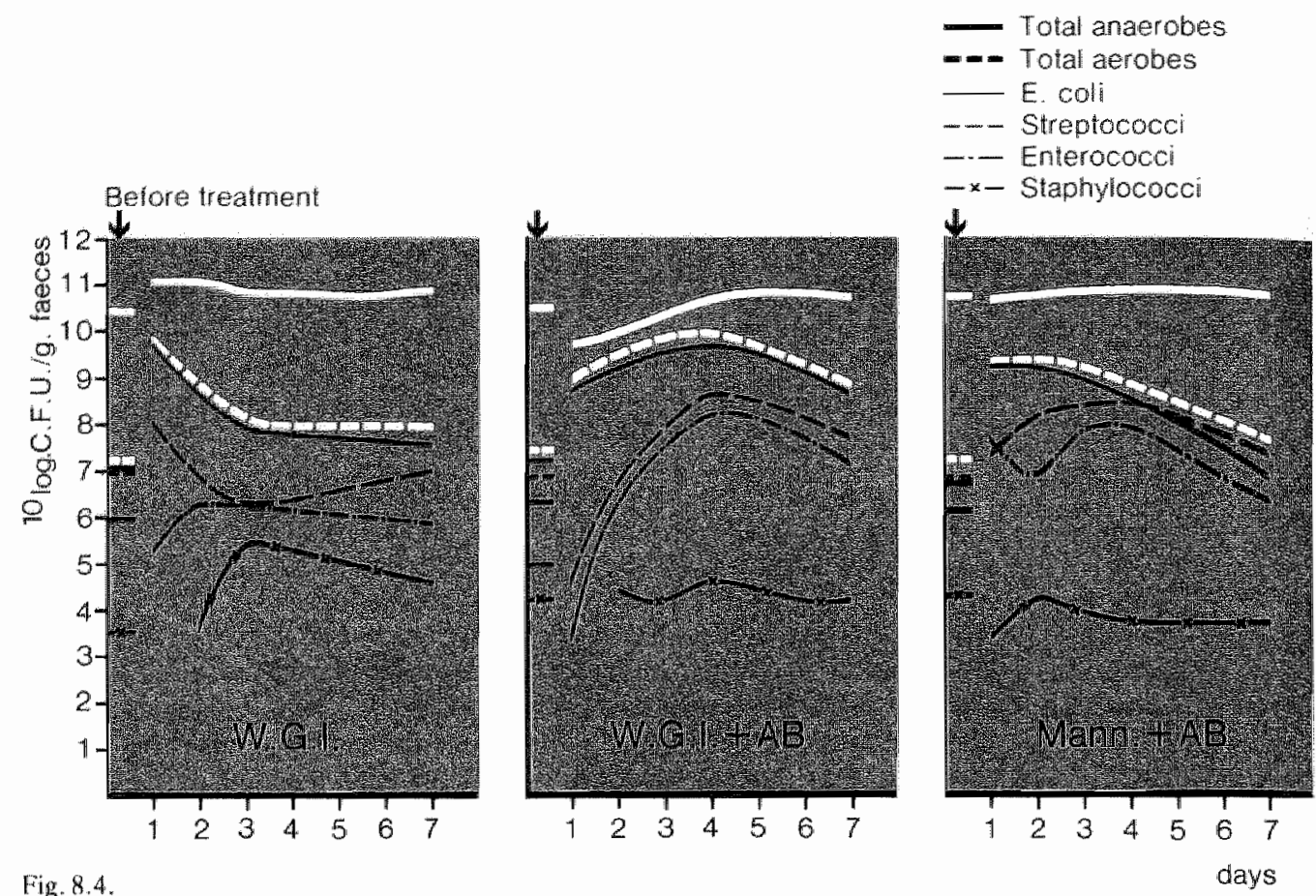

Fig. 8.4.

Recolonization of the aerobic faccal microflora.

counts were reached. The anacrobic microflora recovered from its $4-5 \log$. reduction in 3 to 4 days. The results indicate that as soon as the anaerobic counts reached normal pre-treatment levels, the aerobic count started to decline.

In the group Mann + AB an overgrowth was observed of especially $E$. coll which reached high levels on the first day and declined gradually over a period of one week to pre-treatment levels. The anacrobic flora approached to be hardly affected, and reached normal counts within 24 hours. It is not likely that the antibiotics have caused the observed disturbances because the antibiotic regimen was started the morning after the irrigation procedure. It seems reasonable to assume that apart from the temporary disturbance of the interaction between the acrobic and anaerobic microflora the availability of the readily fermentable nutrient mannitol in relative high concentration is the cause of the observed overgrowth by E. coli.

The cnterococei and streptococci in group W. G.I. showed a minimal increase and were rapidly normalized to pretreatment levels. In group W.G.I. + AB, however, both groups of micro-organisms revealed, after an initial reduction, an increase of 3 logs on the day after the bowel preparation. It took over one week before both groups of microworganisms returned to pretreatment counts. In group Mann $+A B$ a slight increase was seen which returned to normal levels within one week. The growth of staphylococe in either group was not influenced by the different methods of large bowel preparation.

Fig. 8.5 visualized the recuperation of the anaerobic faecal microflora. In group W.G.I. and group Mann. + $A B$ the growth of all anaerobic species was similar as before the large bowel preparation. In group W.G.I + AB a lemporary decrease of the total number of anaerobes was found in particular the Bacteroides sp. and Clostridia sp. showed reduced counts, most likely caused by the action of metronidazole. $C$. difficile was not cultured neither before nor after one of the methods of large bowel preparation. 

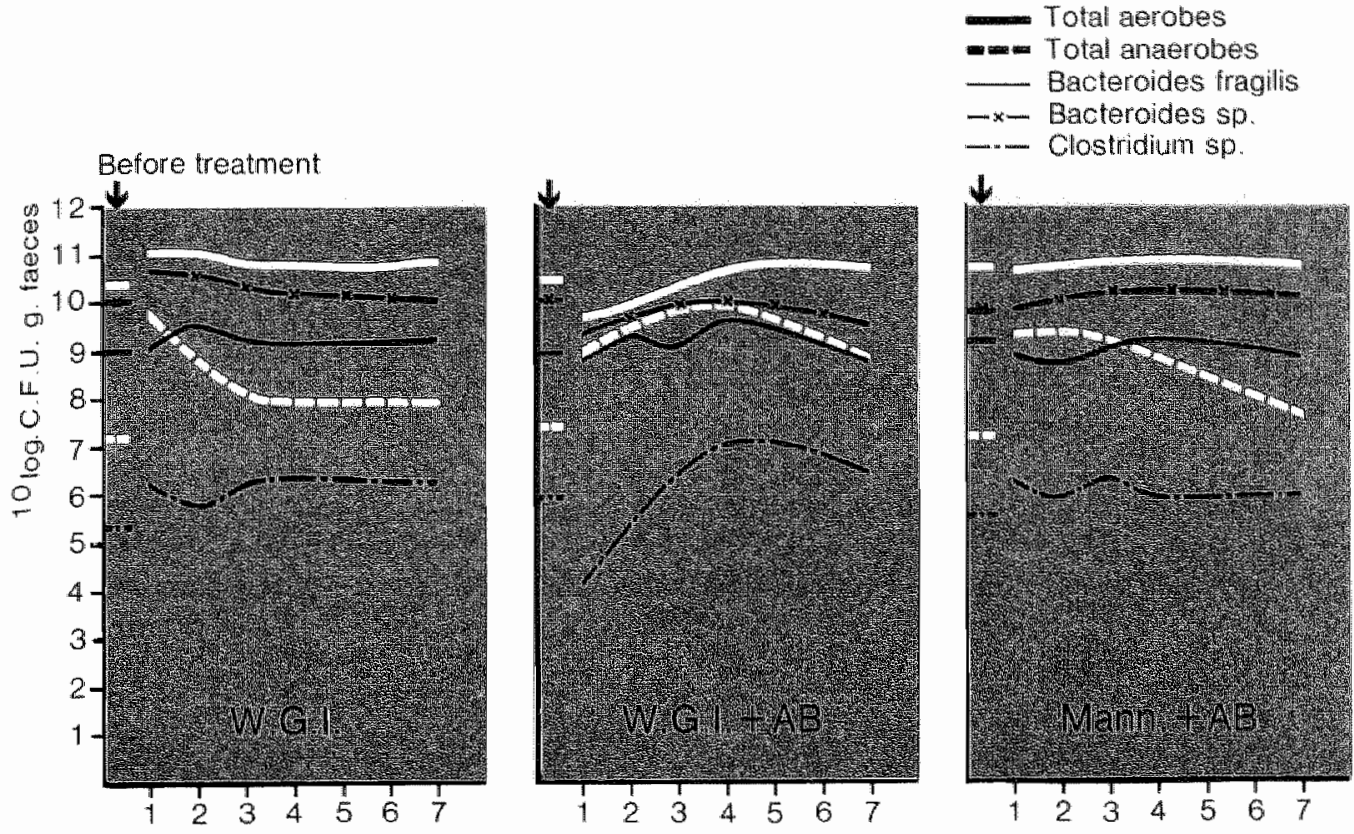

Fig. 8.5 .

Recolonization of the anae robic faecal microflora.

\subsubsection{Colonization Resistance}

\section{Experiment 1}

In three volunteers an inoculum of the neomycin resistant $E$. coli strain as well as the neomycin resistant $P$ s. aeroginosa was administered orally. To each volunteer, who did not undergo a large bowel preparation, a glass of milk was administered containing respectively $10^{9}, 10^{10}$ and $10^{11}$ C.F.U. of both strains. Neither the neomycin resistant $E$. coli nor the Ps. aeroginosa strain was cultured from the faeces of these voluntesers in a period of one week after ingestion.

\section{Experiment 2}

The results of the pilot study in which the 3 different contaminating dosages of the ncomycin resistant $E$. coli and $P_{S}$, aeroginosa were administered one hour after one of the large bowel preparation was finished, are shown in Fig. 8.6. The neomycin resistant $P_{\text {s. aeroginosa was only seen temporary }}$ in the faeces of each volunteers and disappeared completely within 3 days. The faeces of the volunteer who underwent a W.G.I. previous to the administration of the neomycin resistant $E$. coli revealed positive faeces cultures for this bacteria for 13 days. The $E$. coli could not be isolated from the faeces of the volunteer who underwent the bowel preparation Mann. + AB after 18 days. To this volunteer $10^{8}$ C.F.U. of E. coli in $100 \mathrm{cc}$ milk was administered. The "take" of $10^{9}$ C.F.U. E. coli after W.G.I. + AB continued for a period of over 6 weeks. These results made us decide to administer dosages of $10^{6} \mathrm{C}$. F.U. of $E$. coli and Ps. aeroginosa to the volunteers taking part in the subsequent study.

\section{Experiment 3}

The influences of the three different methods of large bowel preparation on the C.R. of the the gastrointestinal tract are shown in Tables 8.7, 8.8 and 8.9. The neomycin resistant $E$ coli was cultured from the faeces after each regimen of large bowel preparation.

Volunteers in group W.G.I. showed positive cultures during the first week although a decrease was observed from the fourth day on. In one volunteer (A) the E. coll was not cultured after 6 days while the others became negative in the following 3 weeks. After an initial disappearance, the $E$, coli could 


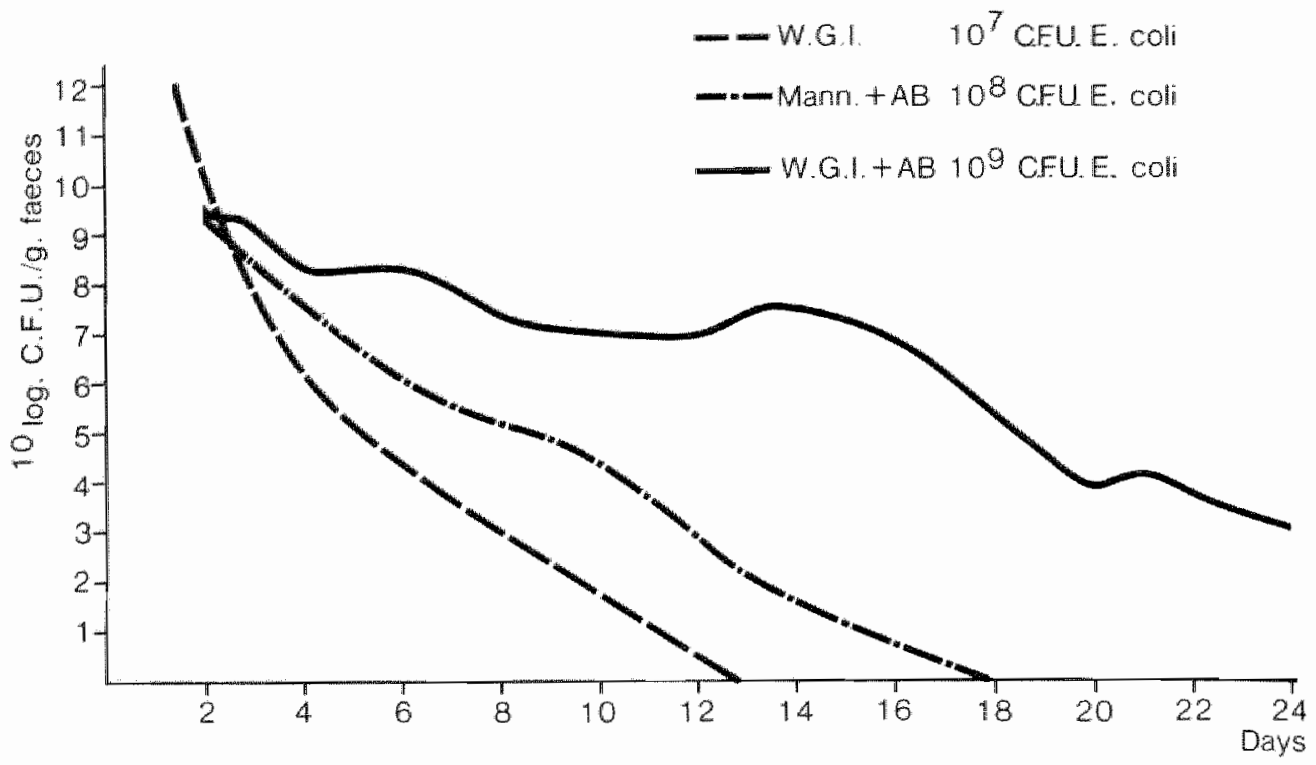

Fig. 8.6

Excretion of a nomycin and gentamicin resistant E.coli test strain in the faeces after 3 different types of large bowel prepatition.

be isolated again in 3 volunteers. After 6 weeks all wolunteers were free of the neomycin resistant $E$. coli.

The impact on the C. R. in group W.G.I. + AB was much more profound. The neonycin resistant $E$. coli was seen for a period of at least 6 weeks. A mean concentration E. coli of $10^{\circ} \mathrm{C} . \mathrm{F}$. U./g faneces on the first day declined to a mean concentration of $10^{5}$ C.F. U. $/ g$ faeces in the 5 th week after the intake. It took 10 weeks before the stools of atl volunteers in this group were free of the neomycin resistant E. coli.

Taible 8.7

Lxeretion of aneonycin and gentaticin resistant Ecolitest st rain in the facces

Group W.G.I.

Volumeds

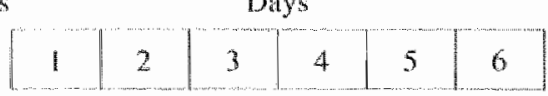

\begin{tabular}{|c|c|c|c|c|c|c|}
\hline & 8 & 9 & 7 & $\mathrm{NC}$ & 3 & \\
\hline $\mathrm{B}$ & 7 & 7 & $\mathrm{NC}$ & 5 & 5 \\
\hline $\mathrm{C}$ & 5 & 6 & 6 & $\mathrm{NC}$ & 3 & 3 \\
\hline $\mathrm{D}$ & $\mathrm{NI}$ & 4 & 6 & $\mathrm{NC}$ & 8 & 6 \\
\hline $\mathrm{N}$ & & 3 & 7 & $\mathrm{NC}$ & 8 & 8 \\
\hline
\end{tabular}

Waeks

\begin{tabular}{|l|l|l|l|}
\hline 2 & 3 & 4 & 5 \\
\hline
\end{tabular}

\begin{tabular}{|c|c|c|c|}
\hline 2 & 2 & & \\
\hline 2 & 3 & & \\
\hline$N C$ & 4 & & 3 \\
\hline 4 & 5 & & 3 \\
\hline
\end{tabular}

Expressed in ${ }^{10}$ Log C.F.U./g faces

NI $=$ Not isolated

NC $=$ Not cultured 
The decrease of the $C$. $R$. in group Mann. + AB was similar to that of group W. G. I. After an initial "take" during the first week the neomycin resistant $E$. coli disappeared in the following weeks. In 3 volunteers in this group the micro-organism disappeared after 1 week, while the 2 others still had positive faeces cultures after 5 weeks, although the quantities were less compared to group W. G. 1 . + $A B$. In one volunteer (O) the same phenomenon of a positive culture after an initial disappearance was seen.

Ps. aerognisa cultures showed an identical behaviour as in experiment 2 . In all 3 groups no neomycin resistant $P$ s. aevogimosa strain could be cuitured from the faces after 3 days.

\subsubsection{Beta-aspartylglycine in the faeces}

The results of the presence of $\beta$-aspartylglycine in the faeces are visualized in Table 8.10 . In group W.G.I. $\beta$-aspartylglycine was not identified in the faeces, while in group W.G.I. $+A B$ aspartylglycine was present in high levels on day 2 . The following days the 8 -aspatylglycino disappeared from the faeces. The systemic antimicrobial prophylaxis in group Mann. + AB resulted in equivocal results on day 2,3 and 4 .

Table 8.8

Excretion of a neomycin and gentamicin resistant Ecoli test strain in the faeces Group W.G.I + AB

Volunteers

\begin{tabular}{|l|l|l|l|l|l|}
\hline 1 & 2 & 3 & 4 & 5 & 6 \\
\hline
\end{tabular}

\begin{tabular}{|c|c|c|c|c|c|c|}
\hline $\mathrm{F}$ & 9 & 8 & 9 & 9 & 7 & 7 \\
\hline $\mathrm{G}$ & 9 & 8 & 9 & $\mathrm{NC}$ & 8 & 7 \\
\hline $\mathrm{H}$ & $\mathrm{NI}$ & 10 & 8 & 7 & 6 & 6 \\
\hline $\mathrm{I}$ & $\mathrm{NI}$ & 8 & 7 & 9 & 9 & 6 \\
\hline $\mathrm{K}$ & 8 & 8 & 6 & 7 & 8 & 8 \\
\hline
\end{tabular}

Expressed in ${ }^{10} \mathrm{Log}$ C.F.U./g faeces

$\mathrm{NI}=$ Noll isolated

$\mathrm{NC}=$ Nort chltured

Table 8.9

Excretion of a ncomycin and gentamicin resistant E.coli lest strain in the facces Group Mann. + AB

Volunteers

\begin{tabular}{|l|l|l|l|l|l|}
\hline 1 & 2 & 3 & 4 & 5 & 6 \\
\hline
\end{tabular}

\begin{tabular}{|c|c|c|c|c|c|c|}
\hline $\mathrm{L}$ & 7 & 7 & 7 & 8 & 6 & 5 \\
\hline $\mathrm{M}$ & 5 & 3 & 8 & 7 & 4 & \\
\hline $\mathrm{N}$ & 6 & 7 & 5 & 8 & 6 & 4 \\
\hline $\mathrm{O}$ & 5 & 6 & 6 & 8 & 7 & \\
\hline $\mathrm{P}$ & 8 & 7 & 6 & 8 & 7 & 6 \\
\hline
\end{tabular}

Expressed in ${ }^{10} \log$ C.F.U./g faeces

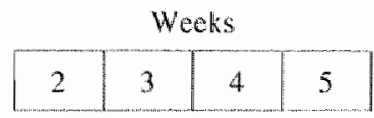

\begin{tabular}{|c|c|c|c|}
\hline 8 & 7 & 5 & 5 \\
\hline 6 & 7 & $\mathrm{NC}$ & 7 \\
\hline 8 & 5 & 8 & 4 \\
\hline 6 & $\mathrm{NC}$ & 6 & 5 \\
\hline 8 & 7 & 3 & 3 \\
\hline
\end{tabular}


6. alsparlylgycine in faeces during 5 days after large bowel preparation.

\begin{tabular}{l|c|c|c|c|c|c|c|c|c|c|c|c|} 
& & Day 0 & Day 1 & Day 2 & Day 3 & Day 4 & Day 5 \\
\cline { 2 - 2 } & + & \pm & + & \pm & + & \pm & + & \pm & + & \pm & + & \pm \\
\hline W.G.l. $+\mathrm{AB}$ & & & 1 & 1 & 4 & 1 & & 3 & & 2 & & \\
\hline Mann + AB & & & & & & 2 & & 1 & & 1 & & \\
\hline
\end{tabular}

\subsubsection{Volatile Fatty Acids in the faeces}

The lewels of V.F.A. in the faeces during the first three weeks after the bowel preparation are visualized in Fig. 8.11 .

After an initial wash out as a consequence of the mechanical cleansing procedure both group W.G.I. and group Mann. + AB showed an increasc of V.F. A. in the faeces which achieved the normal levels within one week in both groups. In group W.G.I. + AB the lewels of V.F.A. remained low during the first few days after the bowel preparation. The high levels of V.F.A. in group W.G.I. as well as in group Mann. + AB are not readily be explained.

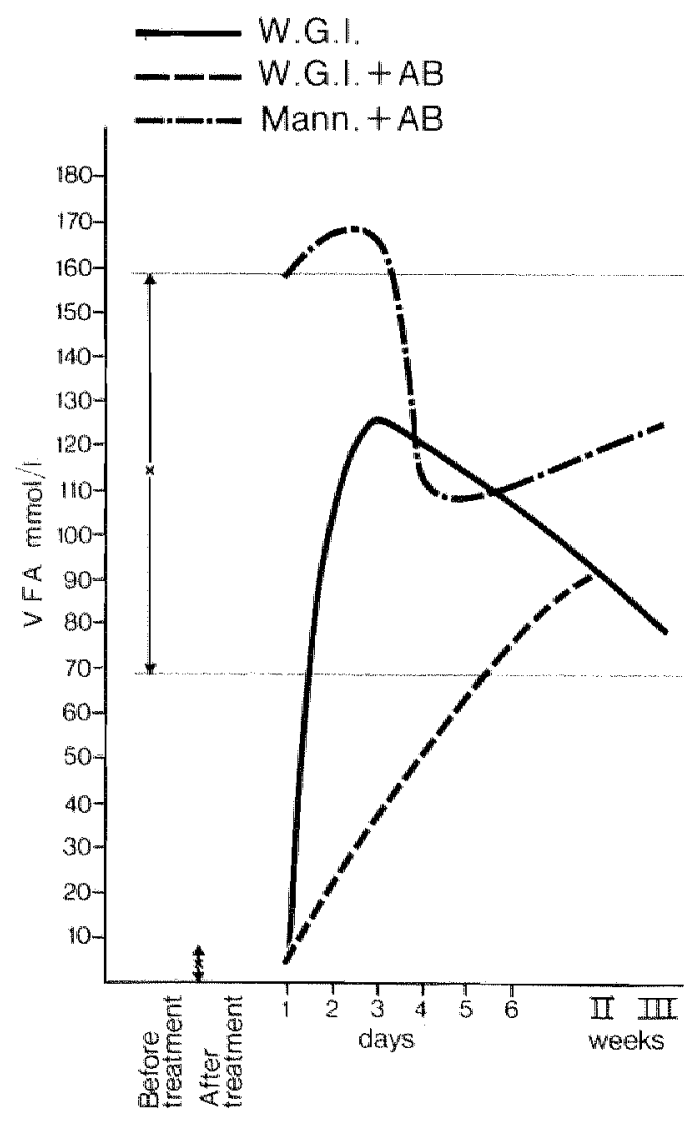

Fig. 8.11.

Volatile Fatty Acids in faeces. 


\subsubsection{Levels of mannitol in the faeces}

The decrease of the mannitol levels in the faeces during whole gut irrigation after previous administration of mannitol are visualized in Fig. 8.12. The mannitol level in the faeces dropped from $3 \times 12 \pm$ $0.63 \mathrm{~g} \%$ at the beginning of the irrigation to $17.50 \pm 12.14 \mathrm{mg} \%$ at the end of the procedure.

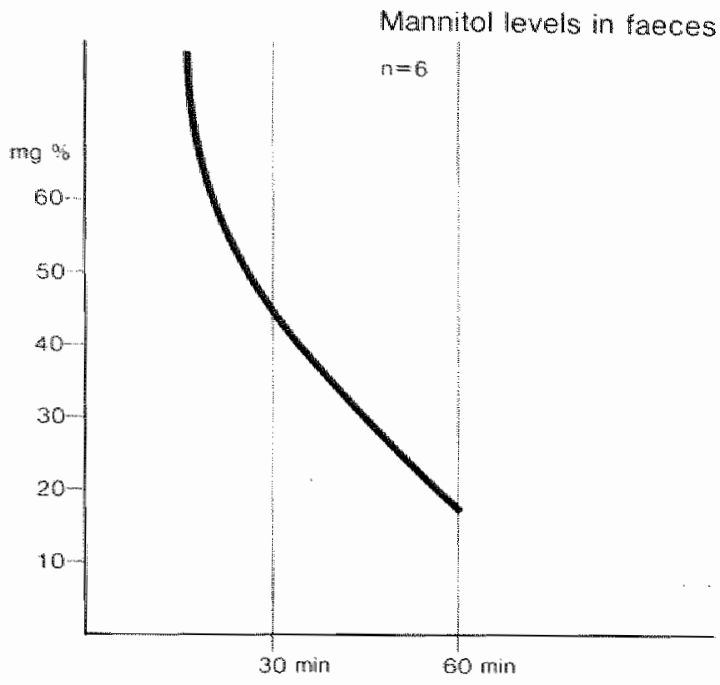

Fig. 8.12.

Levels of mannitol in the faces.

\subsection{Discussion}

Evidence from the literature showed that mechanical cleansing procedures without the administration of antibiotics have no profound impact on the colonic microflora. After conventional mechanical cleansing procedures a decrease of the aerobic flora of 1-2 logs was found, however, 121018 hours later bacterial concentrations had returned to pretreatment levels (Bornside and Cohn, 1969; Gorbach et al., 1970; Nichols, Gorbach and Condon 1971). Stock et al. (1977); Huk et al. (1980) and Hollender et al. (1980) reported that after whole gut irrigation no reduction of the microflora was seen, neither aerobic nor anaerobic.

As expected the colonic microflora in group W. G.I. recovered rapidly. The anacrobic microflora reached the pretreatment levels within 24 hours. The aerobic microflora showed a transient "overgrowth" during 48 hours. The irrigation procedure apparently has influenced the symbiosis between the aerobic and anaerobic microflora. Although the concentration of micromorganisms per gram faeces was hardly influenced by the irrigation procedure, the concentration of metabolites produced by the colonic micro-organisms is reduced by the lavage. The metabolites of micro-organisms, cspecially volatile fatty acids produced by anaerobes play an important role in the equilibrium of the colonic microflora. The results of the determination of B-aspartylglycine and V.F.A. in the faces showed that the decrease of V.F.A. in group W.G.I. + AB is accompanied by the presence of $\beta$-ats partylglycine in the faeces. This finding suggests that the function of the anae robic bacteria is depressed by this bowel preparation. The absence of $\beta$-asparatylglycine and the rapidly restored level of V.F.A. in the faeces, in the group W.G.I. and Mann. + AB, indicate that the function of the anaerobes is hardly influenced after these methods of large bowel preparation.

The reductions of the aerobic as well as the anaerobic faccal microflora in group W.G.I. $A B$ werc identical to those found in patients. According to the literature and previous studies (chapters 6 and 7) the recolonization of the large bowel, however, was totally different from what we expected to find. The anaerobic flora was reduced only for a short period of time. The Bacteroides strains recowered within 24 hours while the total amount of anaerobes returned to pretreatment lewels in 3 days. The aerobic microflora showed the same overshoot as in group W. G.I., but the recovery to pretreatment levels took more than one week. At the time that the anaerobic microflora has recovered the 
aerobic microflora starts to decrease. In addition to the irrigation procedure itself, the oral administration of large amounts of antibiotics probably has disturbed the symbiosis between the colonic micro-organisms resulting in a dysbacteriosis for a longer period of time.

The microbid reductions in the faeces observed in group Mann. + AB are mainly caused by dilution. The systemic antimicrobial prophylaxis in group Mann. $+\mathrm{AB}$ did not influence the anaerobic microflora, which recovered within 24 -hours.

The total amount of aerobes was maintained at high levels for at least three days and was normalized in a week. This aerobic owergrowth was mainly caused by an increase of $E$. coll. The overgrowth of $E_{\text {col }}$ confirms the findings of Keighley et al. (1981) and might explain the high incidence of superficial wound infections in the group of patients described in chapter 7 . The owergrowth of $E$. coli is probably duc to presence of the readily fermented nutrient mannitol within the colon. In the clear rectal effluent marnitol reached mean concentrations of $17.5 \pm 12.4 \mathrm{mg} \%$ and it an excellent nutrient for especially $E$. coli.

The results of this study indicate that all tested methods of large bowel preparation influence the symbiosis between the aerobic and anaerobic microflora, resulting in a temporary "overgrowth" of the aerobes. A short duration, high dose, antibiotic regimen in group W.G.I. + A. B caused an considerable increase of the aerobes, while the anaerobes were less affected. This finding is in contrast with those reported by others. Many investigators found a vigorous reduction of the aerobic as well as the anaterobic faccal flora, after a conventional cleansing procedure and a short or longer oral antibiotic prophylactic regimen (Nichols et al., 1973; Clarke et al., 1977; Arabi et al. 1978). After whole gut irrigation with oral antibiotic prophylaxis profound aerobic and anaerobic reductions were still present at time of operation (Huk et al., 1980; Hollender er al. 1980). All these studies concerned patients with colonic diseases, and no volunteers, while the samples were obtained from bowel contents during operation using the aspiration technique. In case of a stenosis the orall administration of antibiotics may have more time to reduce the faecal microflora than in case of an unaffected colon with normal peristalsis. Arabi et al. (1974) reported a decrease of the aerobic and anaerobic colonic microflora for 2-3 days after a 5 day's regimen with neomycin and metronidazole in healthy wolunteers. However, other investigators (Finegold et al., 1966; Koroleva, 1968; Gorbach ef $a l ., 1969$; Hartley et al. 1978) related that antibiotic regimens which reduced mainly the anaerobic microflora revealed an increase of the aerobic and facultative anaerobic bacteria.

To what extent the administration of the neomycin resistant strains of $E$. coli and $P s$. aeroginosa have influenced the findings about recolonization is unknown. A high dose of $E$. coli and $P_{S}$. aeroginosa, orally administered in healthy volunteers who did not undergo a mechanical cleansing procedure, did not result in a colonization of the gastrointestinal tract with these micro-organisms. "This again confirms that in healthy people the C. R. prevents the colonization of the gastrointestinal tract by potential pathogenic micro-organisms. The colonization, after W.G.I by the E. colt test strain indicates that this method substantially decreased the C.R. The disturbance of the C.R. is not indicated by relative or absolute changes in the numbers of bacteria in the faecal flora. Absolute or proportional changes in the mucosall wall flona, a direct effect of the irrigation fluid on the mucosal wall, or a decrease or elimination of metabolic produces of especially the anaerobic flora, might explain the reduced C.R. It is however, noteworthy that once the $E$. coli strain colonized the gastrointestinal tract it took 2 weeks to eliminate the strain from the colon.

The difference observed between group W.G.I and group Mann. + AB implies a possible role for mannitol in influencing the C.R., as the mechanical cleansing procedure in both groups was identical. Furthermore, it seems likely that the systemic prophylaxis in group Mann. $+A B$ did not influcnce the C.R., because the anterobic microflora returned to a pretreatment level at time the prophylaxis was started.

The mechanism by which mannitol induces this effect is not known, because no data are availlable neither on the effect of nucosal oedema caused by mannitol nor on the influence of the fermentation of mannitol by $E$. coli.

The administration of high doses of neomycin and metronidazole in group W. G. $I$. + AB resulted in a strong decrease of the C.R. In addition to the C.R. reducing mechanism present in group W. G.I., the oral administration of antibiotics is undoubtedly responsible for the further decrease in C.R. Although the colonic microflora was suppressed for only a short period of time, this was sufficient to allow the E. colitest strain to colonize the gastrointestinal tract for a considerable period of time. 
Not all aerobic micro-organisms are able to colonize the gastrointestinal tract when the $C$. $\mathbb{R}$. is diminished. The PS. aeroginosa was only cultured from the faeces during a short period of time indicating that the methods used did not influence the C.R. to such a degree that this strain could colonize the gastrointestinal tract.

This leads to the conclusion that anti-microbial prophylaxis in elective colorectal surgery should be a high dose, short term systemic antibiotic regimen: a short high dosis regimen because only an adequate serum level of an appropriate antimicrobial drug at the time to operation decreases substantially the incidence of postoperative septic complications, and systemic because oral administra. tion of antibiotics decrease the C.R. of the gastrointestinal tract. 


\section{Chapter 9:}

\section{General Discussion}

Colorectal surgery is associated with a high incidence of postoperative septic complications. Most infections are endogenous and are caused by dissemination of intestinal micro-organisms. Attempts to reduce the incidence of septic complications are directed towards the achicvement of a meticulous operative technique, the improvement of the preoperative mechanical cleansing procodures and the prophylactic use of antibiotics.

Cleansing the large bowel is a time honoured method. The conventionally used mothods are not satisfying in every respect. They are attended by varying degrees of starvation, dehydration, and physical exhaustion. The method of whole gut irrigation (W.G.I.) has proven, in the literature as well as in our own studies (chapter 5 and 6 ), to be an excellent alternative method to remove the bowel contents. Quite contrary to popular belief, the method of whole gut inrigation proved to be rapid, economic, effective and surprisingly well tolenated. The preoperative hospitalization could be reduced because the whole gut irrigation took hours instead of days. Instead of starwation and dehydration the nutrional status of the pationts did not deteriorate and in most cases at certain degree of prehydration could be attained. W.G.I. with or without the prior administration of mannitoll (vide infra) can be performed under supervision of a nurse and without control of biochemical parameters. Both investigated methods of whole gut irrigation revealed cxcellent results, giving the surgeon the opportumity to operate upon a collapsed "clean" colon.

Although well tolerated in general, the immobilization of 3 to 4 hours above the commode was experienced as unpleasant by all patients, especially the elderly. Further disadvantages are the possibility of overloading the circulation and the need for constant supervision. To avoid these drawbacks the principle of osmotic diarrhea has been introduced. As shown in chapter 7 , the administration of a $10 \%$ mannitol solution prior to W.G.I. reduces the immobilization time above the commode with $50 \%$, it prevents owerloading of the circulation and has the great advantage that the main part of the mechanical cleansing procedure could take place on the surgical ward. However, the administration of mannitol had some serious side effects. Sometimes an ocdematous mucosa was seen at time of operation, making the handling of tissues at time of the anastomosis more difficult. Another side effect of mannitol was that in spite of the administration of prophylactic antibiotics a high incidence of postoperative superficial wound infections occurred: $19 \%$ with a 24 hours during systemic regimen of gentamicin and metronidazole and $25 \%$ with metronidazole alone. All these postoperative wound infections were caused by $E$. coli. The overgrowth of $E$. coli in the faeces following the preparation with mannitol apparently resulted in an increased contamination and infection of the postoperative wounds with this micro-organism. The concentration of mannitol in the clear rectal effluent at the end of the irrigation is still considerable and mannitol probably serves as an excollent nutrient for the colonic bacterial, especially $E$. coll (chapter 7 and 8 ). Marmitol is for this reason not longer acceptable as an osmotic cathartic and should be replaced by another nonabsorbable compound which is not fermentated by intestinal bacteria. Polyethylenglycol might be such a compound.

Although in the literature the antibiotic prophylaxis in elective colorectal surgery is still al controwersial issue, the results described in chapter 6 clearly showed that the question whether antibiotics should be uscd in elective colorectal surgery should be answered affirmative. The significant reduction in wound sepsis and other more serious septic complications that can be obtained by an adcquate antibiotic prophylaxis strongly indicates that reliance on just excellence in surgical technique and mechanical cleansing alone is thically unwarrented.

Prophylactic administration of antibiotics thas two objectives. The first is to achieve, by systemic or topical administration of antibiotics, an adequate tissue level by which the resistance of the wound against bacterial invasion is enhanced. The second am is to reduce, by oral administration of antimicrobial agents, the number of bacteria in the resident colonic microflora and thereby to reduce the number that is likely to gain access to sterile tissues. However, the use of oral antibiotics for several days thas always the danger of the emergence of antibiotic resistant strairs and, due to the 
change in the composition of the intestinal microflora, a risk of superintection. An advantage of the oral use of nonabsorbable antibiotics is the minimal risk of systemic drug related reactions. Whether an oral antimicrobial prophylaxis regimen is preferable to a systemic regimen in elective colorectal sufgery tas not been thoroughly investigated. The results of the study described in chapter 6 showed that the reductions of the faecal microflora obtained by different methods of large bowel preparation showed no correlation with the incidence of postoperative septic complications. Also the number of bacteria in the quantitative biopsy cultures represenfing the mucosal microflora did not correlate with the septic complications. However, a highly statistical significant inverse correlation was found between the scrum levels of metronidazole at the time of the operation and the incidence of postoperative septic complications: the higher the level (5-10 times M.I.C.) the lower the incidence. It is theretore advisable to administer antibiotics in a high dose in order to obtain at the time of contamination serum levels of 5-10 times the M.I.C.. For this and the reasons mentioned above the systemic antimictobial prophylawis is preferable to an oral regimen in elective colorectal surgery.

Antimicrobial prophylaxis with metronidazole, an antimicrobial agent active against obligate anaerobes, prevented most if not all serious postoperative anaerobic and mixed infections. The addition of aminoglycosides which are active primarily against the facultative anaerobic microorganisms, did not further reduce the incidence of postoperative septic complications (chapter 7 ). It scems therefore that the addition of aminoglycosides to metronidazole in the antibiotic prophylaxis in elective colorectal surgery can be omitted. If the addition of other antibiotics, especially the cephalosporins are of any benefit has to be investigated in prospective randomized controlled trials. However, it has to be realized that the complete removal of bacteria from the lumen will be difficult if not impossible to achieve and that cutting the colon is inevitable attended by spilling of collonic micro-organisms. Elective operations of the colon and rectum have therefore to be considered as clean-contaminated operations and an incidence of postoperative wound infection below $5 \%$ shall never be obtained, irrespective of the antibiotic prophylactic regimen used. Strengthening and stimulation of the host defence mechanisms might in the future be an approach to achieve a further reduction in the incidence of postoperative septic complications after colorectal surgery.

The study in volunteers (chapter 8) of the Colonization Resistance and the faccal content of volatile fatty acids and beta-aspartylglycine yielded more detailed information about the effect of the large bowel preparation methods on the ecology of the bowel flora. All three methods studied affected the Colonization Resistance although in different degree. Especially, the oral administration of antibiotics had a severe impact on the Colonization Resistance, indicating a major disturbance in the microbial ecology. Recuperation of the bowel fllora was slow, and it took a considerable period of time to climinate a colonizing strain of $E$. coli. These findings emphasized again that in prophylaxis a sys. tonic administration ol antibiotics is to be preferred to oral use.

In conclusion, the results of the studies presented in this thesis showed that a preparation of the large bowel before etective colorectal surgery should involve: first, a good mechanical cleansing achicved by an osmotic diarthea induced by a hyperosmolar cathartict which is not fermented by the colonic microflora and which does not cause oedema of the mucosa, followed by a whole gut irrigation. Second, as systemic antibiotic prophylaxis directed against the anaerobic colonic flora, in a high dose for a duration of at most 24 hours. It must, however, be emphasized that a good preoperative large bowel preparation can never substitute for excellence in operative skills, patient and procedure selection, thoroughness of postoperative care, and operating room discipline. 


\section{Summary}

Colorectal surgery is associated with a high incidence of postoperative septic complications. The normal bacterial microflora of the intestinal tract presents a hazard of infection to the patient in any procedure which involves penetration or opening of the gut wall. The prevention of septic complications after elective colorectal surgery is based upon a reduction of the spilling of bowel contents by an adequate preoperative mechanical cleansing procedure, a meticulous operative technique, and the prophylactic use of antibiotics.

This thesis concerns a comparison of different methods of mechanical cleansing procedures and antimicrobial prophylactic regimens in a series of clinical and experimental studies.

In the chapters 1,2 and 3 the literature on these subjects is reviewed.

Chapter 1 deals with the ecology and bacteriology of the healthy and pathologic gastrointestinal tract, in particular the large bowel. The incidence and aetiology of the various septic complications after colorectal surgery and the measures taken to prevent the septic complications are reviewed in chapter 2.

In the first part of chapter 3 , the four regimens used for mechanicall cleansing are described; in the second part the principles of antimicrobial prophylaxis in elective surgery are discussed and the use of antibiotics in elective colorectal surgery, including the topical applications of antibiotics are reviewed.

Chapter 4 contains the considerations for and aims of the studies. The results of the clinical trials and the bacteriological investigations are described in the second part of this thesis.

In chapter 5 the method of Whole Gut Irrigation (W.G.I.) is presented, as a mechanical cleansing procedure of the gastrointestinal tract. In a study of 100 paticnts, W.G.I. proved to be a rapid. economic, effective and surprisingly well tolerated procedure. Compared to the conventional cleansing procedures, the preoperative hospitalization could be reduced and instead of starvation and dehydration some prehydration was obtained. Disadvantages of this preparation were the possibilities of overloading the circulation, the use of a nasogastric tube, the need for constant supervision. Furthermore, the lavage procedure can be exhausting, especially for elderly patients.

In chapter 6 the results are presented of a prospective randomized study in which three methods of preoperative bowel preparations were compared in 60 patients admitted for elective colorectal surgery. The methods used were a conventional method (CONV.), consisting a conventional mechanical cleansing procedure, and an oral antimicrobial prophylaxis with neomycin and metronidazole on the day before operation; whole gut irrigation without the administration of anribiotics (W.G.II.); and whole gut irrigation with neomycin and metronidazole added to the irrigtttion fluid (W.G.I.+AB). The reduction in aerobic and obligatc anacrobic faccal microflora during bowel preparation, cultures of biopsies of the resected part of the colon, and incidences, seriousness and cause of the postoperative septic complications were compared.

Irrigation appeaned to be a much more effective method in reducing the aerobic and especially the anaerobic faecal microflora as compared to the conventional mothod, a difference fur ther enhanced by the addition of the antibiotics to the irrigation fluid.

The reduction in faecal flora appeared to be mainly due to a dilution by the large amounts of irrigation fluid. Irrigation did the refore not influence the number of micromorganisms in the biopsy cultures. However, the number of aerobic and anaerobic bacteria was sharply reduced by the antibioiics administered orally.

In group W. G.1. all wound infections (incidence $50 \%$ ) were caused by mixed infections with acrobic and anaerobic colonic microflora. Anaerobes could not be isolated from the wound infections in group CONV. (incidence 14\%) and in group W.G.I. + AB (incidence 10\%). Analysis of the resilts showed no correllation between the reduction in the microflora of the faccal samples or biopsy cultures, and the postoperative septic complications rate. However, a highly significant correlation $(\mathrm{p} \times 0.01)$ was found between the presence of adequate serum levels of metronidazole during operation and the incidence of septic complications after elective colorcctal surgery. 
In chapter 7 a propective randomized trial is presented in which a 24 -hour systemic antimicrobial prophylaxis with metronidazole and gentamicin is compared to the administration of metronidazole alone. In both groups an identical mechanicall large bowel preparation was performed. In order to reduce the duration of the W.G.I. a $10 \%$ mannitol solution was administered before the irrigation procedure. All parameters to evaluate the different methods were identical to those described in chapter 6.

A significant reduction of the acrobic as well as the anacrobic faecal microflora was encountered after this method of mechanical cleansing. Again it appeared that the results are mainly due to dilution. The numbers of bacteria cultured from the biopsies were lower after the antimicrobial prophylaxis with metronidazole and gentamicin. Analysis of these results and those of chapter 6 shows that each antibiotic prophylaxis containing an aminoglycoside and metronidazole caused a decrease in the amount of bacteria cultured from the biopsies, irrespectrve of the route of administration. These results indicate that a good tissue perfusion and consequently an adeqate vissue level of antibiotics is the most important factor to achieve a decrease of the mucosal microflora.

Although all wound infections in both groups were superficial, the incidence of these infections was relatively high; $19 \%$ in the group with gentamicin/metronidazole prophylaxis and $25 \%$ in the group with a prophylactic regimen with metronidazole alone. From all these wounds $E$. coli was isolated while anaerobic micro-organisms were not cultured. This thigh rate of wound infections is most likely caused by an overgrowth of $E$. coli, due to the presence in the colon of relative high concentrations of mannitol which serves as a nutrient for $E$. colt.

In chapter 8 an experimental study is described in which the influence of different methods of large bowel preparation on the faecal microflora and the Colonization Resistance (C.R.) of the gastrointestinall tract was investigated. In three groups of healthy volunteers three different methods of large bowel preparation were performed; W.G.I., W.G.I. + AB and Mann. + AB. The last method consists of the administration of mannitol, followed by W.G.I. and a systemic antimicrobial prophylaxis with gentamicin and metronidazole. In order to investigate the effect of C.R., $10^{6}$ C.F.U of neomycin and gentamicin resistant strains of E. coli and Ps. aeroginosa were administered orally to all volunteers after the mechanical cleansing procedure. The reduction of the aerobic as well as the anaerobic faccal microflora during the mechanical cleansing procedures was similar in all three groups. The anaerobic faecal microflora returned to pretreatment levels within 24 hours in group W.G.I. and group Mann. + AB, while this took three days in group W.G.I. + AB. Both in group W.G.I. as in group W.G.I. + AB a temporary "overgrowth" with aerobic colonic micro-organisms was seen. A persistent overgrowth occurred in group Mann. + AB. The temporary "overgrowth" is probably caused by a disturbance of the symbiosis between acrobic and anaerobic colonic bacteria, while the real overgrowth with especially $E$. coli in group Mann. + AB may be the result of the reaclily fermentated nutrient mannitol.

The C.R. of the gastrointestinal tract was decreased after each regimen of large bowel preparation. The $E$. coli test strain could be isolated from the faeces during 2-3 weeks in group W. G.I. and group Mann. $+A B$, while it took over 10 weeks before this strain disappeared from the faeces in group W.G.1. + AB. The Ps. aeroginosa strain could be isolated from the faeces for a short period of time, in all three groups. The decrease of the $C$. R. may be partly explained by changes in the colonic wall due to the irrigation procedures but in group W.G.I. + AB this decrease is most likely due to the high dose short duration antibiotic prophylaxis.

Chapter 9. In the general discussion the most prominant findings of the clinical and experimental studies are reviewed. The results indicate that a preparation of the large bowel before elective colorectal surgery include:

- A good mechanical cleansing by means of an osmotic diarrhea induced by a hyperosmotic solution of a non-fermentable cathartic, followed by whole gut irrigation.

- A short 24-hour systemic antibiotic prophylaxis that provides at least an adequate protection against the Gram-negative anacrobic colonic microflora. 


\section{Samenvatting}

In de colorectale chirurgie wordt een hoog percentage postoperatieve septische complicaties gezien. Bij iedere patient waarbij het colon wordt geopend vormt de bacteriele flora uit de tractus digestivus een potentiële bron van infectie. Door middel van een goede mechanische reiniging en een zorgvuldige operatie techniek in combinatie met het profylactische gebruik van antibiotica kunnen de septische complicaties na electieve colorectale chirurgie verminderen.

In dit proefschrift worden verschillende technieken van mechanische darmvoorbereiding en diverse vormen van antimicrobiale profylaxe in een aantal klinische en experimentele studies met elkat vergeleken.

Een literatuur overzicht van de verschillende onderwerpen wordt in de hoofdstukken 1,2 en 3 behandeld. De normale darmflora en de microbiologische aspecten van de gezonde en de pathologisch veranderde tractus digestiwus, in het bijzonder die van het colon, worden in hoofdstuk 1 besproken.

In hoofdstuk 2 worden, aan de hand van de literatuur, de verschillende aetiologische aspecten van de septische complicaties na chirurgie van het colon en rectum, alsmede de maatregelen welke genomen kunnen worden om deze complicaties te voorkomen, behandeld.

Vier verschillende methodes van mechanische darmwoorbereiding worden besproken in het eerste gedeelte van hoofdstuk 3 . Het tweede gedeelte van dit hoofdstuk behandelt de prüncipes en de toepassing van antimicrobiële profylaxe in de electieve chirurgie in het algemeen en die in de electieve colorectale chirurgie in het bijzonder.

In hoofdstuk 4 worden de doelstellingen van de verschillende onderzoekingen uiteengezet.

In de hoofdstukken 5 tot en met 8 worden de resultaten van de klinische en klinisch experimentele studies en de daarbij behorende bacteriologische onderzockingen beschreven.

Hoofdstuk 5 beschrijft de toegepaste methode van darmlavage: Whole Gut Irrigation (W.G.I.), cen mechanische reinigingsprocedure van de tractus digestivus. In een onderzoek bij 100 patiënten be* wees deze methode een snelle, goedkope, effectieve en verrassend goed te verdragen procedure te zijn. Vergeleken met de conventionele methodes kunnen als voordelen genoemd worden; een verkorting van de preoperatieve ligduur; het niet optreden van dehydratie en het overbodig maken van dieetvoorschriften.

Als nadelen dienen vermeld te worden, de kans op overvulling van de circulatie, het gebruik van een neussonde, en het noodzakelijk zijn van een constant toezicht op en bewaking van de patiënt gedurende de lavage. Vooral voor oudere patiënten bleek de 3-4 uur durende procedure cen belasting te zijn. Het resultaat van een prospectief gerandomizeerd onderzoek, waarin drie methodes wan preoperatieve darmwoorbereiding werden vergeleken, wordt in hoofdstuk 6 beschreven. Het onderzoek betrof in het totaal 60 patiènten die verdeeld over drie groepen én van de volgende methodes van preoperatieve darmvoorbereiding ondergingen: een conventionele mechanische reiniging gecombineerd met een antibiotische profylaxe bestaande uit neomycine en metronidazole per os op de dag voor operatie (groep CONV.); Whole Gut Irrigation zonder toediening van antibiotica (groep W.G.I.); en deze darmlavage waarbij neomycine en metronidazole werden toegevoegd aan de spoelvloeistof (groep W.G.I. + AB). De drie groepen werden vergeleken met betrekking tot het kwantitatieve bacteriologische onderzoek van de aerobe en obligaat anaerobe micro organismen in de faeces voor en onmiddellijk na de behandeling; de kwantitatieve kweken van de biopsieën genomen wit het gereserceerde gedeelte van de dikke darm, en de ernst en eventuele oorzaken van de postoperatieve septische complicaties.

Vergeleken met de conventionele methode bleek de darmlavage een veel effectievere methode te zijn on de aerobe maar vooral de anaerobe microflora in de faeces te reduceren. Dit effect werd voornamelijk veroorzaakt door verdunning van de faeces met de grote hoeweelheden toegediende spoelvloeistof. De resultaten van de kwantitatieve kweken van de biopsieèn doen verder vermoeden dat de lavage de microflora gelocaliseerd in de mucosa niet of nauwelijks beinnvloedde. De orale toediening van antibiotica in groep W.G.1. + AB veroorzaakte een toename van de reductic van de faccale microflora. De orale profylaxe, zowel in groep CONV. als in groep W.G.I + AB, was de oorzaak van een afname van de aantallen bacterieën in de biopsicën in vergelijking tol grocp W.G.I. In 
groep W.G.I. ontwikkelden $50 \%$ wan de patiënten een wondinfectie, allen veroorzaakt door een mengflora war zowel aerobe als anaerobe bacterieèn. Anaerobe of gemengd anaerobe/aerobe infecties werden niet gezien in groep CONV. (14\% wondinfecties) noch in groep W.G.I. + AB (10\% wondinfecties).

De werschillen in optreden van postoperaticve septische complicaties tussen de drie groepen bleek niet gecorrelecrd te zijn met de grootte van de faecale reducties. Evenmin werd er een correlatie geyonden tussen de hoeveelheden bacterieën gekweekt uit de biopsieën en het optreden van postoperatieve septische complicaties. Het optreden van postoperatieve septische complicaties werd wel significant (p40.01) beinvloed door de hoogte van de metronidazole serumspiegels ten tijde van de operatie. Deze laatste bevinding gekoppeld aan het feit dat patiënten met anaerobe of gemengd aerobe/anaerobe infecties klinisch in veel slechtere toestand geraakten vormden de aanleiding tot het in hoofdstuk 7 beschreven onderzoek.

In dit hoofdstuk wordt een prospectieve, gerandomizeerde studie van 24-uur systemische antibiotische profylaxe met gentamicine en metronidazole vergeleken met een profylaxe bestaande uit metronidazole alleen. De mechanische darmvoorbereiding in beide groepen was identiek. Teneinde de 3-4 uur durende W.G.I. te bekorten werd aan alle 41 patiënten, enkele uren voor de lavage, een mannitol 10\% oplossing toegediend. Deze hyperosmolaire stof veroorzaakt een osmotische diarrhee.

Uit de kwantitatieve kweken wan de biopsieèn bleek dat de metronidazole en gentamicine een aanzienlijk sterkere reductie van de mucosale bacteriële flora veroorzaakten. De vergelijking van de postoperatieve wondinfectie percentages vertoonde geen significant verschil. Dit bevestigt het resultaat uit hoofdstuk 6, dat de aantallen bacterieën in de darmwand geen belangrijke aetiologische factor zijn voor het ontstaan van postoperatieve septische complicaties. In beide groepen werden uitsluitend oppervlakkige wondinfecties gezien hoewel het percentage van deze infecties hoog was: $19 \%$ in de groep met een gentamicine/metronidazole profylaxe en $25 \%$ in de groep met een profylaxe bestaande uit metronidazole alleen. In deze studie werden geen infecties met anaerobe microorganismen gezien. Uit de pus van alle wondinfecties kon een $E$. coli worden gekweekt. Deze relatief veel voorkomende $E$. coll infecties zijn mogelijk te verklaren uit een overgroei van deze bacterie in het colon veroorzaakt door de mannitol dat een goede voedingsstof voor met name $E$. coli is.

In een experimenteel onderzoek, beschreven in hoofdstuk 8 , werden de invloeden van drie verschillende colonvoorbereidingen op de faecale microflora en de Kolonizatie Resistentie (K.R.) van de tractus digestivus nagegaan. Drie groepen vrijwilligers ondergingen een van de volgende darmvoorbereidingen: W.G.I.; W.G.I. + AB of Mann. + AB. De laatste methode bestond uit het toedienen van een mannitol $10 \%$ oplossing gevolgd door een W.G.I. en een sytemische antibiotische profylaxe met metronidazole en gentamicine. De beïnvloeding van de K.R. werd nagegaan aan de hand van de uitscheiding van toegediende teststammen $E$. coli en $P$ s. aeroginosa in de faeces. Bovendien vormoden de anwezigheid van $\beta$-aspartylglycine en de hoeveelheden vluchtige vetzuren in de faeces parameters voor de $\mathbb{K}$. $R$.

In de groepen W.G.I. en Mann+AB was de anaerobe faecale microflora nat 24 uur hersteld. Tengevolge van een verstoring van de symbiose tussen de aerobe en anaerobe microflora trad er een tijdelijke "overgroei" op in groep W.G.I. In groep Mann. + AB werd een overgroei van langere duur gezien, waarschijnlijk veroorzaakt door vergisting van mannitol door E. coli. In groep W.G.I. $+\mathrm{AB}$ werd de langer durende overgroei van aeroben mogelijk veroorzaakt door een tijdelijke reductie van de totale hoeveelheid anaeroben.

In de drie groepen werd een verlaging van de K.R. gezien. Deze verlaging was het meest uitgesproken in groep W.G.I. + AB. De orale toediening van antibiotica veroorzaakte een langdurige uitscheiding van de teststammen in de faeces gepaard gaande met de aanwezigheid van $\beta$-aspartylglycine in de faeces en lage spiegels vluchtige vetzuren.

In hoofdstuk 9: In de algemene discussie worden de belangrijkste bevindingen van de klinische en de experimentele studies nader besproken. De resultaten duiden erop dat een preoperatieve darm voorbereiding voor electieve colorectale chirurgie moet bestaan wit: 
- Een goede mechanische reiniging door middel van een osmotische diarthee, opgewekt door een niet wergistbare hyperosmolaire stof, gevolgd door een whole gut irrigation.

- Een adequate, 24-uur durende systemische antimicrobiele profylaxe welke in ieder geval gericht is tegen de Gram-negatieve anaerobe collonflora. 


\section{References}

1. Abrams B L, Alsikaf E H, Waterman N G:

Colostomy, a new look at morbidity and mortality. Am. Surg 45: 462, 1979.

2. Ackermann D, Akovbiantz A:

Wendepunkt in der Kolonworbereitung. Helv. Chir. Acta. 45: 835, 1978.

3. Aeberhard P, Flüchïger $M$, Berger J, Novak $A$ :

Antibiotische Darmverbereitung oder peri-opertive parenterale Abscheinung bei Coloneingriffen. Langenbecks Arch. Chir. 353:233, 1981.

4. Alexandier J W, Altemeler W A:

Penicillin prophylaxis of experimental staphylococcal wound infections. S.G. O. 120:243, 2, 1965.

5. Alexander-Williams J, Oates $\mathrm{G} \mathrm{D,} \mathrm{Brown} \mathrm{P} \mathrm{P,} \mathrm{et} \mathrm{al.} \mathrm{:}$

Abdominal wound infections and plastic wound guards. Br. J. Surg. 59: 142, 1972.

6. Alexander-Williams J, Leish A R M, Keighley $K \mathbb{R} B$, Burdon D W:

Prophylactic antibiotics in bowel surgery. Proc. R. Soc. Med. 69:327, 1976.

7. Altemeier W A, Cincinnati M B:

The pathogenicity of the bacteria of appendicitis peritonitis: An experimental study. Surgery 11: 374, 1942.

8. Altemeier W A, Hummal R P, Hill E O:

Staphylococcal enteritis following antibiotic therapy. Ann. Surg. 157: 874, 1963.

9. Altemeier W A:

Control of wound infections. J. Royal Coll. of Surg. 11:271, 1966.

10. Altemeiler W A, Culbertson W R, Fuller W, Stock C:

Intra-abdominal abscesses. Am. J. Surg. 125: 70, 1973.

11. Andersen B, Korner B, Ostergaard H:

Topical ampicillin against wound infection after colorectal surgery. A wnals of Surgery 176: 129, 1972.

12. Anderson C B, Marr J J, Ballinger W F:

Anaerobic infections in surgery. Clinical review Surgery: 313, 1976.

13. Arabi Y, Dimock F, Burdon D W, Alexander-Williams J, Keighley M R B:

Influence of bowel preparation and microbials on colonic microflora. Br. J. Surg. 65: 555, 1978.

14. Arabi Y, Dimock F, Burdon D W, Alexander-Williams J, Keighley M R B:

Influence of neomycin and metronidazole on colonic microflora of volunteers. J. of Antimicrobial Chemotherapy 5: 531,1979 .

15. Arango A, Lestter L, Martinez O, Mallinin Th, Zeppa R:

Bacteriologic and systemic effects of intraoperative segmental bowel preparation with povidone iodine. Arch. Surg. 114: 154, 1979 .

16. Autio V:

The spread of intraperitomeal infection. Acta, Chir. Scan. suppl. 321:1964.

17. Barker K, Graham N G, Mason M C, et al:

The relative significance of preoperative oral antibiotics, mechanical bowel preparation and preoperative peritoncal contamination in the avoidance of sepsis after radical surgery for talceratiwe colitis and Crohn's disease of the large bowel. Br. J. Surg. 58:270, 1971.

18. Bartelsman J F W M, Padmos M, Tytgat G N:

Reiniging van het colon door middel van totale darmlavage. Tijdschrift voor gastroenterologic: 417, 1977 .

19. Bartlett J G, Condon R E, Gorbach S L, Clarke J J, Nichols R L., Ochi S:

Impact of oral antibiotic regimen on colonic flora, wound irnigation cultures and bacteriology of septic conplication. Ann. Surg. 188:249, 1978.

20. Bartlett J G, Condon R E, Gorbach S L, Clarke J J, Nicholls R L, Ochi S:

Veterans administration cooperative study on bowei preparation for elective colorectal operations; impaci of oral antibiotic regimen on colonic flora, wound irrigation cultures and bacteriology of septic complications. Ann. Surg. 188: 249, 1978a.

21. Bates T, Down R H I, Houghton M C V, Lloyd G J:

Topical ampicillin in the prevention of wound infection after appendicectomy. Br. J. Surg. 61:489, 1974.

22. Beart R W, Kelley K A:

Randomized prospective evaluation of the EEA-Stapler for colorectal anastomoses. Am. I. of Surg. 141: 143,1981 .

23. Bigard M A, Gaucher P, Lassalle C:

Fatal colonic explosion during colonoscopic polypectomy. Gastroenterology $77: 1307,1979$. 
24. Mird G G, Bunch G A Croft C B, etal.

Topical noxythiolin antisepsis: Report of controlled triall. Br. J. Surg. 58: 447, 1971.

25. Wohme D H:

The reticuloendothelial system and non-specific resistance. Ann N.Y. Acad. Sci. 88: 172, 1960.

26. Bond J H, Enget $\mathrm{R} R$, Lewitt M D:

Factors influencing pulmonary methane excretion in man. Gastroenterology 58: 1035, 1970.

27. Bohnhofr M, Miller $C \mathrm{P}$ :

Enhanced susceptibility to salmonella infection in streptomycin treated mice. J. infect. Dis. 111: 117, 1962.

28. Bornside $\mathrm{G}_{4}$ Welsh J S, Cohn I:

Bacterialflora of the human small intestine. JAMA 196:109, 1966.

29. Brass C, Richards G K, Ruedy J, Prentis J, Hinchey $\mathbf{E} \mathbb{J}$ :

The effect of metronidazole on the incidence of postoperative wound infection in elective colon surgery. Am. J. Surg. 135: 91, 1978.

30. Braun L, Sanatger $R$, Michalke $H J$ :

Die fortgeschrittene diffuse Peritonitis. Betr. Klin. Chir. 221: 120, 1974.

31. Browning G G, Macksy $\mathbf{C}$, Buchan $\mathrm{KA}$, et al.:

The effect of vagotomy and drainage on bowel habit and small bowel flora in the immediate postoperative period. Gut 10: 1047, 1969.

32. Burdon J G, Morris $\mathbf{P} \mathbf{J}_{\mathbf{3}}$ Hunt $\mathbf{P}$, Watts J M:

A trial of cephalothin sodium in colon surgery prevent wound infection. Arch. Surg. 112: 1169, 1977.

33. Burke J F:

The effective period of preventive antibiotic action in experimental incisions and dermal lesions. Surgery $50: 161,1961$.

34. Burke J F:

Wound infection and early inflammation. Monographs in the surgical science $1:$ nr. 4, 1964

35. Burton $\mathbf{R}$ C:

Gram-negative bacteraemua in colonic and rectal surgery. Med. J. Austr. 1:367, 1972.

36. Burton $\mathrm{R}$ C:

Postoperative wound infection in colonic and rectal surgery. Br. J. Surg. 60: 363, 1973

37. Champault G, Patel J C:

L'Irrigation-lavage de l'intestion. M.C.D. 6: 19, 1977.

38. Chung R S, Gurll N J, Berglund E M:

A controlled clinical trial of whole gut lavage as a method of bowel preparation for colonic operation. Am. J. of Surg. 137: 75, 1979 .

39. Clarke IS, Condon R E, Bartlett J G, Sherwood L, Gorbach S L, Nichols R L, Ochi S:

Preoperative oral antibiotics reduce septic complications of colon operations. Ann. Surg. 186: 251, 1977 .

40. Cohen R, Roth R.J, Dellago A:

Fungal flora of the normal human small and large intestine. New Eng. J. Med. 280: 638, 1969.

41. Collins J P, Butterfield D:

The resuits of colonic anastomoses at the Royal Mellbourne Hospital Current Surgery: 34, 1981.

42. Condlon R E, Bartlett J G, Nichols R L, Schuite W J, Gorbach S, Ochi S:

Preoperative prophylactic cephalothin fails to control septic complications of colorectal operations. Results of controlled elinical trial. Am. J. Surg. 137:68, 1979.

43. Costertion J W, Giessey G G, Cheng K:

How bacteria stick. Sci. Am. 238: 86, 1978 .

44. Crapp A R, Tillotson P, Powis S J A, Cooke W T:

Preparation of the bowel by whole gut irrigation. The Lancet 2: 1239, 1975.

45. Cronin R:

Changing bursting strength and collagen content of the heating colon. Surg. Gyn. \& Obst. 126: 749, 1968.

46. Crosfil M, Hall R, London D:

A controlled trial of chlorhexidine in appendectomy wounds. Br. J. Surg. 56: 906, 1969.

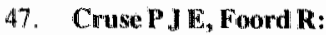

A five-year prospective study of 23,649 surgical wounds. Arch. Surg. 107: 206, 1973.

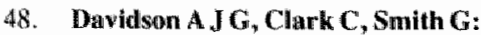

Postoperatiwe wound infection: a computer analysis. Br. J. Surg. 58: 326, 1971.

49. Davidson A J G, Smith G, Smylie H G:

A bacteriological study of the immediate environment of a surgical wound. Br. J. Surg. 58: nr. 5, 1971 . 
50. Davis G R, Santa Ana C A : Moraw ski S G, Forditran J S:

Development of a lavage solution associated with minimal water and electrolyte absorption or secretion. Gastroenterology 78: $991,1980$.

51. Dawson J L:

A study of some factors affecting the mortality rate in diffuse peritonitis. Gut 4: $368,1963$.

52. Degennaro V A, Corman M I, Coller J A, Pribek M C, Veridenhermer M C:

Wound infection after colectomy. Dis. Colon Rectum 21: 567, 1978.

53. Dellaney P, Lalor D:

Enzyme inhibition in colorectal surgery. Br. J. Surg. 63: 23, 1976.

54. Dillard R L, Eastman H, Fordtran J S:

Volume-flow relationship during the transport of fluid through the human small intestine. Gastroenterology 49: 58,1965 .

55. Donovan I A, Arabi Y, Keighley M R B, Alexander-Williams J:

Modification of the physiological disturbances produced by whole gut irrigation by preliminary mannitol adiministration. Br. J. Surg. 67: 138. 1980.

56. Downing R, Keighley M R B, MCLeish, Burdon D V, Allexander-Williams J:

Duration of prophylactic antibiotic cover against anaerobic sepsis in bowel surgery. Dis. Col. and Rectum 401: 1976. Br. J. Surg. 63: 664, 1976.

57. Downing R, Dorricott N J, Keighley M R B, Oates G D, Alexander-Williams J:

Whole gut irrigation: a survey of patient opinion. Br. J. Surg. 66: 201 , 1979.

58. Drasar B S, Shiner M:

Studies on the intestinal flora. II. Bacterial flora of the small intestine in patients with gastrointestinal disorders. Gut 10: $812,1969$.

59. Drasar B S, Hill M J:

Human intestinal flora. Acad. Press London Ltd., 1974.

60. Drasar B S, Shiner M, McLeod G M:

Studies"on the intestinal flora. Gastroenterology 56: 71, 1969

61. Drasar B A, Crowther J S, Goddard P, et al.:

The relation between diet and the gut microflora in man. Proc, Nutr. Soc 32:49, 1973.

62. Edlich R F, Smith Q T, Eigerton M T:

Resistance of the surgical wound to antimicrobial proplyylaxis and its mechanisms of development. Am. J. Surg. 126: 1973 .

63. Ellek S D, Conen P E:

The virulence of staphylococcus pyogenes for man: A study of the problems of wounds. Br. J. Exp. Path. 38: $373,1957$.

64. Ellis H:

Anastomotic integrity after operations for large bowel cancer. Br. Med. J. 281: 746, 1980.

65. Evans, C, Pollock A V:

The reduction of surgical wound infections by prophylactic parenteral cephaloridine. Br. J. Surg. 60: 434 1973.

66. Evans C, Pollock A V, Rosenberg II L:

The reduction of surgical wound infections by topical cephaloridine: A controlled elinical triall. Br. J. Surg. $61: 133,1974$

67. Everett W G:

A comparison of one layer and two layer techniques for colorectal anastomosis. Br. J. Surg. 62: 135, 1975.

68. Eykyn S J, Phillips J:

Metronidazole and anaerobic sepsis. Br. Med. J .2: 1418, 1976.

69. Eykyn S, Lockhart-Mummery H E, Jackson B T, Phillips I:

Prophylactic preoperative intrave nous metronidazole in elective colorectal surgery. Lancet 2: 761, 1979.

70. Farmer R $\mathbf{G}_{\text {: }}$

Preoperative preparation of the patient with carcinoma of the colon. Surg. Clin. of N. Am. $55:$ nr. 6. 1975.

71. Feathers R S, Sagor G R, Lewis A A M, Amirak J D:

Prophylactic systemic antibiotics in colorectal surgery. Lancet $2: 4,1977$.

72. Fekety F R, Murphy J F:

Factors responsible for the development of infections in hospitalized patients. Surg. Cl. of N. Am. 52:1385, 1972.

73. Fielding L, P, Stewart-Brown S, Blesovsky L, Keanry G:

Anastomotic integrity after operations for large bowel cancer: a multi-centre studly. Br. Med. J. 2: 411 , 1980. 


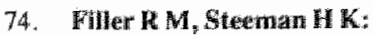

Pathogenesig of peritonitis. The effect of Escherichia coli and hatenoglobin on peritoneal absorption. Surgery $61 ; 385,1967$

75. Fineguld $8 \mathrm{M}$, Rosenblatt:

Practical aspecte of anacrobic sepsis. Medicine $52: 311,1973$.

76. Finegold S M, Sutter V La, Boyle I D, Shimada $\mathrm{K}$ :

The vomallora of ileosicmy and transerse colostomy effuences. I. Infect. Dis. 122,376, 1970.

77. Flynim $\mathbb{N}$, Lawrence $M$ :

Antimicrobial prophylaxis. Med. Chni, of N. Am. 63:1225, 1979

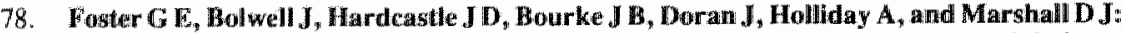

Clinical and economic consequences of wound sepsis after appendicectomy and their modification by metromidazole of povidone-iodine. Lancet: $769,4,1981$.

79. Freter $\mathbf{R}$ :

The frall enteric chollera infection in the guinea pig achieved by inhibition of normal enteria flora. J. Infect. Dig. $97: 57,1955$

80. Fuenfer M M, Olson G E Polk H C Jr.:

Effect of various corticosteriods upon the phagocytosis bactericidal activity of neutrophils. Surgery $78: 27$, 1975.

81. Fullen W D, Munt I, Altemeier W A:

Prophylactic antibiotics in penetrating wounds of the abdomen. J. Trauma 12:282, 1972.

82. Galland R B, Mosley J G, Sanders J H, Danell J H:

Prevention of wound infections in abdominal operations by peroperative antibiotics or povidone-iodine Lancet 2: 1043, 1977.

83. George W L, Sutter V I, Finegoild S M:

Amimicrobial agent induced diar rhoea - a bacterial disease. J. Infect. Dis 136: 822, 1977.

84. Gillespie G, McNaught W:

Prophylactic oral metronidazole in intestinal surgery. J. of Antimicrobial Chemotherapy: Suppl. C, 29, 1978

85. Gilmore $O \mathrm{~J} A$, Samderson $\mathbf{P} \mathrm{J}$ *

An antibiotic policy for surgical patients. Ann. of the Royal Coll. of Surg. of England 57:204, 1975 .

86. Gilmore O J A:

Povidone-iodime in wound infection. Lancet 2: 1284, 1977.

87. Gilmore OJ A, Reid C, Strokon A:

A study of the effect of povidone-iodine on wound healing. Postgraduate Med. J. 53: 122, 1977.

88. Gilmore O J A, Reid C, Houang E T, Shaw E J:

Prophylactic intraperitoneal povidone-iodine in alimentary tract surgery. A m. I. Surg. 135: $156,1978$.

89. Glotzer D J, Goodman W S, Geronimus $L$.

Topical antibiotic prophylaxis an contaminated wounds. Arch. Surg. $100: 589,1970$.

90. Glotater D, Brayle P L, Silen W:

Preoperative preparation of the colon with an efe mental diet. Surgery 74: $703,1973$.

91. Goldman A:

Studies in intastinal bacteriology. J. Infect. Dis. $34: 459,1924$.

92. Goldring J, Me: Naught W, Scott A, Gillesple G*

Prophylactic oral antimictobial agents in elective colonic surgery. Lancet: 997,1975

93. Goligher J C, Morris C, McAdan W A F, Dombal de, Johnston D:

A controlled trial of inverting versus ewerting intestinal suture in clinical lange bowel surgery. Br. J. Surg. $57: 817,1970$.

94. Goligher J C, Lee P R, McMahon M J:

A conirolled comparison of one - and two layer techmiques for suture of high and low colorectal anastomoses. Br. J. Surg. 64:609, 1977

95. Gollgher J $\mathrm{C}$, Lee P $W \mathbf{R}_{*}$ Lintott $\mathrm{DJ}$ :

Experience with the russisan model 246 suture gun for anastomoses of the rectum, S.G. O, 148: 517,1979 .

96. Gorbach S L., Plaut A G, Nahas L, Weinstein L:

Studies on intestinal microflora. II Micro-organisms of the small intestine and their relationship to oral and faecall tora. Gastrocnterology 53:856, 1967.

97. Gorbacin $\mathbf{S} \mathrm{L}$, Neale $\mathrm{G}$, $\mathrm{L}$, witan $\mathrm{R}$, Hepner $\mathrm{G}$ W:

Alterations in human intestinal microflora during experimental diarthoea Gut 11:1, 1970. 
98. Gorbach SL:

Intestinal microflora. Gastroenterology 60: 1110, 1971.

99. Gorbach S L, Bartlett J G:

Anaerobic infections, part I, II, III. New Engl. J. of Med. 290: 1177, 1237, 1289, 1974.

100. Graaf de P W:

The influence of tumorgrowth on wound-healing. An experimental study in the rat. Thesis, 1981.

101. Graham H K, Johnston G W, McKelvey S T D, Kennedly T L:

Five years experience in stapling the oesophagus and rectum. Br. J. Surg. 68: 697, 1981.

102. Gray J G, Lee M J R:

The effect of topical povidone-iodine on wound infection following abdominal surgery. Br. J. Surgery 68 : 310,1981 .

103. Griffiths D A, Simpson R A, Shorey B A, Speller D C, Williams N B:

Single dose peroperative antibiotic prophylaxis in gastrointestinal surgery. Lancet 2: 325, 1976.

104. Grüner O P N, Holler O, Baardsen A:

Combined timidazole and doxycycline prophylaxis in colorectal surgery. Scan. J. Gastroenterology 15: 25, 1980

105. Gurry J F, Pegler E R B:

An elemental diet as preoperative preparation of the colon. Br. J. Surg. 63: 969, 1976.

106. Hagen T B, Bergan T, Liavaog:

Prophylactic metronidazole in elective colorectal surgery. Acta. Chir. Scan. 146: 156, 1979.

107. Halasz N A:

Wound infection and topical antibiotics. Arch. Surg. 112: 1240, 1979.

108. Hall J, Orlans E, Peppard J, Reynold J:

Lymphatic physiology and secretory immunity. Advances in experimental medicin and biology $107: 29$ 1978.

109. Hanel K C, King D W, McAllister ET, Reis-Levy E:

Single dose parenteral antibiotics as prophylaxis against wound infections in colonic operations. Dis. Colon and Rectum 23: 98, 1980.

110. Hartley C L, Clements H M, Linton K B:

Effects of cephalexin, erythromycin and clindamycin of the aerobic gram negative faecal flora in man. $\mathbf{J}$. Med. Microbiol. 11: 125, 1978.

111. Hau T, Hoffman R, Simmons R L:

Mechanisms of the adjuvant effect of haemoglobin in experimental peritonitis. In vivo inhibition of peritoneal leucocytosis:Surgery 83: 223, 1978.

112. Hawley P R, Faulk W P, Hunt T K, Durphy J E:

Collagenase activity in the gastrointestinal tract. Br. J. Surg. 57: 896, 1970.

113. Heald $\mathbf{R}$ J, Leicester $\mathbf{R} \mathbf{J}$ :

The low stapled anastomosis. Br. J. Surg. 68:333, 1981.

114. Hewitt J, Reeve J, Rigby J, Cox A G:

Whole gut irrigation in preparation for large bowel surgery. Lancet: 337,1973 .

115. Higson R H, Kettlewell M G W:

Parietal wound drainage in abdominal surgery. Br. J. Surg. 65: 326, 1978.

116. Hill M J, Drasar B S:

The normal colonic flora. Gut 16:318, 1975

117. Hirt von H J, Stock W, Schaal K P:

Die orthograde Darmspülung zur präoperativen Vorbereitung in der Dickdarmchirurgie. Zentralblatt für Chirurgie 9: 569,1977 .

118. Hillsabeck $\mathbf{J} \mathbf{R}$ :

Enterorectal and colorectal anastomosis. Arch. Surg. 116:921, 1981.

119. Hoffmann C E, Rexnikov M, Hakendorf P H, McDonald P J, Watts J M:

Short-course prophylaxis with cefoxitin in colorectal surgery. S.G.O.: 1217, 1980.

120. Hoffmann C E, McDonald P J, Watts J M:

Use of peroperative cefoxitin to prevent infection after colonic and rectal surgery. Ann. Surg. 193: 353, 1981.

121. Höjer H, Wetter fors J:

Systemic prophylaxis with doxycycline in surgery of the colon and rectum. Ann. Surg. 187: 362, 1978.

122. Follender LF, Calderoli H, Schoenahl C, Penthgem v. R, Meyer C:

Die orthograde Darmspülung in der präoperatieve Dickdarmworbereitung. Aktuelle Chirurgie $13 ; 43$,

1978. 


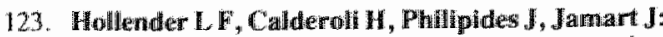

Advantages of whote gut irrigation in coloredal surgery. Current Surg.: 227,1980

124. Hoogkamp, Korstanje I A A, Lindner J G F. M, Marcellis J H, Daas-Slagt H:

Composition and ecology of the human intestinat fora. Antonie $\mathrm{w}$, Leuwenhoek $45: 35,1979$

125. Howe CW:

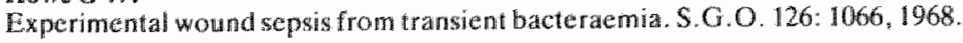

126. Howe C W:

Experimental wound sepsis from transient Escherichia coli bacteriaemia. Sumgery $66: 570,1969$.

127. Hughes $\mathbf{R}$, Hardy K I, Cuthbertson A M, Rubbo $\mathbf{D}$ :

Chemoprophylaxis in large bowel surgery. Effect of intravenous administration of penicillin on incidence of postoperative infection. Med. J. of A ustria 1:305, 1970 .

128. Huk $L$, Starlinger $M$, Schiessell $R$, Wewalka $G$, Rotter $M$ :

Orthograde Darmspülung zur präoperatiełen Darmvorbereitung. Der Chüng 2: 106, 1980.

129. Ingham H R, Sisson P R, Tharagonnet D, Selkon J B, Ciopp A A:

Inhibition of phagocylosis in vitro by obligate anaerobes. Lancet: 1252, 1977.

130. Ings R MS:

Biochemical investigations into the mode of action of metronidazole in the parasite and bost. Ph. D. Thesis. Council for National Academic A wards, 1973.

131. Irvin T T, Colligher J C:

Actiology of dismuption of intestinal anastomoses. Br. J. Surg. 60: 461, 33, 1973.

132. Irvin T T, Hunt T K:

Reappraisal of the healing process of anastomosis of the colon. S.C.O. 138: 741, 1974 .

133. If in $\mathbf{T} \mathbf{T}$, Wostock $\mathbf{T}$ :

The effect of mechanical preparation and acidification of the colon on the healing of colonic anastomoses. S.G.O. 143:443, 1976.

134. Irvin T T:

Effects of malnutrition and hyperalimentation on wound healing. S.C. O. 146:33, 1978.

135. Jackson D W, Pollock A V, Tindel DS:

The value of a plastic adhesive drape in the prevention of wound infection. Br. J. Surg. 58: 340,1971 .

136. Jacomina A A, Weil Korstan V D, Winkler $\mathbf{K}$ C:

The faecal flora in ulce rative colitis. Med. Microbiol. 8: 491, 1975.

137. Johnson M W, Marbach $\mathrm{H}$ I, Salmon S E:

Skin reactivity in patients with cancer. Impaired delayed hypersensitivity or faculty inflammatory respons. New Engl. J. Med. 284: 1255, 1971 .

138. Johnson W C:

Oral elementall diet. Arch. Surg. 108: 32, 1974.

139. Wones $\mathrm{F}$ li, Decosse $\mathrm{J}$, Condon $\mathrm{k}$ li:

Ewalluation of "instant" preparation of the colon with povidone-iodine. Ann. Surg 184: 74, 1976.

140. Jorgensen $\mathbf{S}, \mathbb{N}$, Welle $\mathrm{F}$ :

Prophylactie treatment with bacitracin-neomycine and tetracycline in surgery of colon and rectum. Act. Chir. Scand. 140:491,1974,

141. Jostandi L, Thiede A, Sommtag $\mathrm{H} \mathrm{G}$, Hameiman H:

Die systemische Antibiothcumprophylaxe in der electieven Colonchirurge. Chirurg 52: 398, 1981.

142. Keighlley M R B, Crapp A R, Burdon D W, Cooke W T, Allexander-Williams J: Prophylaxis against anaerobic sepsis in bowel surgery. Br. J. Surg. 63: 538, 1976.

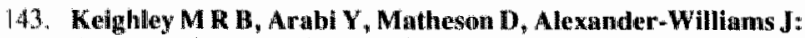

Aspects of preventing sepsis in colo-rectial surgery: result of recent clinicall trials. J, of Antimicrobial Chemoterapy $4: 33,1978$.

144. Kelghley M R I, Arabi Y, Dinock F, Burdon D W, Allan R W: Influence of inflammatory bowel disease or intestimal microflora. Gut 19: 1099, 1978.

145. Kelghley M R B, Arabi Y, Willians J A, Youngs D, Burdon D W:

Comparison between systemic and oral antimicrobial prophylaxis in colorectal surgery. Lancet 1: 894, 1979.

146. Keighley M R B, Taylor E W, Hares M M, Araby Y, Youngs D, Bently S, Burdon D W: Oral mannitol and colonic microflora. Br. J. of Surg. $68: 554,1981$.

147. Kent: Osborne, Wende:

Intestimal Illora in whole-body and intestinal irradiated rats. Radiat. Res. 35: 635, 1968. 
148. Kiene K, Kniekmecht A, Peerrenboom H, Wienbeck M:

Die intestinale Perfusion als Methode der Darmreinigung. Zeitschrift für Gastroenterologie 17: 827, 1979

149. Kislak J W:

The susceptibility of bacteroides to 24 antibiotics. The J. of Inf. Dis. 125: 1972.

150. Kjellgren $\mathbf{K}$, Sellistroem $\mathbf{H}$ :

Effect of prophylactic systemic administration of cephalothin in colorectal surgery. Act. Chir. Scand. 143: 473,1977 .

151. Klastersky J, Meumier-Carpentier $\mathbf{F}$, Prewost J M:

Significance of antimicrobial synergism for the outcome of Gram-negative sepsis. Am. J. Med. Sci. 273: 157,1977 .

152. Krizek T J, Robson M C:

Biology of surgical infection. Surg. Clin. N. Am. 55: 1261, 1975.

153. Kujat R, Grosse H, Gans E, Pichlmair R:

Veränderungen im Wasser - und Elektrolythaushalt nach orthograder Darmspülung. Chirurg 52: 586 , 1981 .

154. Kusche J, Stahlknecht C E:

Antibioticaprophylaxe bei colorectalen Operationen: gibt es ein Mittel der Wahl? Chirurg 52:577, 1981.

155. Law D K, Dudrick S J, Abdon N I:

The effect of protein caloric malmutrition on immune competence of the surgical patient. S.G.O. 139:257, 1974.

156. Lawrence P F, Tietjen $\mathbf{G}$ W, Gingrich $S$, King $T$ C:

Bacteroïdes bacteremia. Ann. Surg. 186:559, 1977.

157. Lee A, Gemmell F L:

Changes in the mouse intestinal microflora during weaning: role of volatile fatty acids. Inf. Imm, 5:1, 1972.

158. Leigh D A:

Wound infections due to bacteroides fragilis following intestinal surgery, Br. J. Surg. 62: 375, 1975.

159. Leigh D A, Pease R, Henderson H, Simmons K, Ruys R:

Prophylactic lincomycin in the prevention of wound infection following appendectomy: a double blind study. Br. J. Surg. 63:973, 1976.

160. LeVeen H H, Wapnick s, Falk G, Olivas O, Bhat D, Gaudra M, Patel M:

Effects of prophylactic antibiotics on colonic healing. Am. J. Surg. 131:47, 1976.

161. Levison M E, Kaye D:

Faecal thora in man: effect of cathartic. J. Inf. Dis 119:591, 1969.

162. Levy A, Benson J, Hewlett E, Hardt J R, Doppman J, Gordon R S:

Saline lavage, a rapid, effective, and acceptable method for cleansing the gastrointestinal tract. Gastroenterology 70 : $157,1976$.

163. Lewis R T, Allen C M, Goodall R G, Lloyd-Smith W C, Marien B, Wiegand F: Antibiotics in surgery of the colon. Can. J. Surg. $21: 339,1978$.

164. Louie T J, Bartlett J G, Ondierdonk A B, Gorbach S L:

Failure of chloramphericol therapy of experimental intra-abdominal sepsis. Abstract 25, 17th 1nterscience Conference on Antimicrobial Agents and Chemotherapy, New York, 1977.

165. Love A H G, Mitchell T G, Phillips:

Water and sodium absorption in the human intestine. J. Physiol. 195: 133, 1968.

166. Love A H G, Rohde J E, Abrams M E, Veall N:

The measurement of bidirectional sodium fluxes across the intestinal wall in man using whole gut perfusion. Cl. Scienc. 44:267, 1973.

167. Lykkegaard N. M., Scheibel J H, Wamberg T."

Septic complications in colorectal surgery after 24 hours versus 60 hours of preoperative antibiotic bowel preparation. Acta Chir. Scan. 144:523, 1978.

168. Marti M C, Pouret J P:

Eine neue Methode zur raschen präoperatieven Vorbereitung des Dickdarm. Langenbecks Arch. Chir. $343: 275,1977$.

169. Martin W J, Gardner M, Washington J A:

In vitro antimicrobial susceptibility of anaerobic bacteria isolated from clinical specimens. Antibiot. Chemother. 1: 148, 1972.

170. Matheson N A, Irving A D:

Single layer anastomosis after rectosigmoid resection. Br. J. Surg. 62: 239, 1975.

171. Matheson D M, Arabi Y, Baxter Smith D, Alexander-Williams J, Keighley M R B:

Randomized multicentre trial of oral bowel preparation and antimicrobials for clective colorectal operattions. Br. J. of Surg. 65: 597, 1978. 
172. MCI adk

Anterior andstomosis of the rectosigmoid colon: An experimental study. Surgery $80 \times 306,1976$.

17.1. Meallines, I L:

Pathophysiologic determinants and prediction of sepsis. Surg. CI. N. Am. 56: 847, 1976.

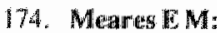

Factors that influence surgical wound infections. Role of prophylactic antibiotic therapy review article. Urology 6:535, 1975

175. Mergenhagen S Ex Thomard J C, Scherp $\mathrm{H} \mathrm{W:}$

Sududies on symergistic infection. I experimental intections with anaerobic streptococci. J. Inf. Dis. 103: 33 , 1958

176. Miles A, Miles B, Murke I:

The value and duration of defence reactions of the skin to the primary lodgment of bacteria. Brit. 1 . Exp. Path. 38: 79, 1957 .

177. Miller D W, Wichern W A Jr:

Perforated signoid diverticulitis: Appraisal of primary versus delayed resection. Am. J. Surg. 121:536, 1971 .

178. Minerwin S, Alexanden-Williams $\mathbb{J}$, Donewan $\mathbf{I}$, Dentley $\mathbf{S}$, Keighley M R B:

Comparision of thee methods of whole gut irrigation. Am. J. of Surg. $140: 400,1980$.

179. Moore W L C, Cato E P, Holdeman L V

Anacrobic bicteria of the gastrointestinal flora and their occurrence in clinical infections. J. Infect. Dis. $119: 641,1969$

180. Moylan.J A."

The proper use of local antimicrobial agents in wounds. World J. Surg. 4: 433, 1980.

181. Nahai F, Lamb J M, Lavican R G, Stone H H:

Factors inwolved in disruption of intestinal anastomoses. Am Surgeon 45: 1977.

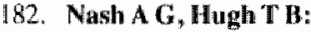

Topical ampicillin and wound infection in colon surgery. Br. Med. 1. 1: 471, 1967

183. National academy of sciences, mational researchcouncil, Division of Medical Sciences, Ad Hoc Committee of the Committec on trauma.

Postoperative wound infections: influence of ultraviolef irridation of operating from and of warious other factors. Ann. Surg. 160: supp. 2:2, 1964.

184. Nelson D P, Mata L J:

Bacterial flora associated with the human gastrointestinal mucosa. Gastroenterology 58: 56, 1970.

185. Newstead G La, Morgan B P:

Bowel preparation with mannitol. Med. I. A usitr. 2: 582, 1979.

1.86. Nicholls R R Condinn R.

Prooperative preparation of the collon. $5.0,0,33: 323,1971$

187. Nichols K I, Condon R E, Gorbuch S I, Nyhus L M:

Ericacy of preopkative antimicrobial preparation of the bowel. Ann. Surg. 186:227, 1972.

186. Nichols R L, Broido P, Condon R F, Sterwond I Gorbach $L_{\text {, }}$, Nybus M:

Eeftects of preoperative neomycih-erythromycin intestinal preparation on the incidence of infectious com plications following colon stretery. Ann, Surg, 178:433, 1973

189. Nielsen M L, Scheibel I H, Wamberg T"

Septic complications in colorectal surgery after 24 hours versus 60 hours of properative antibiotic bowe prepatation. Acta Chir. Scand. 144:523, 1978.

190. Nygatad $\mathbf{K}$, Hognested J:

Infectious prophylaxis with doxycycline incolorectal surgery. Scan. J Gastroenterology 15: 37 " 1980.

191. Ofitaki 1:

Mucin as a resistance-lowering substance, Bacteriol. Rev, 12:149, 1948.

192. Onderdonk A B, Weinstein $\mathbf{W}_{n}$ Sullivan $\mathbf{N}_{\text {, }}$ " al.

Experimental intra-abdominal abscesses in rats: quantitative bacteriology of infected animals. Infect Immun. 10: 1256, 1974 .

193. Onderdonk A B, Bartllett J G, Loule T, Sullivan N, Gorbach S:

Microbial synergy in experimental intra-abdominal abscess. Infection and Immunity 13: 22, 1976.

194. Onderdonk A B, Moon N E, Kasper D L, Bartlett J G:

Adherence of bacteroides fragilis in vittro. Infect. Immun. 19: 1038, 1978.

195. Orth H D, Gierhake F W, Zimmermann $\mathrm{K}$, Hofman K, Ruscher S:

Intraoperatieve bacte riaemieèn in der abdominale Chirugie. Langenbecks Arch. Chir. 330: 307, 1972 
196. Paul M E, Wall W J, Duff I H:

Delayed primary closure in colon operations. Can. J. Surg. 19:33, 1976.

197. Phillips S F, Giller J:

The contribution of the colon to electrolyte and water conservation in man, J. Lab. Clin. Med. 81: 733, 1973.

198. Pittinger C B, Eryara Y, Adamson A:

Antibiotic induced paralysis. Anesthesia and Analgesia 49: 487, 1970.

199. Polk H C, Lopex Mayor 』 F:

Postoperative wound infection: a prospective study of determinant factors and prevention. Surgery 66: 97, 1969.

200. Polk H C:

Postoperative wound infection: prediction of some responsible organisms. Am. J. of Surg. 126:592, 1973.

201. Polk H C, Miles A A:

Enhancement of bacterial infection by ferric iron: kinetics, mechanisms, and surgical significance. Surgery $70: 7 \%, 1971$.

202. Polk H C, Miles A A:

The decisive period in the primary infection of muscle by Escherichia coli. Br. J. Exp. Path. 54: 99, 1073.

203. Pollock A V, Evans M:

Povidone-iodine for the control of surgical wound infection: a controlled clinical trial against topical cephaloridine. Br. J. Surg. 62:292, 975.

204. Pollock A V, Froome K, Evans M:

The bacteriology of primary wound sepsis in potentially contaminated abdominal operations: the effect of irrigation povidone-iodine and cephaloridine on the sepsis rate assessed in a clinical triat. Br. J. Surg. 65 : 76, 1978.

205. Pollock A V, Arnot R S, Leaper D J, Evans M:

The role of antibacterial preparation of the intestine in the reduction of primary wound sepsis after operations in the colon and rectum. S.G.O. 147:909, 1978.

206. Psaila J V, Wheeler M H, Crosby D L:

The role of plastic wound drapes in the prevention of wound infection following abdominal surgery. Br. J. Surg. 64: 729, 1977.

207. Raahave D:

Effect of plastic skin and wound drapes on the density of bacteria in operation wounds. Br. J. Surg, 63:421, 1976.

208. Rifkin G D, Silva J Jr., Fekety F R:

Antibiotic induced colitis implication of a toxin neutralized by Clostridium sordellii antitoxin. Lancet 2 : $1103,1977$.

2009. Rifkin G D, Silva J Jr., Fekety F R:

Gastrointestinal and systemic toxicity of faccial exuacis from hamsters with clindamycin induced colitis. Gastroenterology 74:52,1978.

210. Robertson M D, Polk H C Jr.:

The mechanism of infection in pattients with diabetes mellitus: a review of leucocyte malfunction. Surgery $75: 123,1974$.

211. Rose H D, Schreier J:

The effect of hospitalization and antibiotic therapy on the grann negative faceal flora. Am. J. of Med. Science 255: 228, 1968 .

212. Rubbo S D, Hughes ES R, Blainey B, Russel I S:

Role of preoperative chemoprophylaxis in bowel surgery. Antimicrob. Chemother. 5: 649, 1965

213. Rudek W, Haque K:

Extracellular enzymes of the germs bacteroides. J. Clin. Microbiol. 4: $458,1976$.

214. Russel R I:

Elemental diets. Gut 16:68, 1975.

215. Scheibel J H, Lykkegaard-Nielsen $M$, Wamberg T:

Septic complications in colorectal surgery after 24 hours versus 60 hours of preoperative anvibiotic bowel preparation. Significance of bacterial concentrations in the bowel for contamination of the operation field and subsequent wound infection. Acta Chir. Seand. 144.527, 1978.

216. Schiessed $\mathbf{R}$, Starlinger $M$, Rotter $M$, Furrovics J, Dinstl K:

Die orthograde Darmspü̈lung zur Dick dlarm Vorbereitung. Langenbecks Arch. Chir. 344: 265, 1978

217. Schneiders H, Haralambie E, Towfigh H, Eyler F W, Linzenmeier G:

Uber die Wirksamkeit der Antibiotica Vorbereitung in der Colonchirurgie. Der Chirurg 47: 33, 1976 
218. Setnelerson $\mathrm{S}_{\text {, Amsterdam }} \mathrm{D}$, Periman $\mathbb{E}$ :

Entrancement of intraperitoneal staphylococcal wiruferce for mice with different bile salts. Nature 190 : 829,1976

219. Schrock T T, Devemay C W, Dumphy J E:

Factors contributing to leakage of colonic anastomoses. Ann. Surg. 177:513, 1973.

220. Selkon J B:

Choice of chemotherapy for the anaterobe. Metronidazole: Royal Society of Medicin International Congress and Symposium series nr. 18, published jointly by Acad. Press Inc. (London) Ltd and the Royal Society of Medicin, 1980.

221. Sell wood R A Burn JI, Waterworth P M, Welbourn R B:

A second clinical trial to compare two methods for preoperative preparation of the large bowel. Br. J. Surg. $56: 610,1969$

222. Sindelar W F, Mason G R:

Intraperitoneal irrigation with povidone-iodine solution for the prevention of intra-abdominal abscesses in the bacterially contaminated abdomen. S.G.O. 148:409, 1979.

223. Sisel R J, Donowan A J, Yellin A E:

Experimental faecal peritonitis: Influence of barium sulfate or water soluble radiographic contrast material on surviwall. Arch. Surg. 104: 765, 1972.

224. Skornik W A, Dressler D P:

The effects of short term therapy on lung bacterial clearance and survival in rats. Ann. Surg. 179:415, 1974.

225. Skucas J, Cutclliff W, Fischer H W:

Whole gut irrigation as a means of cleansing the colon. Radiology 121: 303, 1976.

226. Sladen G E, Dawson A M:

Effects of flow rate on the absorption of glucose in a steady state perfusion system in man. Clin. Sci. 36: 133, 1969.

227. Sladen G E, Dawson A M:

Interrelationship between the absorption of glucose, sodium and water by the normal jejunum. Clin. Sci $36: 119,1969 \mathrm{~b}$.

228. Slama T G, Carey L C., Fass R J:

Comparative efficacy of prophylactic cephalothin and cefamandole for elective colonsurgery: results of a prospective, randomized, double blind study. Am. J. Surg. 137: 593, 1979.

229. Speelman P, Bartelsman J F W M, Huibregtse K, Den Hartog Jager F C A, van Bentem N, Lesmana L, Geraedts A A M, Tytgat G NJ:

Reiniging van het colon door totale darmspoeling. Ned. T. Geneeskunde 125:36, 1981.

230. Spier :

Prevention of experimental staphylococcal wound infections in rabbits with topical kanamycin. Surgery 55 : $421,1969$.

231. Stahlknecht C E, Kusche J, Richter H, Pappel H:

Diagnostik der Frühstörungen nach Eingriffen am Colon. Gastrointestinale Endoskopie Hrsg: M. Reifferscheid, H. Peters, Biblioned. Melsungen.

232. Steinlberg B:

Infections of the peritoneum. New York, Paul Hoeber Inc. 1944.

233. Stevenson T R, Rodeheaver G T, Golden G T, et al.:

Damage to tissue defences by wasoconstrictors. JACEP 4: 523, 1975.

234. Stock W, Hirt H J, Schaal K P, Pichlmaier H:

Die präoperatieven Darmkeimverminderung durch orthograde Dickdarm spülung. Chirurg 48: 161, 1977.

235. Stokes E J, Waterworth P M, Franks V, Watson B, Clark C:

Short term routine antibiotic prophylaxis in surgery. Br. J. Surg. 61: 739, 1974.

236. Stokes E J, Howard E, Peters J L, Hackwatly C A, Milne S E, Witherow R O:

Comparison of antibiotic and antiseptic prophylaxis of wound infection in acute abdominal surgery. World J. of Surg 1:777, 1977 .

237. Stone H H, Hester T R:

Incisional and peritoneal infection after emergency celiotomy. Ann. Surgery 177: 669, 1973.

238. Stone H H, Kolb L. D, Geheber C E:

Incidence and significance of intraperitoneal anaerobic bacteria. Ann. Surg. 181: 705, 1975.

239. Stone H H, Kolb L D, Geheber C E:

Incidence and significance of intraperitoneal anaerobic bacteria. Ann. Surg. 181: 705, 1975.

240. Stone H H, Hooper C A, Kolb L D, Geheber C E, Dawkins E J:

Antibiotic prophylaxis in Gastric, Biliary and Colonic surgery. Ann. Surg. 184: 443, 1976 
241. Sutter V L, Vargo V L, Finegold $\$$ M:

Wadsworth anaerobic bacteriology manual $2 \mathrm{nd}$ ed. Wadsworth Hospital Centre: Veterans Administration, Los Angeles, 1975.

242. Swenson R M, Lorber B, Michaelson T C, Spaulding E H:

The bacteriollogy of intra-abdominal infections. Arch. Surg. 109: 1974.

243. Sykes P A, Boulter K H, Schomeld P F:

The microflora of the obstructed bowel. Br. J. Surg. 63: 721, 1976.

244. Taat C W, Boissevain A C H, Coevorden v. F, Leguit P, Brummelkamp:

De orthograde darmspoeling als preoperatieve darmvoorbereiding bij elektieve colorectale chirurgie.

Ned. Tijdschrift voor Geneeskunde $125: 1456,1981$.

245. Tally F P, Gorbach S:

Pathogenesis of bacteroides infections. J. of Infect. 1:5, 1979.

246. Taylor E W, Bentley S, Youngs D, Keighley M R B:

Bowelpreparation and the safety of colonoscopic polypectomy. Gastroenterology 81: 1, 1981.

247. Tedesco F, Markham R, Gurwith M, et al :

Oral vancomycin for antibiotic associated pseudomembranous colitis. Lancet 2:226, 1978 .

248. Tedesco $\mathbb{F}$, Barton R W, Alpers D H:

Clindamycin-associated: a prospective study. Anm. Intern. Med. 81:429, 1974.

249. Thiede A, Jostandt L, Trödl H, Poser H I, Bertz V, Hamelman H:

Der Wert der zirkulären maschinellen Colon- und Rectum-anastomose (EEA). Chirurg 52:30, 1981.

250. Tsilibary E C, Wissig S L.:

Absorption from the peritoneal cavity: SEM study of the mesothelium covering the peritoneal surface of the muscular portion of the diaphragm. Am. J. Anat. 199: 127, 1977.

251. Tyson R R, Spaulding E H:

Should antibiotics be used in large bowel preparation? S.G.O. 108: 623, 1959.

252. Ulrich C:

Short term systemic antibiotic prophylaxis in colorectal surgery. Thesis 1981.

253. Vargish T, Crawford L. C, Stallings R A, Wasilauskas B I, Myers R T:

A randomized prospective evaluation of orally administered antibiotics in operations on the colon. S.G.O. $146: 193,1978$.

254. Vargo D, Moskovitz M, Flock M H:

Faecal bacterial flora in cancer of the colon. Gut 21: 701, 1980.

255. Viddel K O, Semb LS:

Tinidazole and doxycycline compared to doxycycline alone as prophylactic antimicrobial agents in elective. colorectal surgery. Scan. J. Gastroenterology 15:21, 1980.

256. Waaij vd D, Berghuis-de Vries J M, Lekkerker-Wees vd:

Colonization resistance of the digestive tract in conventional and antibiotic treated mice. J. Hyg. Camb. 69 $405,1971$.

257. Waaij wd. D, Berhuils-de Vries J M:

Selective elimination of enterobacteriaceae species from the digestive tract in mice and monkcys. J. Hyg. Camb. 72: 205, 1974.

258. Walsh J A, Watts J M C K, McDonald P J, Finlay-Jones J J:

The effect of topical povidone-iodine on the incidence of infection in surgical wounds. Br. J. Surg. $68: 185$, 1981.

259. Wapnick S, Guinto R, Reizis I, LeVeen H H:

Reduction of postoperative infection in elective colonsurgery with preoperative adminisiration of kanamycin and erythromycin. Surgery: $85,317$.

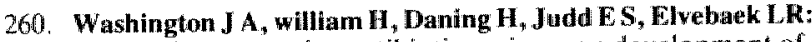

Effect of preoperative antibiotic regimen on development of infection after intestinal surgery. Ann. Surg. $184: 567,1974$.

261. Weidema W F, Meyenfeldt w M F, Soeters P B, Wesdorp R I C, Greep J M:

Pseudomembranous colitis after whole gut irrigation with neomycin and erythromycin base. Br. J. Surg. $67: 895,1980$.

262. Weinstein L:

The spontaneous occurence of new bacterial infections during the course of treatment with streptomycin or penicillin. Am. J. Med. Sci. 214: 56, 1947.

263. Weinstein W M, Onderdonk A B, Bartlett J G, Louie T J, Gorbach S:

Antimicrobial therapy of experimental intra-abdominal sepsis. J. of Infect. Dis.: 132: 1975 
264. Weich J P, Donaldison G A:

Perforative carcinoma of the colon and rectum. Ann. Surg. 180: 734, 1974.

265. Welling $G W_{\text {, Groen }} G$ :

Belta-Aspartylglycine, a substance unique to caecal contents of germ-free and antibiotic treated mice. Biochem. J. 175:807, 1978.

266. Welwart K, Illoogstraaten M M:

Preparation of the colon by whole gut irrigation, some practical remarks. Neth. J. of Surg. 32: 71, 1980.

267. Wensinck F, R useler-Embden $\times \mathbf{J} \mathrm{G} \mathrm{M}$ :

The intestinal fora of colonization resistant mice. J. Hyg. Camb. 69: 413, 1971.

268. Wensinck $\mathrm{F}$;

Proceedings: The faecal flora of patients with Crohn's disease. Ant. v. Leewwenhoek 41:214, 1975.

269. Wenzel IR P, Hunting K J, Osterman Ch A:

Postoperative wound infection rates. S.G.O. 144: 749, 1977

270. Wesley-Alexander A J:

Host defence mechanisms against infection. Surg. Clin. N. Am. 52: 1367, 1972.

271. Whelan J P F:

The effect of metronidazole on the gut flora in humans. May \& Baker Internal Report: nr. PQG, 505, 1969.

272. Whitaker B L:

Anastomotic failure in relation to blood transfusion and blood loss. Proc. R. Soc. Med. 63: 751, 1970.

273. Willis A T, Ferguson I R, Jones P H, Phillips K D, et al.:

Metronidazole in prevention and treatment of bacteroides infections in elective colonic surgery. $\mathrm{Br}$. Med. J. $1: 607,1977$.

274. Winitz M, Adams R F, Seedman D A, Danis P N, Jayko L G, Hamilton J:

Studies in metabolic nutrition employing chemically defined diets. II Effects on Gut Microflora Populations. Am. J. Clin. Nutr. 23:546, 1970.

275. Wirts C W, Goldstein F:

Studies of the mechanism of postgastrectomy steatorrhea. Ann. Int. Med. 58:25, 1963.

276. Yull A B, Abrams JS, Davis J H:

The peritoneal fluid in strangulation obstruction: The role of the red blood cell and $\mathrm{E}$. colli bacteria in producing toxicity. J. Surg. Res. 2: 223, 1962.

277. Yura J, Kato F, Shibata K:

Postoperative infections in colorectal surgery. Intemat. Surg. 63: 61, 1978. 


\section{Acknowledgements}

This thesis could only be completed with the enthousiasm and contributions of many others and it is impossible to thank everyone in person for their great help. I would like to take the opportunity. however, to express my gratitude towards those without whom this thesis would never have bocn written.

With gratitude lacknowledge the invaluable help of Ton van den Bogaand. Ton, you learned me the basic principles of microbiology and our collaboration has led to a warm friendship.

I would like to express my gratitude to Prof. Dr. Cees van Boven who offered me the opportunity to do all the bacteriological investigations in his laboratories. For your moticulous and enthousiastic guidance to complete this thesis I an deeply grateful.

I feel much obliged to Prof.Dr. J.M. Greep, under whom I received my surgical training and who conwinced me, on his wellknown dynamic way, to write this thesis and to complete it.

I offer my warm thanks to "partner" Ai Frusch who helped me with the survey of the literature.

My special thanks to Rob Wesdorp for his ideas and coaching of the studies.

$I$ also acknowledge gratitude to Prof.Dr. W. H. Brummelkamp. Prof. Dr. Dick van der Waaij and Prof.Dr. E. Marres for their critical reading of the manuscript and their valuable commentary

Special thanks must be reserved for Math Hazen who incubated thousands of plates.

The constructive attitude of Sjef Roos gave me the benefit of his statistical knowledge.

I feel much obliged to Chris J. Lawrence F.F.A.R.C.S. for his assistance in correcting the Enghish; to Chris Voskamp for his high quantity illustrations and preparation of the lay out to Maarijc Duyzings for her accurate, patience and intelligent typing on the computerized type-setter; to Miss Helmus who detected the beta-aspartylglycines and to all the voluntecers for their collaboration.

Finally, my thanks to the staff, residents and nurses of the Department of Surgery of the St. Annadal Hospital for their willingness to suffer the inconvenience caused by my involvement in this thesis. Last but not least, I owe great dept to my wife Mariëlle and our daughter Jikke for their endurance of my selfishness and fretfulness during the preparation of this thesis.

\section{Curricullum Vitae}

Wibo Fedde Weidema was born on November 21, 1948 in Utrecht, The Netherlands. He attended High School in Zeist (H.B.S.-B) where he passed his final exam in 1968 . In 1968 he went to Medical School at the Uniwersity of Utrecht and graduated in 1975. From August 1975 to March 1977 he served Her Majesty, Queen Juliana of The Netherlands as a medical officer in the Royal $N$ avy. In April 1977 he started his surgical residency at the Department of Surgery of the St. Annadal Hospital, University of Limburg (Head: Prof. Dr. J.M. Greep) and will be registered as a general surgeon in October 1983 . 